\title{
IntechOpen
}

\section{The Role of \\ Technology in Education}

Edited by Fahriye Althay
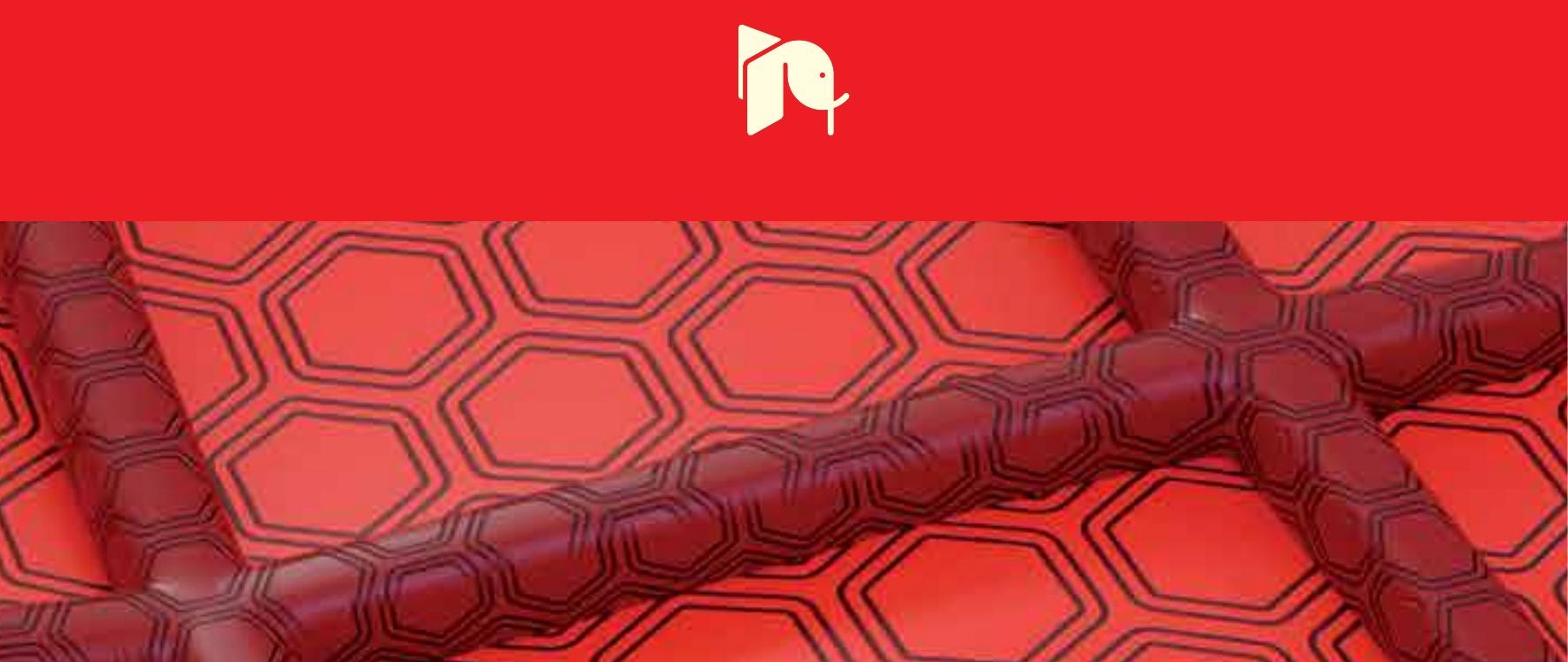



\section{The Role of Technology in Education}

Edited by Fahriye Altlnay 

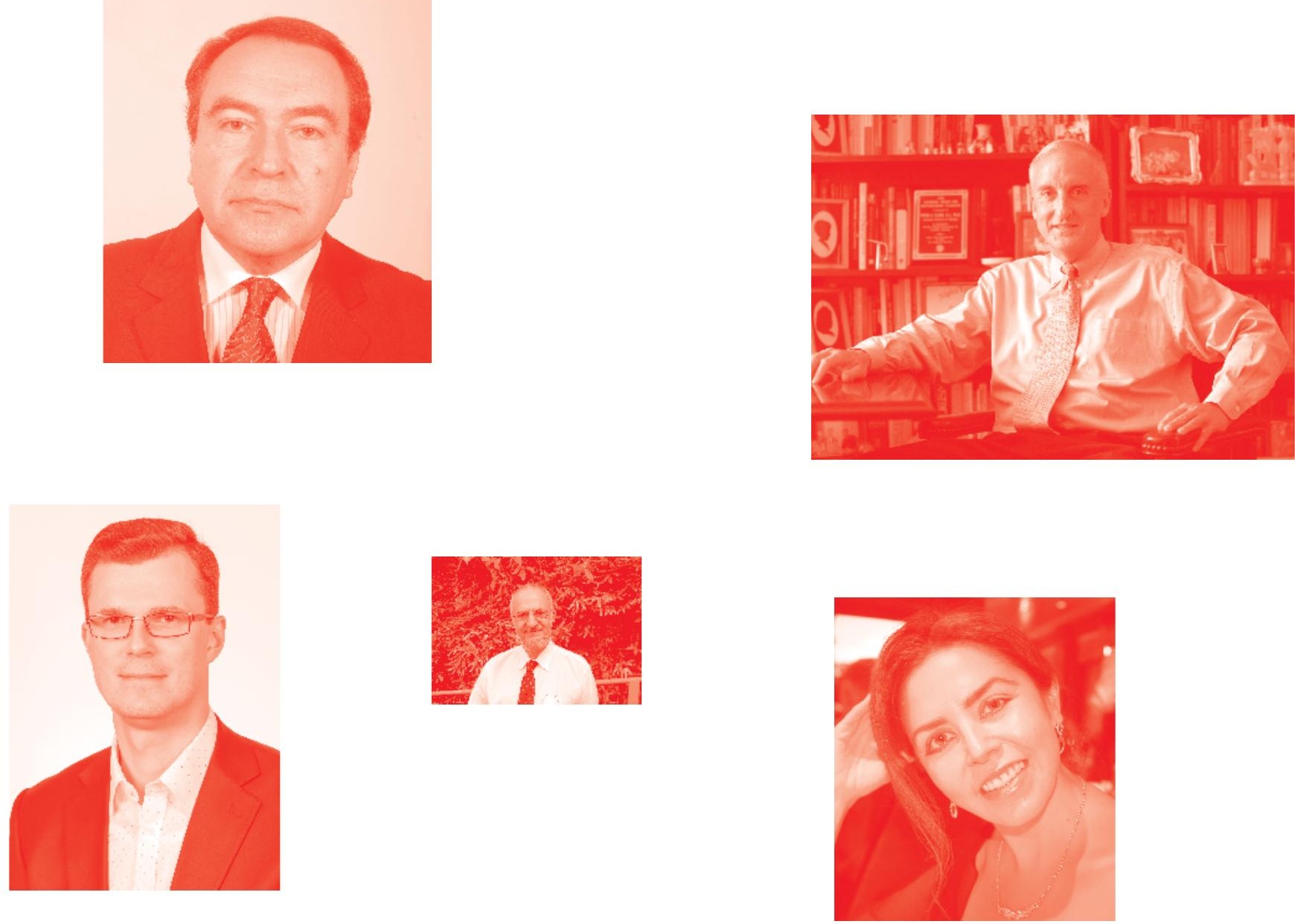

Supporting open minds since 2005
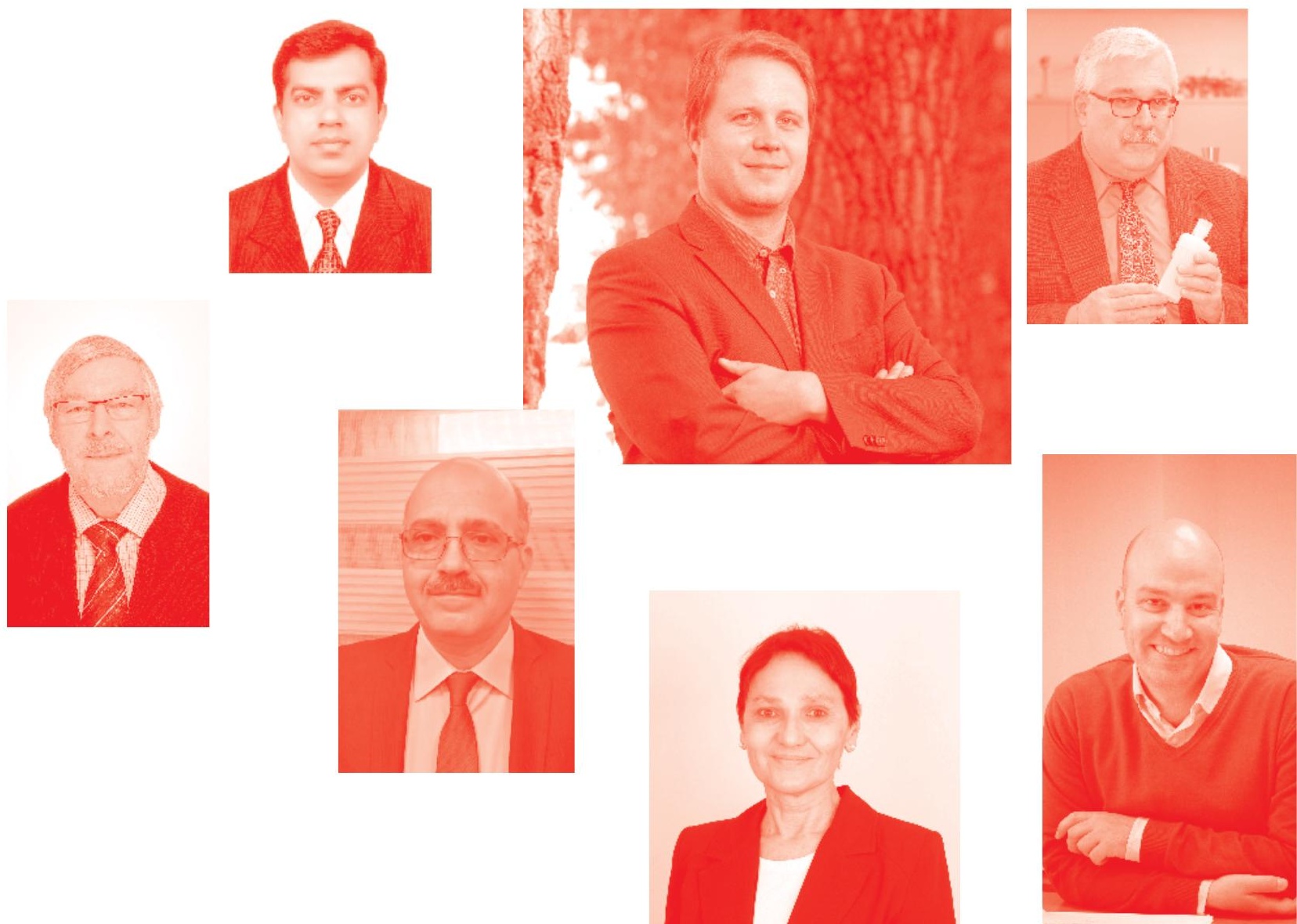
The Role of Technology in Education

http : //dx. doi . org/10.5772/intechopen. 77620

Edited by Fahriye Altlnay

\section{Contributors}

Karim Dahdouh, Ahmed Dakkak, Lahcen Oughdir, Aliyu Mustapha, Abdulkadir Mohammed, Abdullahi Raji Egigogo, Abdullahi Abubakar Kutiriko, Ahmed Haruna Dokoro, Koji Uenishi, Robert Repnik, Milan Svetec, Eva Klemencic, Robi Arcet, Kshama Pandey, Anil Shukla, Keisha Varma, Irfan Simsek, Tuncer Can

(-) The Editor(s) and the Author(s) 2020

The rights of the editor(s) and the author(s) have been asserted in accordance with the Copyright, Designs and Patents Act 1988. All rights to the book as a whole are reserved by INTECHOPEN LIMITED . The book as a whole (compilation) cannot be reproduced, distributed or used for commercial or non-commercial purposes without INTECHOPEN LIMITED's written permission. Enquiries concerning the use of the book should be directed to INTECHOPEN LIMITED rights and permissions department (permissions@intechopen.com).

Violations are liable to prosecution under the governing Copyright Law .

\section{(cc) BY}

Individual chapters of this publication are distributed under the terms of the Creative Commons Attribution 3.0 Unported License which permits commercial use, distribution and reproduction of the individual chapters, provided the original author(s) and source publication are appropriately acknowledged. If so indicated, certain images may not be included under the Creative Commons license. In such cases users will need to obtain permission from the license holder to reproduce the material. More details and guidelines concerning content reuse and adaptation can be found at http : //www . intechopen . com/copyright-policy. html.

\section{Notice}

Statements and opinions expressed in the chapters are these of the individual contributors and not necessarily those of the editors or publisher. No responsibility is accepted for the accuracy of information contained in the published chapters. The publisher assumes no responsibility for any damage or injury to persons or property arising out of the use of any materials, instructions, methods or ideas contained in the book.

First published in London, United Kingdom, 2020 by IntechOpen IntechOpen is the global imprint of INTECHOPEN LIMITED, registered in England and Wales, registration number: 11086078 , 7th floor, 10 Lower Thames Street, London, EC3R 6AF, United Kingdom

Printed in Croatia

British Library Cataloguing-in-Publication Data

A catalogue record for this book is available from the British Library

Additional hard and PDF copies can be obtained from orders@intechopen.com

The Role of Technology in Education

Edited by Fahriye Altlnay

p. cm.

Print ISBN 978-1-78984-662-1

Online ISBN 978-1-78984-663-8

eBook (PDF) ISBN 978-1-78985-862-4 


\section{We are IntechOpen, \\ the world's leading publisher of Open Access books}

Built by scientists, for scientists

\section{$4,700+$}

Open access books available

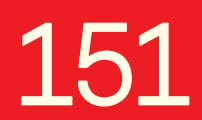

Countries delivered to
$120,000+$

International authors and editors

Our authors are among the

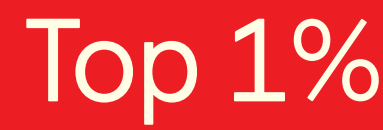

most cited scientists

Contributors from top 500 universities
$135 \mathrm{M}+$

Downloads

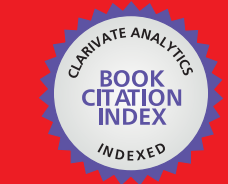

WEB OF SCIENCE ${ }^{\mathrm{MM}}$

Selection of our books indexed in the Book Citation Index in Web of Science ${ }^{\mathrm{TM}}$ Core Collection (BKCI)

\section{Interested in publishing with us? \\ Contact book.department@intechopen.com}

Numbers displayed above are based on latest data collected.

For more information visit www.intechopen.com 



\section{Meet the editor}

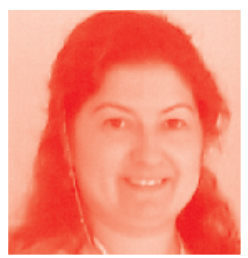

Prof. Dr. Fahriye Altınay is a Director of the Graduate School of Educational Sciences at Near East University. She is Vice Chair of the Societal Research and Development Center. She is currently teaching at the Near East University and University of Kyrenia. Her research interest is educational technology and management. She is actively working on unobstructed information technology for disability. She has authored several scientific publications and books. 



\section{Contents}

Preface

Section 1

Merits of Online Learning and Environment

Chapter 1

Technology-Enhanced Parent Involvement in Science Education

by Keisha Varma

Chapter 2

Improving Online Education Using Big Data Technologies

by Karim Dahdouh, Ahmed Dakkak, Lahcen Oughdir and Abdelali Ibriz

\section{Section 2}

New Technologies in Learning and Teaching

Chapter 3

Using Tablets for Technology Integration in Classroom Differentiation by Irfan Simsek and Tuncer Can

Chapter 4

The Usefulness of Original Teaching Materials for Motivation

by Koji Uenishi

\section{Section 3}

New Tendencies for the Technology in Education

Chapter 5

Factors Affecting the Utilization and Adoption of Technology in Education by Aliyu Mustapha, Abdulkadir Mohammed, Abdullahi Raji Egigogo,

Abdullahi Abubakar Kutiriko and Ahmed Haruna Dokoro

Chapter 6

Educational Technology at the Study Program of Educational

Physics at the University of Maribor in Slovenia

by Milan Svetec, Robert Repnik, Robi Arcet and Eva Klemenčič

Chapter 7

Endorsement of Individualized Instruction and Learning Performance through Mobile-Based Learning Management by Anil Shukla and Kshama Pandey 



\section{Preface}

Technology has become a bridge to solve theory and practice. Especially in education, technology is a medium to foster learning and teaching in a qualified manner. For professional development, it is important to integrate technology as a strategic action for quality. Following up the merits of technology in learning is crucial.

Technology provides equal access and usability for learners. In this repsect, there is an intensified need to consider new trends in education and the integration of technology. Therefore, being digital natives plays a great role. Providing education and technology for everyone is crucial in order to facilitate connected learning and connected society within equal and accessible perspectives.

Social justice and equality have become facilitated through the development of open online learning and education. Quality in education relies on learning and teaching activities. Nowadays, technology facilitates us to underline the importance of open education resources, emerging technologies, learning management systems, and blockchain applications by different examples and experinces.

As technology is a medium of enriching the learning and teaching activities, it has a major role to foster connected learners for adapting to the smart life and society considitions. Tranformation in education is the main focus of this century, therefore conducted research needs to pay attention to the transformational research theory to consider accessibility through universal values by the facilitation of new technologies. The role of technology in education is a dynamic agenda that encapsulates new pedagogical tendencies to adopt changes for quality.

Dr. Fahriye Altınay Professor, Graduate School of Educational Sciences, Societal Research and Development Center, Near East University, Nicosia, Cyprus 

Section 1

Merits of Online Learning and Environment 



\title{
Technology-Enhanced Parent Involvement in Science Education
}

\author{
Keisha Varma
}

\begin{abstract}
Parent involvement is a critical facet of academic success. Empirical studies and meta analyses highlight that it can increase students' motivation, self-efficacy, and academic performance. Even though they recognize the importance of being involved, minority and immigrant parents are likely to have lower levels of parent involvement than white parents. This could be a contributing factor to the academic gaps that exist between white students and minority and immigrant students. Technology can provide new ways to increase parent involvement and can address equity issues by providing more innovative and flexible opportunities for parents to be involved in their students' academic experiences. This chapter summarizes ideas from (ESPRIT) Fostering Equitable Science through Parent Involvement and Technology, a National Science Foundation funded project that utilizes a technology-rich social learning environment (SLE) to engage middle school science teachers and student-parent pairs in culturally responsive, science-related activities. A new model of parent involvement is presented, followed by a discussion of the roles parents play as they participate in the SLE activities with their children.
\end{abstract}

Keywords: social learning environment, parent involvement, parent roles, computer supported collaborative learning, science education, technology

\section{Introduction}

When students know that their parents are invested in their education experiences, they understand the importance of education and the expectations their parents have for them [1]. When parents are engaged in students' academic experiences they are more likely to know what is being taught in students' classes and can to find ways to support their learning at home. As the significance of parent involvement becomes more evident school leaders, teachers, and policy makers are exploring ways to expand parent involvement. There is a motivation to move beyond traditional approaches such as parent-teacher conferences to more dynamic, engaging approaches where parents' knowledge is valued and leveraged to create culturally responsive education experiences. Even though the structure of formal K-12 schools creates more opportunities for parents to participate in young elementary students' education experiences, middle school students still show great benefit when their parents participate in school-based events and academic experiences [2].

If parents can engage in academic tasks with their students, it extends students' instruction experiences. Students have more opportunities to discuss content, relate it to real world contexts and make meaningful connections to their lived 
experiences. These experiences could improve students' science, technology, engineering, and math (STEM) knowledge and lead to increased learning outcomes.

This chapter summarizes some of the work being done on the Fostering Equitable Science through Parental Involvement and Technology (ESPRIT) Project that focuses on the ways that parents participate in activities designed to increase their involvement in middle school students' science education experiences. In the ESPRIT project work, ethnic and racial minority and immigrant parents are invited to create video responses to questions and activities assigned by their middle school students' science teachers.

ESPRIT leverages a technology-enhanced social learning environment (SLE) called Flipgrid $^{\mathrm{TM}}$ (flipgrid.com) to engage science teachers and student-parent pairs in discussions and activities designed to create connected learning experiences [3] that prompt middle school students to connect their personal interests and cultural knowledge with their academic science learning experiences. The Flipgrid social learning environment is available via an app that works on laptops, tablets, and smart phones. In a typical sequence of events, teachers create a video or text based question or assign a brief activity within the SLE and share the question via a secure link sent to students and parents. Then parents and students create a video-based response between 90 seconds and 5 minutes long. Teachers can show the video responses during class, respond to them individually, or ask students to engage in an online discussion by responding to each other's videos. This project is well-situated to examine the rich affordances of computer supported collaborative learning experiences as we focus on how teachers, students, and parents form a dynamic knowledge building community via interactions with the SLE activities [4].

A major facet of the ESPRIT project research is to understand the ways in which participating in the SLE activities increases parent involvement. This chapter presents a new model intended to expand the notion parent involvement to focus on behaviors and activities that shift and adjust as teachers, students, and parents participate in a range of constructive, collaborative activities. The chapter also highlights roles that parents take on as they participate in an online social learning environment. These ideas are relevant for researchers, teachers, and curriculum designers interested in new ways to support parent involvement and incorporate technology into science education experiences.

\section{Conceptualizations of parent involvement in education}

Parent involvement is broadly defined as the behaviors that parents engage in with their children at home and the activities they participate in in school contexts. In their conceptualization of parent involvement, the authors in [5] describe parent involvement as having three dimensions related to behavioral, affective, and cognitive behaviors. They further specify that in order for children to experience the positive benefits of parent involvement, they must actively process information related to the involvement behaviors and incorporate it into their attitudes, motivations, and school-based schemas.

Recent research aimed at understanding home-school relationships asks that we reconceptualize parent involvement as parent engagement that is "a two-way interaction process between school and home, referring to a mutual exchange of values and knowledge. It places emphasis on reciprocity, empowerment, empathy, change and opportunities for both parents and the school" [6], p. 11.

Other perspectives of parent involvement discuss the distinction between parent involvement and parent engagement as a continuum of roles [7]. At one end of the continuum, parents participate in traditional parent involvement activities. They 
are primarily recipients of information from teachers and participants in schooldirected activities. The other end of the continuum represents more active parent engagement where parents have agency and participate in activities that directly support student learning. This continuum framing aligns with the call for schools to view families as partners who can play important roles that support students' academic success [8].

Many types of parent involvement have been shown to support students' educational experiences and increase student learning outcomes [9]. To build on this knowledge, teachers, curriculum designers and researchers can leverage technology to take advantage of the fact that parents are driven to be engaged in meaningful ways and are willing to take on significant roles in their students' education experiences. As we consider how technology can support student learning, we can also focus on how it can enhance parent involvement.

The ESPRIT project embodies this approach to broadening the impact of technology in education. In the social learning environment, teachers ask open-ended questions that allow parents and students to determine how they want to respond. Parents are asked to participate in activities that invite them to make cognitive, socio-emotional, or cultural contributions to the tasks. Parents also have more agency to structure the activities they engage in with their children. For example, as they record a video response, parents might share an experience from their lives that relates to an academic lesson their child is learning at school. In discussions with their child, they could share their ideas about how a particular content area relates to real world issues, or they could explain a scientific phenomenon and the factors that influence it. Prior to recording their video responses, parents and students are likely to have offline discussions to decide what they are going to say. After they post their responses, they may continue to discuss the content and ideas included in their response. The full cycle of parents and students creating responses that teachers can use during instruction creates the mutual exchange of knowledge that supports the type of parent involvement being called for in current educational research.

\section{Supporting equitable parent involvement in education}

\subsection{Barriers to parent involvement}

Multiple studies indicate that parents from diverse cultural and ethnic backgrounds recognize the importance of education and are keen to participate in their students' education experiences. However, there are barriers to participation that parents from minority, immigrant, and low-socioeconomic status groups are likely to experience [10]. For instance, parents from minority groups have expressed challenges related to transportation and scheduling issues. Immigrant parents who do not speak English may experience additional obstacles that prevent them from participating in traditional parent involvement activities [11]. Language and communication are among the most frequently cited variables that influence the ways that immigrant families participate in school events [12].

In an interview based study of Latino immigrant parents, participants summarized the communication and scheduling frustrations they experience when trying to participate in activities like parent-teacher conferences and open house night. Time was also mentioned as a barrier because some parents work evenings and cannot attend after school events. Communication was reported as a barrier because translators were not always available. Parents also expressed confusion about knowing the ways to best support their children's learning. A general frustration with not knowing what was expected of them created a culture of dissatisfaction and confusion [13]. 
In addition to these reported barriers, narrow views of parent involvement are likely to overlook ways that parents from diverse cultural and ethnic backgrounds are involved in students' education experiences [6].

\subsection{Utilizing technology to support parent involvement}

Parents have access to multiple types of technology platforms (i.e., laptop computers, mobile phones, tablets) and recognize that these tools can be used to broaden the ways that they are involved in their children's education [14].

In the ESPRIT Project, parents and students create video-based responses in their homes or other locations in their community, and they are able to do it in a fairly short timeframe that fits their schedules. In several cases, parents speak in Spanish, Somali, Hmong, or Karen. Members of our research team translate those responses, or the teachers ask students to translate as they show the response during class. By using the SLE environment, teachers emphasize and value the diversity of languages spoken in their students' families.

When teachers design prompts and activities for parents and students to complete together, parents are developing an awareness of the content being covered in their child's science lessons. In addition, parents are included in the school community when teachers show parents' recorded responses in their classrooms. Because teachers are able to use the SLE across multiple curriculum units, they create several SLE assignments throughout the school year and establish an expectation that parents and students should work together to discuss content being covered in their science lessons.

For example, in her lesson about scientific practices, a fifth grade teacher created a prompt asking parents to explain what scientists do. Parents recorded videos in the social learning environment. Their responses included ideas about discovering cures for illnesses, conducting experiments, and solving problems. During her lesson, the teacher quickly transcribed the responses on a post-it note while she played the parent video responses for the class. Then, she asked the class which scientific practice they thought the parent was talking about according to a chart in the classroom. Once the students agreed on the practice, the student whose parent was speaking in the video response took the post-it note and placed it in the section of the chart with the practice identified in the discussion.

In addition to the home-school connections that are being created, it is also important to note that because parents and students can view responses from other families, they are getting to know more about the families in the school community. Overall, using the social learning environment addresses some of the typical barriers immigrant and minority parents face and provide meaningful opportunities for all parents. These types of parent involvement are changing the ways that parents are engaged in their children's learning and enriching the ways that teachers are providing instruction.

\section{A new model of productive parent involvement}

Currently, the ways that parents are invited to participate in their children's learning are largely routine; whether they are asked to help them study for tests, complete daily homework, or assist with large project-based assignments. Still, these activities have been shown to have positive impacts on academic outcomes and are customarily offered as involvement opportunities in most K-12 schools in the US. The argument presented in this chapter is not that these types of involvement are not important and impactful. Instead, I am suggesting that there are ways to expand our thinking about parent involvement so that parents and students are 
continually exploring ways to connect academic experiences to meaningful, realworld contexts and students' lived experiences.

Figure 1 presents a new model of productive parent involvement that illustrates the ways that parents participate in students' academic experiences. It builds on ideas related to adaptive expertise [15], and is meant to provide a framework for thinking about how parents experience parent involvement activities.

When parents are new to the school environment or are engaging in unfamiliar activities they are involved novices. They do not have enough experience engaging in the tasks to feel that they can be innovative or creative nor do they have enough practice so that participating in the activities feels familiar. If parents are unable to develop a comfort level and knowledge base so that the parent involvement activities become familiar, they may view it as a generally frustrating endeavor. They are also unlikely to advance from being novices.

In cases of routine involvement, parents become familiar with particular opportunities for involvement and are able to master particular ways of being involved. They may participate in a variety of activities ranging from attending parent teacher conferences and other school events to assisting their children with homework. These behaviors are largely unidirectional. School administrators and teachers create the experiences and have a fairly scripted role for parents to play. Parents and students may become bored, passive, and unmotivated in these instances of routine parent involvement.

In this model, productive parent involvement occurs when parents are invited to participate in a broad range of activities that support their child's education. They have the scaffolded support needed to try new activities and become familiar with them. Over time, they can further enhance their involvement by personalizing activities and connecting them students' everyday lived experiences. The model is intended to illustrate the idea that productive parent involvement requires multiple experiences that allow parents to become familiar with the activities. It also underscores the need for to challenge and inspire parents to engage in innovative thinking about their students' education.

Figure 2 presents the model with technology featured as a mechanism for supporting parent involvement activities and for promoting productive parent

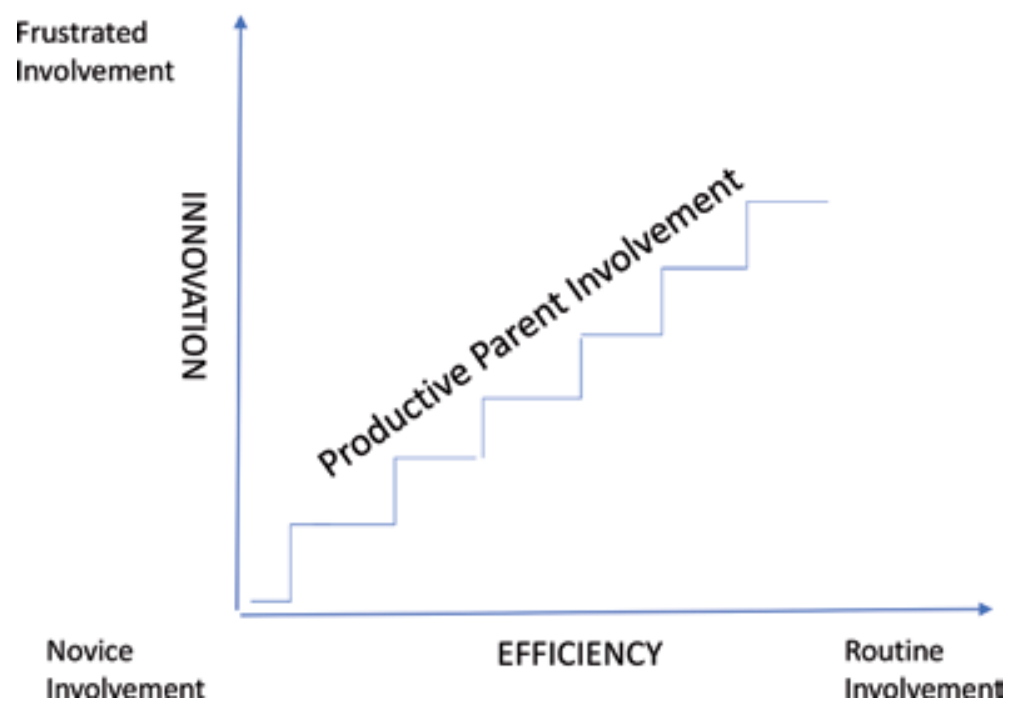

Figure 1.

New model of productive parent involvement. 


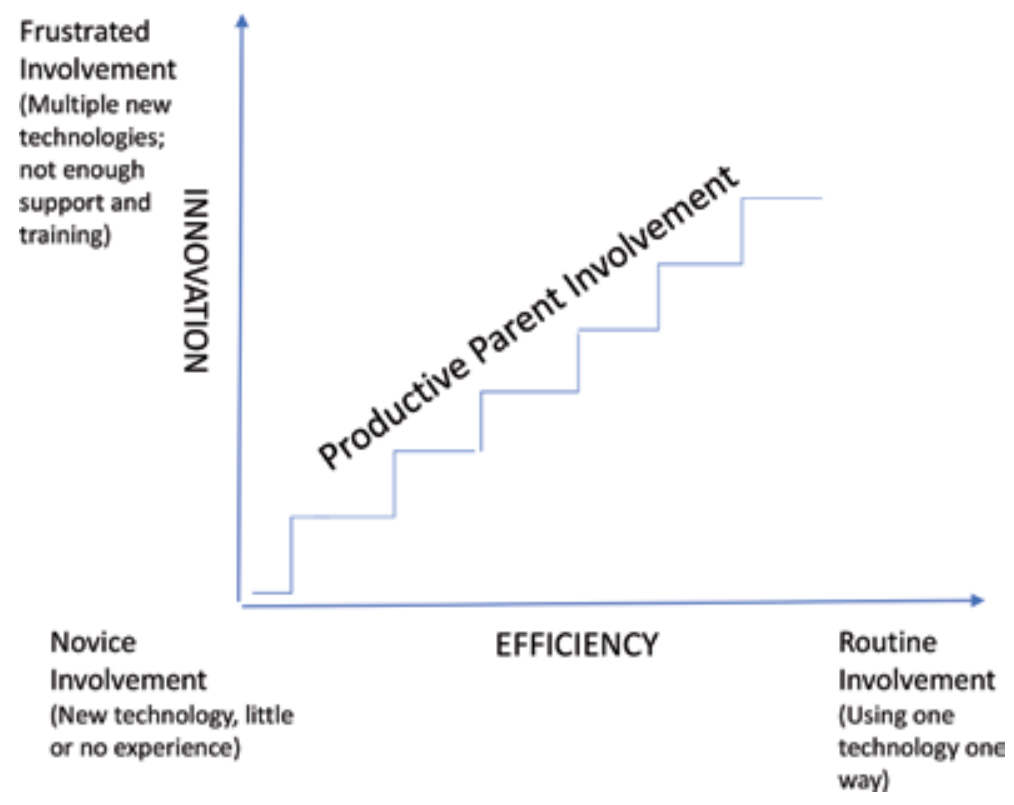

Figure 2.

Technology and productive parent involvement.

involvement. In this version of the model, novice involvement is that in which parents have little to no experience or knowledge of a new technology being utilized. As an example, imagine that schools and/or teachers are attempting to try new technologies to support parent involvement. However, parents are not receiving the proper guidance or support to experience the value of the technology. Parents may try the new tools, become frustrated, and then ultimately decide not use them. At the school level, this might include utilizing a new parent portal designed to provide information about school events and grades. At the classroom level, teachers may ask parents to help their students use specific apps to complete homework assignments. When parents are new to the technology, they do not feel comfortable enough to use it efficiently nor do they have enough experience with it to support their students' learning.

Frustrated involvement occurs when parents are asked to learn to use multiple technologies with little support. They might also be asked to use too many technologies (i.e., apps for homework, texting and email for communication, and portals for information). As more school districts adopt one-to-one device programs, parents are likely to see a wide range of technologies that their children are being asked to use. Without proper guidance and support, they may become frustrated and decide that they are unable to be involved as much as they would like. Parents are also likely to become frustrated when they are asked to utilize technology to increase homeschool connections that are primarily unidirectional [16].

When parents use a particular technology one way without making adjustments based on the academic content, students' understanding, cultural knowledge, or personal interests and routine involvement becomes the norm. While this type of involvement may be fine in the short term [17], it does not hold much promise for sustained engagement.

By using a technology-enhanced social learning environment, we avoid frustrated and routine parent involvement because parents are invited to participate in students' learning in a variety of activities. They are asked to engage in familiar activities like discussing everyday ideas and explaining scientific phenomena. They are asked to complete demonstrations and experiments at home with their students 
and they are invited to share their cultural knowledge and expertise. The social learning environment remains the same, but the activities that parents participate in with their students is ever-changing. Over time, parents are able to become active and engaged participants in students' academic experiences. They are more likely to understand what students are learning in their classes and know how to support them at home. They are empowered to engage in productive parent involvement where share knowledge, learn new ideas, and try new activities with their children.

\section{Parent roles in a technology-enhanced social learning environment}

In the ESPRIT Project, parent involvement occurs through discourse within a technology-enhanced social learning environment. By assigning prompts that students and parents complete together, teachers are inviting parents to take on a variety of roles that enhance students' learning experiences. In our work, one way that we explain the various participation dynamics is to characterize parents' participation by describing the roles they play. The roles could vary based on the structure and content of the prompt. They could also vary based on the parents' personality and experience with the project activities. We have observed four main roles that parents take on as they generate video responses with their children: [1] passive participant, [2] scientific knowledge resource, [3] cultural knowledge resource, and [4] co-learner.

Many parents begin as passive participants. They watch and listen as their children create responses or engage in activities specified in prompts assigned by their science teachers. Even though they are not speaking, parents show signs of being involved and attentive. They look from the student to the camera and smile and nod as the student talks. Although they are largely observing the student's response, parents who are passive participants are showing support and involvement, and the students and parents are experiencing positive benefits. When parents take on this role, students are aware that their parents have an interest in their academic endeavors, and parents are learning about the content students are covering in their science classes. An example of passive participation is illustrated in a response between a student and her father. The prompt asks, "What is one example of a chemical change you have observed at home or at work, and what evidence do you have that it was a chemical change and not just a physical change of matter?" The video response begins with the student introducing herself and her father. Her father says, "Hi.," smiles and waves and then looks at his daughter. The daughter proceeds to explain that there are chemical changes taking place when cornbread bakes while her father watches. In responses like these, the students are sharing scientific knowledge and modeling how to respond so that parents are more likely to actively participate in future responses.

Another SLE prompt asks, "What is the oldest thing you own? Do you know how old it is and where it came from?" In one of the responses, we can see and hear the student talking while her mother is off camera giving her details about the items she is describing and directing her to turn the camera around to show some of the items. Even when they are responding directly to the prompts, several parents' initial responses are voice only responses. They do not show their faces, but they provide information related to the prompt.

After observing their children creating one or two prompt responses, parents are likely to transition from being passive participants to engaging in more active roles. Once parents are actively participating it is possible to further characterize their roles by the type of information they share.

In some cases, parents serve as a scientific knowledge resource. They respond to prompts by primarily discussing scientific content. For example, in some video 
responses, parents use scientific terms for rocks they have observed and weather events they have experienced. In other responses, they share their understanding of scientific practices and how they use science in their everyday lives and careers.

Parents take on the role of a cultural knowledge resource when they respond to a prompt by primarily sharing cultural knowledge and experiences from their everyday lives. For example, in one prompt, the teacher asks how parents use plants in their everyday lives. Parent responses include information about how they use plants for cooking, for decoration, and for medicinal purposes. In both of these roles, students are off camera or are seen watching and listening to parents. In response to a prompt asking parents and students to describe the most interesting rock they have seen, parents shared details about the rock and also explained why is it so interesting. They often mentioned family vacations, other family members, or their home countries. Students did the same. In some of the responses posted by Latinx families, the student speaks in English and the parent speaks in Spanish. Multiple teachers have mentioned that they use these "dual language" responses as powerful opportunities to connect home and school experiences.

When parents are involved in their students' learning as a resource the experience is largely passive for the students. However, students are benefitting from revisiting scientific information covered in their classes or hearing new scientific ideas. When parents share cultural knowledge, students see the value of their funds of knowledge [18] and make important home-school connections.

A fourth role we have observed is that of co-learner. In this role, parents discuss the content targeted in the prompt or activity with their child. The responses may focus primarily on cultural knowledge, scientific knowledge, or integrated ideas that include cultural and scientific knowledge. Parents and students engage in turn taking as both participants actively make contributions to the learning experience. For example, in a video response describing chemical changes, a mother and son take turns speaking as they present a lighted candle and discuss that there is evidence of a chemical change as it gives off heat and light. In this role, parents and students are actively engaged in sharing ideas. They are both likely to learn new knowledge. Students see that parents have knowledge $v$ to their academic studies. In discussions with parents about their experiences in the social learning environment activities, several of them mentioned that they were delighted by the new appreciation their students had for them as they realized that their parents had knowledge relevant to what they were learning in school. Teachers highlight parents' knowledge and students' culture when they show the responses during class.

\section{Conclusions}

New understandings of parent involvement are necessary as more efforts are made to use technology to connect students' home and school environments. The work in this chapter expands parent involvement research by focusing on how parents are involved in academic tasks with their students. It also recognizes the power of technology to create new pathways for parent involvement and contributes to a growing body of work focusing on parent roles and outcomes [19].

The flexibility and accessibility of mobile technologies and apps allow parents who may not be typically involved in education to engage in a range of activities that can enhance their children's educational experiences. Technology can expand parent involvement from unidirectional, school-based, experiences to communitybuilding experiences that encourage parents to discuss academic ideas with their children, their family members, and other families in their school community. 
In the ESPRIT project, we have observed how technology can help parents from diverse backgrounds to engage in academic activities with their students and have an impact on their students' classroom experiences. Parents share their knowledge in their own voice and in their first language. In some instances, the teacher shows the video response in class and the student translates. This sends a powerful message that the students' funds of knowledge are valued in their classrooms. Even if teachers do not show all of the video responses in class, the act of being asked to engage in the SLE tasks, has impressive impacts. Students see that their parents have valuable knowledge to share, and parents feel validated as key advocates in their children's academic experiences.

The roles that parents play in the SLE activities illustrate that technology enhanced interventions can increase and sustain parent involvement so that parents are able to engage in productive parent involvement. The SLE is flexible enough that teachers can invite parents to participate in a multiple roles across a wide range of content areas. Parents and students are able to participate in academic activities that are culturally rich and personally meaningful.

There is evidence that when teachers enact technology-enhanced systems, parents are likely to use the system as well. Additionally, the more frequently teachers incorporate these systems into their classroom practices, the more they become a normative aspect of parent involvement [19]. Once this happens, a critical feedback loop can be created so that parents have a better understanding about what is happening in classrooms and teachers develop an awareness of the wealth of knowledge parents have that can enhance their instruction [20].

Parent involvement requires innovative thinking about ways to provide opportunities for parents to participate in their children's education experiences. This type of thinking is especially important in order to include parents from underrepresented groups who are more likely to experience inequities and disadvantages that prevent them from being as engaged as parents from majority populations. Technologyenhanced parent engagement activities like those discussed in this chapter can elicit academic discourse that is culturally responsive and personally relevant.

\section{Acknowledgements}

The ESPRIT project is funded by a grant from the National Science Foundation (\#1657088). Any opinions, findings, and conclusions expressed in the chapter are those of the author and do not necessarily reflect the views of the National Science Foundation. I would like to acknowledge the hard work and creative ideas from all of the ESPRIT research team members: Tayler Loiselle, Elena Gullickson, Isabel Lopez, Abdirashid Abdi, Corissa Wurth, Samuel Bullard, Madeline Quickstad, Daria Zharova, and Lucas Simpson. This work would not be possible without all of you.

\section{Conflict of interest}

Keisha Varma has NO affiliations with or involvement in any organization or entity with any financial or non-financial interest in the subject matter or materials discussed in this chapter.

\section{Notes/thanks/other declarations}

Thank you to all of the teachers, students, and parents who have participated in the ESPRIT project activities. 


\section{Author details}

Keisha Varma

University of Minnesota, Minneapolis, MN, United States

*Address all correspondence to: keisha@umn.edu

\section{IntechOpen}

(C) 2019 The Author(s). Licensee IntechOpen. This chapter is distributed under the terms of the Creative Commons Attribution License (http://creativecommons.org/licenses/ by/3.0), which permits unrestricted use, distribution, and reproduction in any medium, provided the original work is properly cited. (cc) BY 


\section{References}

[1] Fan W, Williams CM. The effects of parental involvement on students' academic self-efficacy, engagement and intrinsic motivation. Educational Psychology. 2010;30(1):53-74

\section{[2] Hill NE, Tyson DF. Parental} involvement in middle school: A metaanalytic assessment of the strategies that promote achievement. Developmental Psychology. 2009;45(3):740-763. DOI: 10.1037/a0015362

[3] Ito M, Gutiérrez K, Livingstone S, Penuel B, Rhodes J, Salen K, et al. Connected Learning: An Agenda for Research and Design. Irvine, CA: Digital Media and Research Hub. BookBaby; 2013

[4] Zhang J, Scardamalia M, Reeve R, Messina R. Designs for collective cognitive responsibility in knowledge-building communities. The Journal of the Learning Sciences. 2009;18(1):7-44

[5] Grolnick WS, Slowiaczek ML. Parents' involvement in children's schooling: A multidimensional conceptualization and motivational model. Child Development. 1994;65(1):237-252

[6] Schneider C, Arnot M. Transactional school-home-school communication: Addressing the mismatches between migrant parents' and teachers' views of parental knowledge, engagement and the barriers to engagement. Teaching and Teacher Education. 2018;75:10-20

[7] Goodall J, Montgomery C. Parental involvement to parental engagement: A continuum. Educational Review. 2014;66(4):399-410

[8] Ferlazzo L. Involvement or engagement. Educational Leadership. 2011;68(8):10-14
[9] Jeynes WH. The relationship between parental involvement and urban secondary school academic achievement: A meta-analysis. Urban Education. 2007;42(1):82-110

[10] Karıbayeva A, Boğar Y. To what extent does parents' involvement in middle school influence children's educational progress? Procedia-Social and Behavioral Sciences. 2014;152:529-533.

DOI: 10.1016/j.sbspro.2014.09.222

[11] Turney K, Kao G. Barriers to school involvement: Are immigrant parents disadvantaged? The Journal of Educational Research. 2009;102(4):257-271

[12] Coll CG, Akiba D, Palacios N, Bailey B, Silver R, DiMartino L, et al. Parental involvement in children's education: Lessons from three immigrant groups. Parenting: Science And Practice. 2002;2(3):303-324. DOI: 10.1207/S15327922PAR0203_05

[13] Ramirez AF. Dismay and disappointment: Parental involvement of Latino immigrant parents. The Urban Review. 2003;35(2):93-110

[14] Özdamlı F, Yıldız EP. Parents' views towards improve parent-school collaboration with mobile technologies. Procedia-Social and Behavioral Sciences. 2014;131:361-366

[15] Schwartz DL, Bransford JD, Sears D. Efficiency and innovation in transfer. In: JP. Mestre (Ed.). Transfer of Learning From a Modern Multidisciplinary Perspective. Greenwich, Connecticut: Information Age Publishing; 2006

[16] Selwin N, Banaji S, HadjithomaGartska C, Clark W. Providing a platform for parents? Exploring the nature of parental engagement with school learning platforms. Journal 
of Computer Assisted Learning. 2011;27(4):314-323

[17] Lewin C, Luckin R. Technology to support parental engagement in elementary education: Lessons learned from the UK. Computers \& Education. 2010;54(3):749-758

[18] González N, Moll LC, Amanti C, editors. Funds of Knowledge: Theorizing Practices in Households, Communities, and Classrooms. Mahwah, NJ: Lawrence Erlbaum Associates, Inc.; 2006

[19] Paiva JC, Morais C, Moreira L. Activities with parents on the computer: An ecological framework. Educational Technology \& Society. 2017;20(2):1-14

[20] Blau I, Hameiri M. Teacherfamilies online interactions and gender differences in parental involvement through school data system: Do mothers want to know more than fathers about their children? Computers \& Education. 2012;59(2):701-709 


\title{
Improving Online Education Using Big Data Technologies
}

\author{
Karim Dahdouh, Ahmed Dakkak, Lahcen Oughdir \\ and Abdelali Ibriz
}

\begin{abstract}
In a world in full digital transformation, where new information and communication technologies are constantly evolving, the current challenge of Computing Environments for Human Learning (CEHL) is to search the right way to integrate and harness the power of these technologies. In fact, these environments face many challenges, especially the increased demand for learning, the huge growth in the number of learners, the heterogeneity of available resources as well as the problems related to the complexity of intensive processing and real-time analysis of data produced by e-learning systems, which goes beyond the limits of traditional infrastructures and relational database management systems. This chapter presents a number of solutions dedicated to CEHL around the two big paradigms, namely cloud computing and Big Data. The first part of this work is dedicated to the presentation of an approach to integrate both emerging technologies of the big data ecosystem and on-demand services of the cloud in the e-learning field. It aims to enrich and enhance the quality of e-learning platforms relying on the services provided by the cloud accessible via the internet. It introduces distributed storage and parallel computing of Big Data in order to provide robust solutions to the requirements of intensive processing, predictive analysis, and massive storage of learning data. To do this, a methodology is presented and applied which describes the integration process. In addition, this chapter also addresses the deployment of a distributed e-learning architecture combining several recent tools of the Big Data and based on a strategy of data decentralization and the parallelization of the treatments on a cluster of nodes. Finally, this article aims to develop a Big Data solution for online learning platforms based on LMS Moodle. A course recommendation system has been designed and implemented relying on machine learning techniques, to help the learner select the most relevant learning resources according to their interests through the analysis of learning traces. The realization of this system is done using the learning data collected from the ESTenLigne platform and Spark Framework deployed on Hadoop infrastructure.
\end{abstract}

Keywords: online education, e-learning, online learning, big data, cloud computing

\section{Introduction}

Firstly, distance education has been developed mainly to make distance education accessible to all those who cannot follow face-to-face education, whether for reasons of geographical distance, lack of financial resources, or for lack of time. 
In fact, since the emergence of programming languages, several learning systems have been created that aim to computerize the pedagogical activity in order to facilitate learners' access to training without having to be physically present. So, e-learning platforms are mainly computer applications dedicated to education [1] The Francophone community, which is interested in the development of teaching through computer technologies, calls all systems, platforms or software for learning by Computing Environments for Human Learning (CEHL). In this context, a CEHL is a set of tools, systems and learning platforms based on the use of new information and communication technologies to enable to the learner to realize his formation course without constraints of time and distance. They are designed to promote learning and build knowledge for the learner through computer-based learning situations in the form of classes, exercises, or other activities. Many terms have been used to describe this mode of distance learning, including E-learning, online learning, CAT (Computer Assisted Teaching), ITS (Intelligent Tutorial Systems), Distance Education, Distance Training, WBT (Web-Based Training), M-learning (Mobile Learning), MOOC (Massive Open Online Courses), etc. [2]. As e-learning has many advantages such as flexibility, diversity, openness, etc., it becomes an essential way to acquire new knowledge and skills and to take lessons anytime, anywhere and from any device. And, this will not replace face-to-face teaching but greatly enhances the effectiveness of education.

Today, the IT world is experiencing a strong technological development in terms of resource acquisition, data management, and manipulation. This development is marked by the evolution of the cloud computing model and the advent of the new generation of big data technologies. All of these technologies have upset existing practices by introducing new forms of on-demand services, scalable architectures, and distributed approaches for distributed data processing and analysis.

In this context, the cloud aims to meet the strong demand for e-learning from universities and training organizations that need to develop, execute and deploy high-performance applications at an optimized cost. It also aims to enable e-learning professionals to deal with the multiplicity of devices (desktop, smartphones, and tablets), operating systems, programming languages, and development frameworks. Furthermore, big data technologies will allow an e-learning system to automatically evolve and adapt to different situations depending on the learner's profile and interactions. Indeed, thanks to the integration of big data in CEHL, an online learning system now has the ability to make decisions and make predictions automatically, without the intervention of a human being, through very advanced models and algorithms of machine learning, which is an integral part of big data.

Recent IT innovations have transformed all areas, including the field of distance learning. Indeed, CEHL have always evolved. Since, the computer, at first, the Internet, then, the cloud computing and the big data, at the moment, appeared for educational use. However, these CEHLs have never been perfect. They are constantly asking for improvements and adjustments simply because we are facing many changing realities and technological developments. So systems, structures, and e-learning processes must remain flexible to be able to adjust to these changes. Our work is part of the research work on CEHL and focuses on the integration of new information and communication technologies into distance education. More specifically, this chapter situates in the context of the development and continuous improvement of CEHL through the implementation of an open, adapted and intelligent online learning platform, which takes into account dimensions of resource sharing, availability and quality of the learning service, and at a lower cost.

To do this, it has proved essential to incorporate modern technological innovations into the CEHL. Thus, this work chooses to use the services provided by cloud computing, as a promising IT model, enabling the outsourcing of hardware, 
software, and platform resources to remote servers of a cloud provider in order to make them accessible on the internet in the form of services while facilitating their acquisition and optimizing their exploitation. Moreover, it uses the latest technological advances through the implementation of advanced technologies of the big data ecosystem in e-learning systems. Big data offers, in addition to massively parallel computational powers and distributed storage capabilities, sophisticated methods, and algorithms dedicated to machine learning to process and extract knowledge from the various types of data produced by e-learning systems, including learner profile information, activities, preferences, results, etc. This work set up a recommendation engine, the world's most popular big data application, to help and guide the learner to easily identify and select the most relevant educational resources by offering him an intelligent system capable of generate a catalog of courses adapted to their interests and their cognitive level through the analysis of historical data of learning activities.

\section{Related works}

The integration of big data and the cloud into e-learning systems is one of the main tracks of this research work which aims to take advantage of on-demand services, and exploit powerful technologies of distributed storage, parallel processing, and real-time analysis to solve some problems of e-learning systems, e.g. recommendation, prediction, motivation, and handle huge amounts of heterogeneous data. This section presents the state of the art of big data and cloud in relation to the e-learning domain. It explores the research that has been done by researchers to integrate these three great paradigms by proposing architectures, approaches and use cases.

In this context, the work [3] addresses the incorporation of the big data into the online learning system by proposing a framework to provide a high quality learning service. This framework facilitates the combining of the e-learning field and big data ecosystem in order to benefit from the advanced techniques of data management and analysis. It consists of three layers. Firstly, there is the e-learning layer which includes educational pedagogical methods, teaching contents, and a set of technologies dedicated to education such as Learning Management System (LMS), Virtual Class Room (VCR). This layer also contains learner information, e.g. profile, preferences, interests, and interactions with the learning system. Secondly, there is the big data layer. Indeed, the data collected from the e-learning platform are passed through this extraction and processing layer in order to prepare, to analyze this data which will be transmitted, subsequently to the third layer of results interpretation and data visualization via several presentation techniques provided by dedicated user applications.

This work [4] aims to show how big data can help solve some distance learning problems by exploiting its technologies in learning content analysis to ensure efficiency and reliability e-learning systems. It uses some powerful big data techniques and tools, such as Hadoop, MapReduce, and HDFS. It also aims to propose a methodology to incorporate the tools and Frameworks big data in the field of CEHL. This methodology includes four steps, which are: first, identifying likely sources of educational data. These data can be of various types such as e-learning databases, e-mails, social networks, etc. Then the third step is data extraction which concerns the collection of data from different sources. Next, there is the big data processing step, which consists in choosing the most appropriate programming language and identifies an appropriate algorithm for returning the results requested by the user. The visualization of data is the fourth step that aims to present the results of analyzed data in an interactive visual form for accessible and understandable. 
The research work [5] addresses the use of big data in the academic context. It proposes a model for adapting big data technologies with e-learning platforms. This aims to integrate existing LMSs already in universities with the Hadoop Framework deployed as a cloud SaaS service. In order to exploit the data of a traditional LMS system, Hadoop uses two methods for this purpose. The first method is to migrate the relational database from LMS to an HDFS distributed file system. The second mechanism is to transfer the structured data from LMS into a Data Warehouse. After integrating LMS data into the Hadoop Framework, it is possible to apply conversions and filtering to this data, and then perform advanced analysis. These analyses can greatly contribute to the development of an adaptive and personalized learning system.

We note the research work that was done in this field does not provide a real use case or application based on the software libraries of big data ecosystem in online learning systems, such as high performance machine learning techniques of Spark MLlib or scalable algorithms of Mahout Framework. This is why in this work we were interested, firstly, in proposing a new approach for integrating big data, cloud computing and online learning systems. In addition, this chapter attempts to set up a large-scale big data application. It consists in developing a recommendation system capable of providing adapted and personalized courses to each learner according to his preferences, his cognitive level and his learning style.

\section{Big data}

In the literature, the term big data first appeared in 1997 according to the IEEE digital library archives, in a published scientific article [6] by two NASA researchers: Michael Cox, and David Ellsworth, on the technological challenges of visualizing large data sets and the difficulty of systems in dealing with massive volumes of data.

In 2003, Google has published a paper about the idea behind of its file system [7], and reveals the first secrets of the success of its search engine. One year later, Google developed MapReduce as a parallel and distributed computing model programming for massive data processing. A year later, Doug Cutting and Michael Cafarella, at that time employed at Yahoo and inspired by the principle of MapReduce, develop Nutch Search Engine, which will become today Apache Hadoop [8].

\subsection{Defining big data}

According to International Data Corporation (IDC), "Big Data Technologies describes a new generation of technologies, architectures, tools, and techniques designed for extracting value from very large volumes of a wide variety of data, allowing a high speed of capture, discovery and/or analysis “ [9]. Gartner in his report [10] gave the following definition: "big data brings together data of great variety, arriving in increasing volumes, at high speed. This is called 3V". In other words, big data is composed of complex and very diverse data. This large data is generated at a high speed as current database systems become unable to handle it. So, big data tools can provide effective solutions to overcome these challenges. NIST suggests that, "Big data is when data volume, acquisition speed, or data representation limits the ability to perform efficient analysis using conventional relational models or requires the use of a significant horizontal scale for effective handling. big data refers to the need to distribute and parallelize the data computing and storage in data-intensive applications" [11].

Specifically, big data can be divided into data science and big data technologies. Data science is "the study of techniques covering the acquisition, conditioning, 
evaluation and exploitation of data", while big data technologies are "systems, software libraries, tools, Frameworks with their algorithms associates that allow distributed processing and analysis of big data problems between clusters of machines" [9].

\subsection{Big data characteristics}

The characteristics of big data are five, or the $5 \mathrm{~V}$ model. Vs refer to five key elements that are: volume, variety, velocity, veracity, and value. Figure 1 gives a summary of the different characteristics of big data.

Volume refers to the huge amount of data to be stored, processed, analyzed and disseminated by big data tools and technologies. Indeed, the volume of data, generated and handled by companies, is constantly increasing. Currently, the data is measured in petabytes, exabytes, even zettabyte.

Variety refers to the variety of formats and types of data. In fact, big data technologies can handle heterogeneous data from various sources. The classic format is that of the relational database, in which the data is stored according to a rigid and organized schema. But currently, more than $80 \%$ of the data generated by companies is of the semi-structured and unstructured type, for example, text, image, video, voice, etc. For this, big data offers the ability to gather all these data and analyze them.

Velocity refers to the speed or frequency at which the data are generated and used. This aggregated data must be exploited in real time. This requires highperformance computing and storage powers and robust analysis tools. In this sense, the IaaS services of the cloud prove to be an adequate solution allowing theoretically unlimited computing resources.

Veracity means the validity and quality of the data captured. It is the credibility and reliability of the data on which a data scientist is based to perform analysis in order to make decisions. Therefore, the big data platform and solutions aim to select and search the exact data in giant databases by eliminating useless data, through innovative tools and techniques [12].

Value refers to the ability of big data to derive value from huge masses of heterogeneous data. It's good to have access to large volumes of data, but we still have to

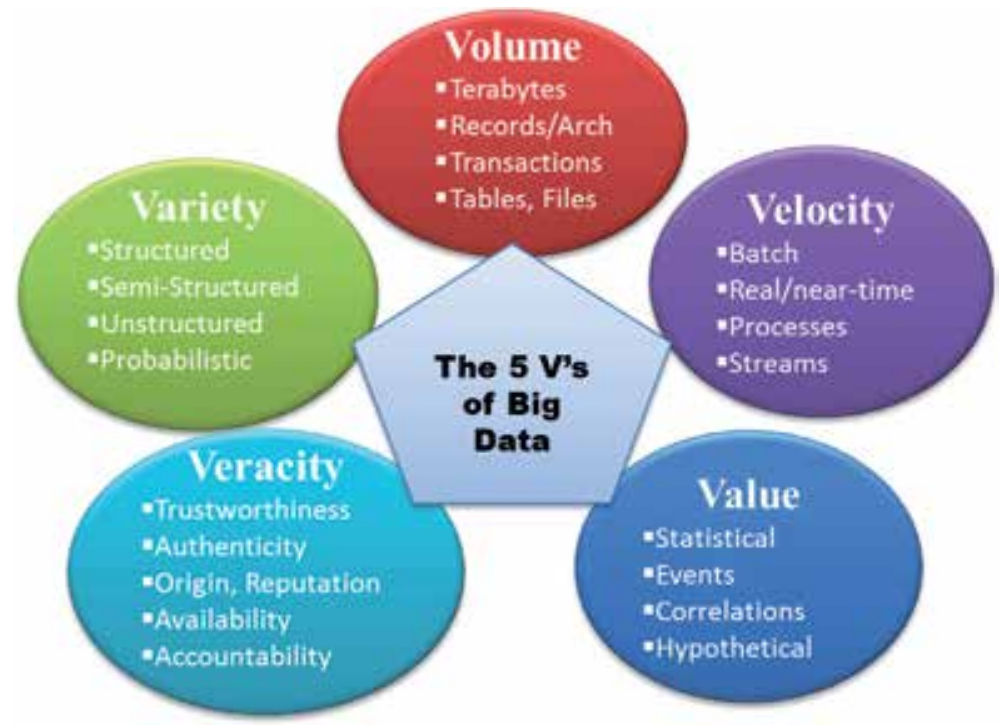

Figure 1.

Characteristics of big data or $5 \mathrm{~V}$. 
turn them into value. Indeed, it is necessary that the new generation of distributed technologies (Hadoop, Spark, etc.), DBMS NoSQL, and advanced methods, serve something useful and usable for businesses and universities.

\subsection{Types of data}

In general, there are three types of data to consider. In addition to structured type managed by a relational database management system, there are two other new types of data, including unstructured and semi-structured ones which are handled by the big data technologies. First, the structured data are those whose set of possible values is determined and known in advance. They respect a predefined model that allows them to be accessed and managed very easily. Structured data is often managed by relational database management systems in the form of tables, and it is handled using a query language such as SQL or PL/SQL. Secondly, the type is the unstructured data which is the opposite of the first type (structured). These are data that do not respect a data schema and are not organized in a predefined way. This type of data can have various formats such as videos, pdf, images, doc, text files, activities on social networks, etc. They are both complex and bulky, and traditional databases cannot manipulate or query them. In addition to structured and unstructured data, there is also a third category, called semi-structured data. Semi-structured data is information that is not stored in a structured dataset, but its structure contains tags that make it easier to manipulate and analyze. Examples of semi-structured data may include XML files, text emails, and JSON documents.

\subsection{Big data and cloud computing}

Big data technologies require processing power, speed of execution and huge storage space. This requires big computers with processor, memory, and disk space resources that offer tremendous computing power and performance. In this context, the services of cloud computing can be used. In fact, cloud computing and big data are two inseparable elements. Cloud computing offers theoretically infinite processing power and storage capacity, in addition to the availability of resources. Indeed, we cannot discuss the integration of big data and e-learning platforms without considering the cloud, because it gives the resources needed to deploy big data technologies and tools, as well as learning management systems (LMS). In addition, the cloud offers a preconfigured, ready-to-use environment that incorporates massive data processing technologies.

\section{Integration of big data and online learning systems}

\subsection{Proposed approach for integrating big data, online learning systems, and cloud computing}

Big data and the cloud have become key components of any information system, including e-learning systems. As a result, their integration is a major necessity to free themselves from hardware and technical architecture installation issues and to take advantage of the important volumes of data generated by such a system, as well as to gain flexibility in processing and analysis. Identifying useful information from learning data is a big challenge, especially with the significant increase in the amount of data produced every day by online learning platforms. To overcome this problem, big data ecosystem provides advanced technologies, methods, and techniques trough machine learning algorithms in the form of software libraries (APIs, 


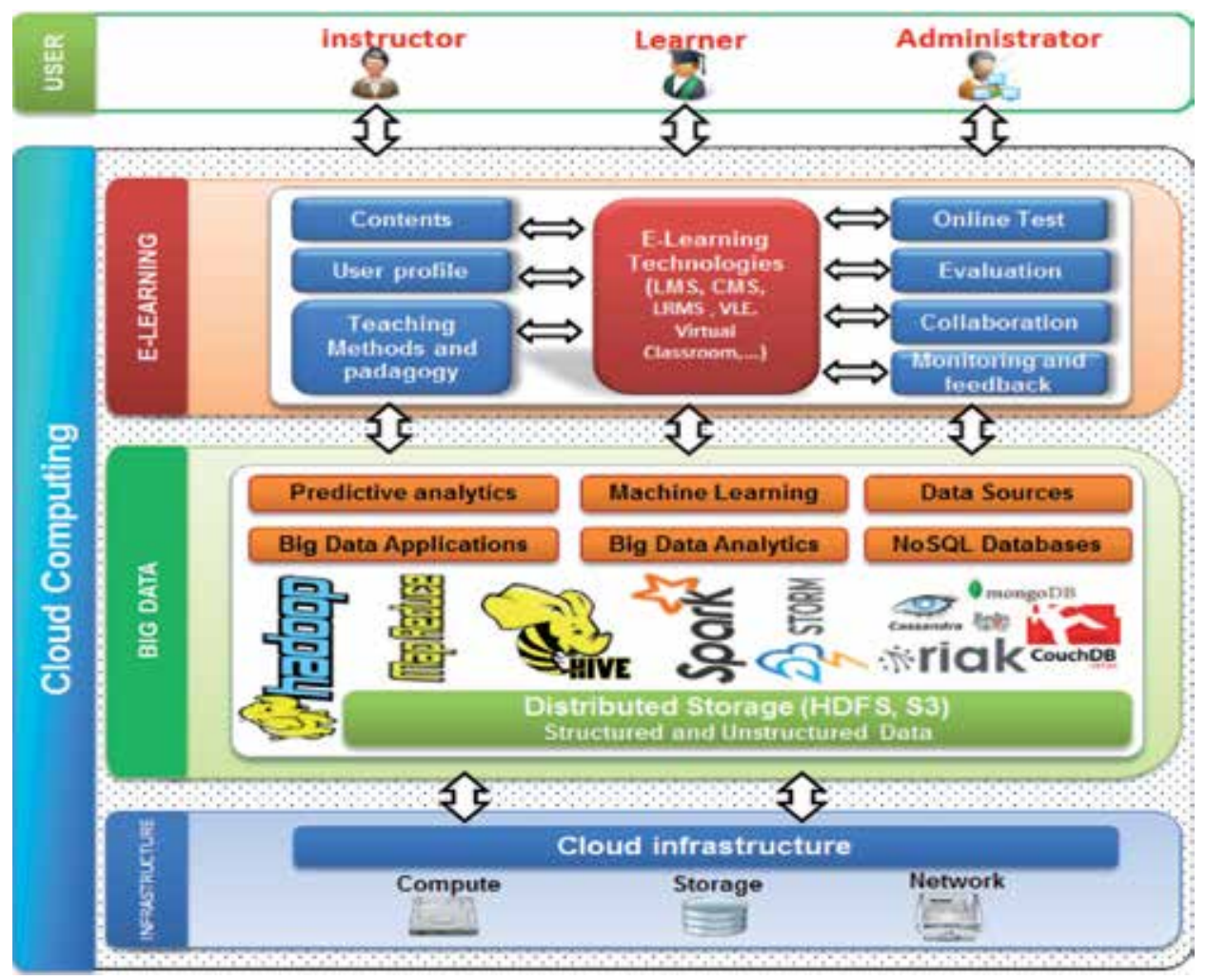

Figure 2.

Integration of big data, online learning systems, and cloud computing.

Frameworks, etc.) that are very powerful and easy to use. Such technologies make it possible to prepare and analyze, in a distributed manner, large amounts of data in order to make the best decision and to help e-learning professionals to be able to continuously enrich and enhance their strategies to be adapted to the interests and preferences of each learner [13] (Figure 2).

Infrastructure is the first layer that is the lowest level of the proposed approach. The infrastructure layer is built with compute, storage, and network resources that are virtualized and delivered as services through the cloud. The latter is responsible for providing virtual computing resources and the big data technologies needed to provide e-learning systems with a favorable execution environment. The resources of this layer are scalable. If, for example, when analyzing a massive volume of data, an application requires a huge amount of computing time or disk space, the cloud infrastructure will automatically expand to allocate the resources required by this application. This mechanism allows great flexibility over the traditional approach based on traditional hosting technologies in which server resources are limited. The great advantage of this layer is that it offers a scalable, resilient and fault-tolerant infrastructure.

The second layer of this approach is that of the big data ecosystem. The big data layer includes decentralized storage technologies and distributed large data, massively parallel computing, advanced analysis, optimization and visualization of the processing results. It groups together various big data technologies which can be classified in:

- Distributed file systems: stores data in multiple nodes in a cluster in a replicated manner to provide redundancy and high availability. HDFS remains best known as an open source solution for distributed data storage and management. 
- NoSQL movement: represent the new generation of databases management systems. They allows moving away from the relational model and overcoming the limitations of RDBMS in terms of the amount and types and formats of the data handled. Among the distributed databases are CouchDB (documentoriented), Cassandra and Hbase (column-oriented), which do not impose strict schema rules as in the case of the relational model.

- Distributed processing and predictive analysis infrastructure: allows parallel computing of large data sets across machine clusters. The best known open source example of distributed systems is Hadoop developed by the Apache Foundation. They are also tools implementing mathematical methods applied to computing for the analysis of giant databases via predictive models of machine learning. In addition, Apache Spark is a high-performance framework dedicated to the design and creation of large-scale applications for predictive analysis in memory.

The e-learning system represents the third level. This is the application layer represented by the e-learning system containing, in particular, learning management tools (LMS), content management systems (CMS), virtual learning environments (VLE), etc. The information in this layer can be data in the form of educational content, information on the learner or teacher profile, course registrations, etc. These data play a very important role and will be useful in generating personalized learning resources by adapting learning content to the needs of each learner to provide a more appropriate learning platform. To perform this adaptation mechanism, the e-learning system must use the technologies of the lower layer (big data) to exploit advanced predictive models by applying parallel algorithms of machine learning on the learning data.

Generally, an online learning is a platform consisting of hardware, software, and user. The hardware includes memory capacity, network bandwidth, and CPU provided by the IaaS services of cloud. The e-learning system is the software. Users are actors who use the system to communicate, store and process information. The users are mainly the learner, the teacher, and the system administrator. In addition, a fourth player is data scientist can be added who is responsible for configuring, installing, monitoring and controlling the distributed environment of the cluster, as well as developing and deploying analytics models and implementing data mining techniques on platforms. Big data.

\subsection{Methodology}

Generally, in the different areas, it is a priority to have a clear methodology before starting the implementation phase or the operationalization of a project. This methodology shows the process and the mechanism to better manage big data projects. So, we must address a personalized methodology adapted to the context of e-learning. To do this, we identify the key steps in the big data process that, from the sources of data generated by online learning platforms, extract value and insights to help educational distance to make good decisions. This includes the acquisition, discovery, preparation, modeling, processing and visualization of the results of the data analysis. When data is effectively captured, processed and analyzed, e-learning professionals can have a complete understanding of their learners, educational resources, assessment results, and so on. In this way, they will be able to offer more personalized learning activities, produce relevant teaching strategies, provide adaptive learning to each learner, and improve the quality of educational content. Figure 3 schematizes our methodology for using big data in 


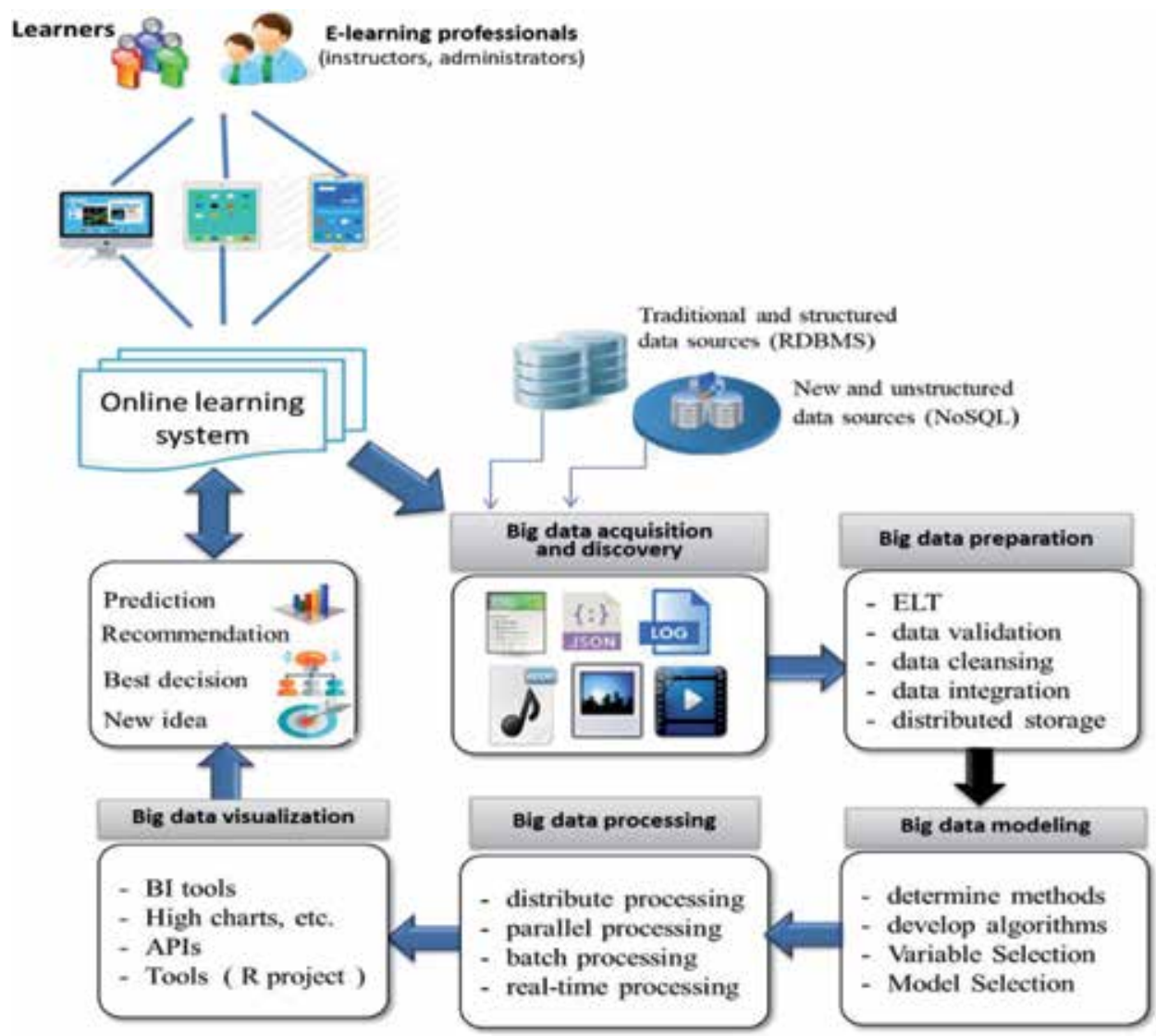

Figure 3.

Methodology for dealing with massive data in online learning.

distance learning environments. It describes the different stages, including big data acquisition and discovery, preparation, modeling, processing, and visualization.

Actually, in order to handle the large volume of data produced by online learning platforms, the data itself must go through a series of five steps:

discovery and acquisition phase describes the process of collecting and discovering the data produced by the distance learning environments, which can be information about the learner (profile, knowledge, skills, etc.), and educational resources including all formats (text, image, video, web page, etc.). They also can captured from learners' interactions between learners and teachers through social networks, wikis, and forums.

The second phase of our methodology is that of data preparation that comes just after the acquisition and discovery phase. It is a coherent set of operations that retrieve, load, and transform (ELT) multiple data sources. Indeed, this phase includes the integration of the data generated by the e-learning platforms, prepare them and transfer them to be stored in a distributed file system or a NoSQL database such as Cassandra, HBase, etc. Data preparation is a crucial step in the analysis process because it is at this level that we have to filter the collected data to rule out unnecessary or noisy data such as redundancy and keep only those that are relevant and good quality, something that will be used later as input of the analytical model.

Big data modeling is the third phase of our methodology. It aims to specify a suitable method to take advantage of large datasets. To do this, it is necessary to determine the right model to apply on these data. Indeed, during this phase, we 
must identify the model, determine the appropriate method to use and develop the appropriate algorithm to implement the chosen method. In this sense, big data technologies implement various large-scale machine learning techniques, including: classification, clustering, association rules, regression, collaborative filtering. The best model depends on the type, quality, and size of the data to be analyzed and the available computing resources. It also involves data explorion to learn more about the relationships between variables and then selecting the most appropriate key variables for such a model.

Big data processing represents the fourth phase of our methodology. Actually, big data relies on a parallel computing approach to deal with the intensive processing needs and the increase in data volume. Technologies dedicated to data manipulation are transformed chronologically into batch processing, real-time processing and hybrid computing. Batch processing try to solve to the volume problem, real-time computing respond to speed issues, and hybrid computing is good for both. Distributed computing systems are widely developed, primarily to support the analysis of gigantic data, including Frameworks Hadoop MapReduce [14] and Apache Spark [15].

This phase aims to clearly and effectively visualize and communicate the results of the analysis of the learning data through rich tools and advanced software libraries to synthesize the information of the treatment. This often contains tables, in the form of graphical representations, such as curves, bars, sectors, and histograms. It also describes a set of techniques, software and utilities designed to help e-learning professionals to have a clear view of the enormous data generated by learners.

\section{Implementation and results}

To validate our model based on the integration of big data technologies and methods in the context of CEHL, a course recommender system has been implemented to show the effectiveness and usefulness of our contribution. It is about a recommendation engine acting as a predictive unit able to adapt to a given learning profile by anticipating its next actions through the suggestion of relevant pedagogical resources that best meet its preferences and interests. The aim is, therefore, to provide the learner with a personalized educational and pedagogical plan according to his profile. For this purpose, our recommender system uses advanced machine learning techniques, especially association rules method for extracting knowledge through the analysis of learning traces. The realization of this system was made using the historical data of learner's activities collected from the ESTenLigne platform of the Higher School of Technology of Fez. Our recommender system relies on a totally distributed architecture which consists in setting up a large-scale course recommender system. It was developed and tested using the FP-growth parallel algorithm, and the Apache Spark Framework. The deployment of this version is done through the Hadoop distributed cluster infrastructure.

\subsection{ESTenLigne project}

The present work is a part of the ESTenLigne [16] project, which is the result of several years of experience for the development of e-learning in the Sidi Mohamed Ben Abdellah University of Fez. It was started since 2012 by the EST network of Morocco, which aims the development of distance education based on new information and communication technologies through the implementation of open, adapted and free online learning platform, and taking into account the dimensions of exchange, sharing and mutualization of pedagogical resources $[17,18]$. Several 
works have been done as part of this project including the training of experts across e-learning in the context of the Coselearn I project, and teacher training through Franco-Moroccan EST [19] and IUT [20] cooperation [18, 21]. Furthermore, there are some researches that have been done around this project such as the analysis of the use of educational resources where the objective was to analyze the use of pedagogical resources in some courses namely the algorithmic course [22]. Also, a case study for collaboration analysis of online course based on activity theory [23]. In addition, the development an e-learning recommender system based on $\mathrm{R}$ environment [24].

In fact, the students have a lot of difficulties and are lost in the diversity of educational resources, particularly the large number of available courses. This requires the adaptation of the teaching to meet the needs of students. To solve these problems, we develop a course recommender system to promote learning to learners through creating a smart solution. It is able to generate the most appropriate courses automatically based on historical data of learner's activities.

\subsection{Association rules method}

In the area of machine learning, Association rules [25] is an unsupervised learning method, widely used in many areas, including referral engines, online purchase transaction analysis, and flow analysis. Clicks on multiple web pages [26]. Its purpose is to discover relationships between variables in a set of data, which we will call transactions, in the form of interesting association rules. In other words, this method consists in detecting associations between data stored in a giant database. It is a set of powerful exploratory techniques widely used in many sectors but also for scientific research purposes. The most popular application using the association rules is the one concerning the analysis of consumption habits. The power of the association rule method lies in its ability to extract hidden structures in a massive amount of data.

Generally, association rule technique produces a large number of rules, but to select interesting rules in the set of generated relationships, it has two important criteria for determining the quality of a rule by measuring its strength, namely: the minimum thresholds of support and confidence. Support is the percentage (\%) of transactions containing the set of items $\mathrm{X}$, while confidence is defined as the percentage (\%) of transactions containing $\mathrm{X}$, which also contain $\mathrm{Y}$. Therefore, a force association rule $\mathrm{X} \Longrightarrow \mathrm{Y}$ should satisfy: $\operatorname{supp}(\mathrm{X} \cup \mathrm{Y}) \geq \sigma$ and $\operatorname{conf}(\mathrm{X} \Longrightarrow \mathrm{Y}) \geq \delta$, where $\sigma$ and $\delta$ represent the minimum threshold of support and confidence, respectively.

As part of our research, we applied the rules of association technique in the context of a computer environment for human learning dedicated to e-learning. Therefore, a transaction in our case is represented by the learner profile. Likewise, the items are replaced by all available resources in the database. A transaction is represented by a learner's enrollment in a number of courses during his or her learning path. We can therefore define the support (1) and the confidence (2) as follows:

$$
\begin{gathered}
\operatorname{supp}(X \Longrightarrow Y)=\frac{\text { nombre d'apprenants inscrits aux } X \text { et } Y}{\text { nombre total d'inscriptions d'apprenants }} \\
\operatorname{conf}(X \Longrightarrow Y)=\frac{\text { nombre d'apprenants inscrits aux } X \text { et } Y}{\text { nombre d'apprenants inscrits aux } X}
\end{gathered}
$$

\subsection{FP-growth algorithm}

FP-growth [27] (Frequent Pattern Growth) is a very powerful algorithm for extracting the most frequent elements from large data sets by allowing a very fast discovery of the association rules without generation of candidates, which requires 
more memory and time processor. In fact, the generation and testing of candidates requires several analyzes of the database. By using FP-growth, the number of database scans is reduced to two. The first scan aims to count the support of each item, the non-frequent items are deleted, while the frequent items are sorted in descending order of support, in the form of a list of frequent items (L). Then, in the second scan the algorithm builds the FP-tree structure with the creation and insertion of the different nodes. These operations constitute the first step of the algorithm. On the other hand, the second step is to extract sets of frequent elements from the constructed FP tree. The FP-growth algorithm is based on the "divide and conquer" strategy of breaking down a problem into subproblems. First, it compresses frequent itemsets represented in the database using a compact data structure called FP-Tree (frequent-pattern tree) whose branches contain the possible item associations. The FP-growth method transforms the problem of finding the longest frequent itemset by searching for the smaller one and its concatenation with the corresponding suffix. This reduces the cost of research.

\subsection{Big data technologies and its components}

This section introduces all the big data technologies used as well as their different components. Each technology has a definite role and participates in the process of extracting prediction knowledge by providing a list of highly recommended courses according to the needs and interests of each learner. These technologies are deployed on a cluster infrastructure of nodes that are interconnected via network protocols to be able to communicate and exchange data during the analysis of learning traces. These technologies can be organized in three layers. Figure 4 describes the different big data frameworks used to develop the large-scale course recommendation system.

All implemented technologies can be grouped in 3 layers:

First, there is the layer of distributed data storage. We chose to use Hadoop's Distributed File System (HDFS). In fact, HDFS is a fault-tolerant file system capable

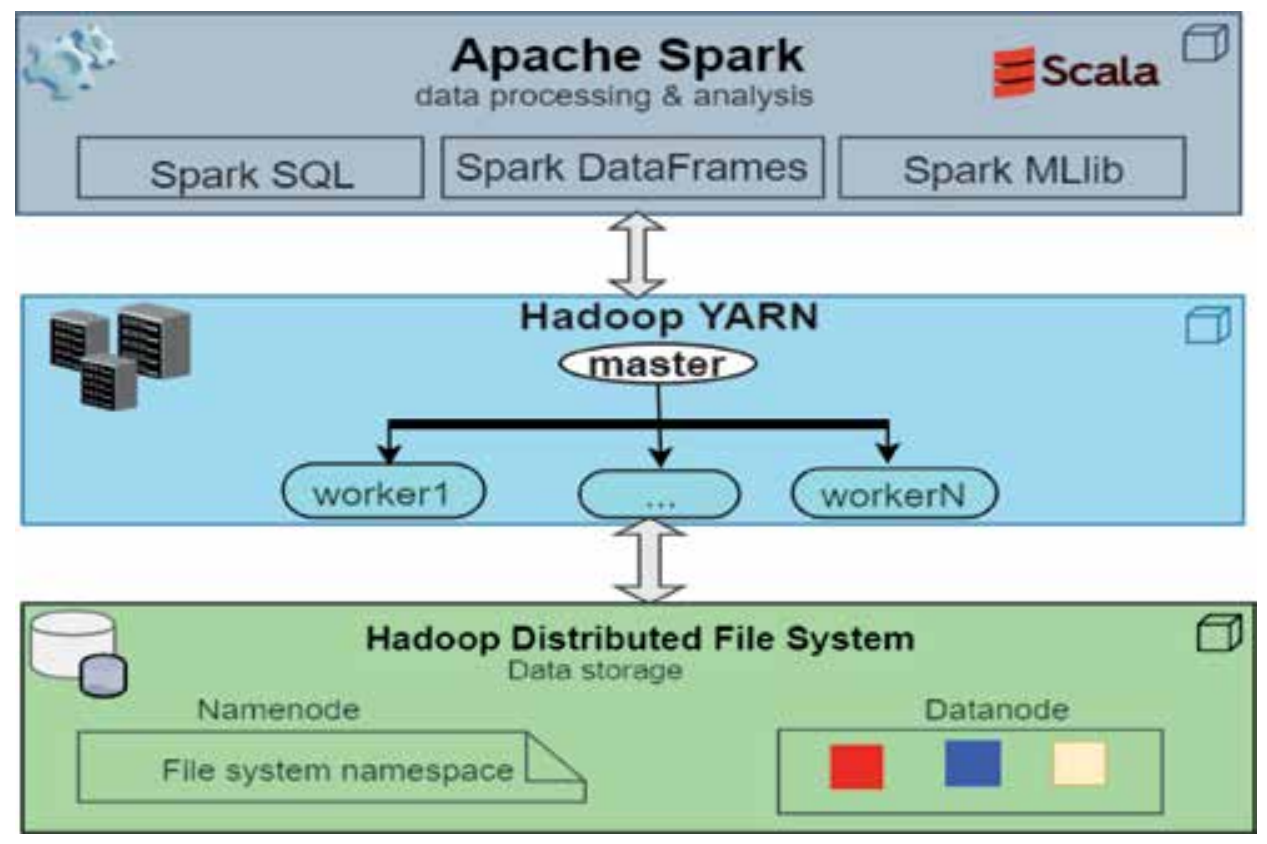

Figure 4.

Big data technologies. 
of managing distributed data across large clusters. It has a master/worker architecture. HDFS provides high performance access to large amounts of data. It creates an abstraction of hard drive resources to allow the management of distributed physical storage of multiple nodes as if there is only one storage space. In the HDFS architecture, data is managed across the cluster, in different Datanodes, by the workers in the form of block-structured files. The locations of these blocks and the namespace of the files and directories are kept in the Namenode component in the master node [28].

In the second level, Yarn [29] is found as the node cluster resource manager. This is a Hadoop module dedicated to scheduling and executing tasks, at the same time, on a number of computers in a cluster. It is also responsible for managing disk resources, memory, CPU and cluster network. Yarn's main idea is to separate resource management from the computational model. Indeed, Yarn will take care to rent the necessary resources and to distribute the basic tasks on different units of calculation of the machines of a cluster.

Finally, the upper layer represented by the Spark Framework [15] is responsible for the manipulation and analysis of the data. It is used to apply association rules techniques to learner learning data, collated from the ESTenLigne project. To implement our course recommendation system, Scala was chosen as the development language. The advantage of Spark is its ability to support multiple programming languages such as Java, Python and R. This framework provides many libraries. In our use case, we focused on just three components: Spark SQL, Spark DataFrames, and Spark MLlib.

- Spark SQL allows you to connect to the moodle LMS database and execute SQL queries.

- Spark DataFrames is a Spark module for structured data processing.

- Spark MLlib implements several machine learning algorithms, including the FP-growth parallel algorithm.

\subsection{Distributed system architecture}

In general, our approach is to generate recommendations by analyzing the traces of learning activities that are the source of knowledge in the process of personalization of learning resources provided to learners. The entry of the system thus consists of the history of course registrations, imported from the database of the e-learning platform. Figure 5 describes this architecture in detail.

In the beginning, we need to load the data produced by the learners' interactions with the ESTenLigne platform. Then, this data, loaded by the Spark SQL library, is processed in a distributed manner using the Spark Framework that runs on a Hadoop cluster and uses the Yarn Resource Manager. Indeed, Apache Spark provides a special library dedicated to machine learning techniques, called MLlib. This library proposes an implementation of the parallel FP-growth algorithm in the Scala language. Subsequently, the prepared data is analyzed using the FP-growth algorithm of the Spark MLlib library. Then, Spark connects to Hadoop HDFS to store the data on machine clusters. Then, the recommendation system generates the catalog of the most relevant courses. Finally, the results of the recommendation engine can be presented to the user in order to guide them and suggest the educational resources most suited to their interests. Thus, the learner can go through the courses recommended by our system and begin to learn those that suit his cognitive level and preferences.

Besides, our system uses the open source tool Ganglia. It is a highly scalable, distributed and scalable solution for monitoring large environments such as clusters 


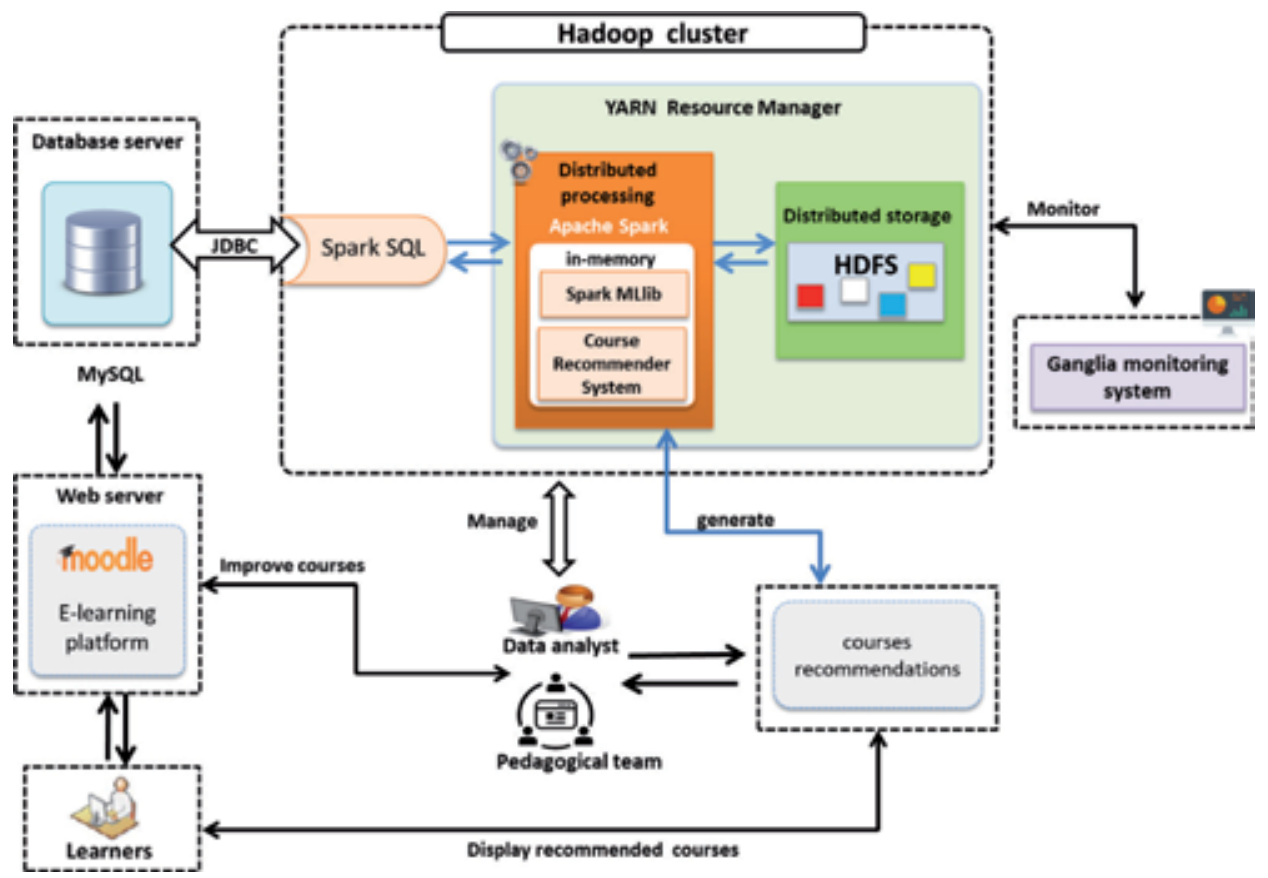

Figure 5.

Distributed architecture of course recommendation system.

and grids, as well as measuring performance and resource consumption such as CPU utilization, memory, and data storage of each node of the cluster. It also controls and visualizes network traffic, such as bandwidth usage or the amount of data transported over the network.

\subsection{Setting up the big data environment}

Considering the high cost of installing a physical infrastructure of big data clusters, the use of virtualization tools for a distributed architecture represents an alternative solution to configure, develop, test and validate our course recommendation system. The Hadoop multi-node configuration is done in a fully distributed environment consisting of three nodes. The machine with the IP address: 192.168.56.101 works as the Hadoop master, which contains the Hadoop components, namely ResourceManager and NameNode. The master node runs Hadoop processes to manage and coordinate cluster tasks and services. In fact, the virtual machine identified by the IP address 192.168.56.101 works as a master and worker at the same time. The other machines in the cluster are workers. The worker nodes are responsible for running the processes or the basic tasks of the parallel application. They also provide resources to the cluster to perform the processing of data assigned by the master. As shown in Figure 6, they respectively have machines with the IP addresses 192.168.56.102 and 192.168.56.103.

In order to build our big data infrastructure, we have prepared a cluster of three virtual machines. As a virtualization solution we used the free and popular VirtualBox solution. With the available computing resources, we created three virtual machines by installing the Ubuntu 18.04.1 LTS operating system on each node of the Hadoop cluster. These nodes are connected to each other using a private LAN. The capacity and configuration of all virtual machines are described in Table 1. 


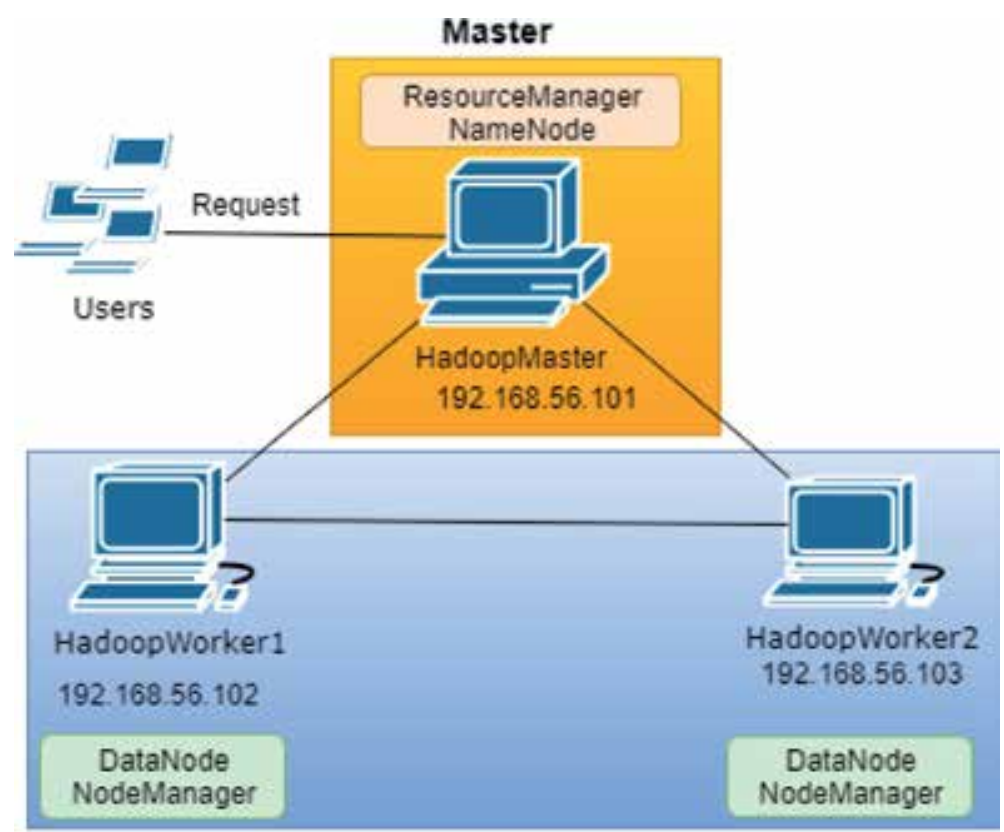

Workers

Figure 6.

Hadoop cluster configuration.

\begin{tabular}{lcccc}
\hline Machine & Network & Cores & Memory & Disk \\
\hline Master & 192.168.56.101 (master.domain.com) & 8 Core i5 (7th Gen) & 8 GB & 32 GB \\
\hline Worker1 & 192.168 .56 .102 (worker1.domain.com) & 8 Core i5 (7th Gen) & 8 GB & 32 GB \\
\hline Worker2 & 192.168 .56 .103 (worker2.domain.com) & 8 Core i5 (7th Gen) & 8 GB & 32 GB \\
\hline
\end{tabular}

Table 1.

Configuration of Hadoop cluster nodes.

After configuring the virtual cluster network, we unzipped and installed Hadoop 3.1.1 and Spark 2.3.1 at the master node of the cluster. Then we moved the installation folder of both Frameworks to the worker nodes using the SSH protocol. Similarly, we used the power of Secure Copy (SCP) to get the same copy of Apache Hadoop and Spark. The Java version 1.8 has been installed on each node and we have configured a password-free ssh between the nodes so that the master Hadoop node can connect, start, stop, and execute tasks in different workers.

\section{Results}

To run parallel FP-growth, we had to specify the minimum support and confidence thresholds in order to find the strongest correlations between course enrollments in learning activity traces. The number of interesting association rules changes according to the value of the support, the confidence and the size of the database. Thus, we used the minimum support threshold of $5 \%$ and we set $60 \%$ as the minimum confidence threshold. In fact, the course recommendation system generates two types of results that meet the specified support and confidence criteria. First, it finds the list of frequent courses in the database of the e-learning system based on the calculation of the support and the confidence of each itemset, it keeps only the list of itemsets that 
satisfy the condition of the minimum threshold of confidence. The 10 main rules of interest, ordered according to the confidence measure, are shown in Table 2.

According to the results obtained in Table 2, the rule of association between courts $\{11$ and 46$\}$ and $\{45\}$ has the greatest confidence. Similarly, the rule of association between the courts $\{7\}$ and $\{6\}$ has the lowest confidence. Based on calculated values and support and confidence, we can clearly identify the courses most likely to be followed by learners, and most relevant to recommend them. For example, rule $1\{11$, $46\}=>\{45\}$ has the greatest confidence, that is, the strongest. Our system therefore suggests course 45 to students who have already enrolled in courses $\{11$ and 46$\}$. According to the results of Table 2 , the confidence of rule 1 is $100 \%$, because, at the level of the database, we find that 56 students have enrolled in courses $\{11$ and 46$\}$, and that these 56 them also enrolled in course $\{45\}$. For association rule number 2 , the analysis of historical student registration data from the ESTenligne platform shows that 57 students took courses $\{11$ and 45$\}$, and 56 of them followed also the course $\{46\}$. So, the confidence of association rule 2 is $98 \%$. Therefore, our recommendation system recommends the course $\{46\}$ to students enrolled in courses $\{11$ and 45$\}$. With regard to association rule number 3 , there are 123 learners enrolled in the course $\{46\}$, of which 118 are also enrolled in course $\{45\}$. Thus, the confidence of rule 3 is $95 \%$. Our system therefore offers the $\{45\}$ course to students enrolled in $\{46\}$. For the 10 strongest association rules, we note that the confidence values are between 0.69 (69\%) and 1.00 (100\%), which demonstrates that we have achieved good results. We can therefore conclude that the course recommendation system that we have proposed can provide relevant teaching resources by recommending courses suitable to each learner in order to guide them through their learning path.

After establishing the recommendation model using the training dataset $(70 \%)$, it can also be used to predict the result of recommending courses to learners through the database. Test (test dataset) (30\%). The recommendation system generates a catalog of courses for each learner profile. Table 3 shows the top 10 predictions out of a total of 48 predictions.

The results of the prediction of the recommendation system that we have developed gives for each learner (id) the list of courses in which he participates and a catalog of the predictions of the courses. For example, our course recommendation system suggests courses 18 and 7 to the learner ( $\mathrm{id}=541$ ) who is already enrolled in courses 46, 6, 11 and 45. Also, he recommends course 14 to the learner ( $\mathrm{id}=720$ ) which follows courses 45,46 and 15 courses, etc.

\begin{tabular}{lccc}
\hline Rule & Antecedent & Consequent & Confidence \\
\hline$[1]$ & {$[46,11]$} & {$[45]$} & 1.000 \\
\hline$[2]$ & {$[45,11]$} & {$[46]$} & 0.975 \\
\hline$[3]$ & {$[46]$} & {$[45]$} & 0.952 \\
\hline$[4]$ & {$[45]$} & {$[46]$} & 0.919 \\
\hline$[5]$ & {$[7,6]$} & {$[18]$} & 0.868 \\
\hline$[6]$ & {$[7]$} & {$[18]$} & 0.818 \\
\hline$[7]$ & {$[6,18]$} & {$[7]$} & 0.785 \\
\hline$[8]$ & {$[7,18]$} & {$[6]$} & 0.733 \\
\hline$[9]$ & {$[6]$} & {$[18]$} & 0.711 \\
\hline$[10]$ & {$[7]$} & {$[6]$} & 0.690 \\
\hline
\end{tabular}

Table 2.

Parallel FP-growth results. 
Improving Online Education Using Big Data Technologies

DOI: http://dx.doi.org/10.5772/intechopen.88463

\begin{tabular}{lcc}
\hline Learner ID & Items (course) & Recommendations \\
\hline 541 & {$[46,6,11,45]$} & {$[18,7]$} \\
\hline 720 & {$[45,46,15]$} & {$[14]$} \\
\hline 19 & {$[6]$} & {$[18,7]$} \\
\hline 277 & {$[18,14,6,9,3, \ldots$} & {$[43]$} \\
\hline 287 & {$[17,43,42,9,2, \ldots$} & {$[6]$} \\
\hline 155 & {$[15,17,42,9]$} & {$[14,43]$} \\
\hline 1157 & {$[6]$} & {$[18,7]$} \\
\hline 184 & {$[40,6,43,42]$} & {$[18,7]$} \\
\hline 274 & {$[7,6,15,4,3, \ldots$} & {$[43]$} \\
\hline 766 & {$[15,45,46]$} & {$[14]$} \\
\hline
\end{tabular}

Table 3.

Prediction results of the course recommendation system.

\section{Conclusion}

This chapter aims to integrate the new generation of information and communication technologies, especially the big data ecosystem, in Computing Environments For Human Learning dedicated to online learning. In fact, big data provides a wide range of tools and systems for distributed storage, massively parallel processing, and predictive analytics. This set of technologies can be used in the processing and analysis of massive data produced by learners interactions. It offers high-level frameworks allowing a lot of advantages to greatly improve the quality and disponibility of distance learning platforms.

So, our model can really improve the online learning field which every learner can have the maximum benefits from that. Furthermore, pedagogical teams and administrators of e-learning platforms have valuable tools and advanced APIs for analyzing data in order to improve learning strategies, make better decisions and offer a big variety of new learning methods.

To implement big data technologies in e-learning systems, this chapter has designed and developed a course recommender system to provide an adaptive learning solution, which consists of adapting teaching resources to individual preferences and needs of each learner. The implementation of the proposed course recommendation engine uses machine learning techniques, in particular, the association rules technique to find all the interesting relationships from historical student enrollment data. The results obtained show the effectiveness of our system in terms of quality and relevance of course recommendation and execution time performance thanks to the decentralization approach of the processing and analysis of data. The deployment of our system is done in the distributed infrastructure of Hadoop and the powerful in-memory processing and advanced analysis of the Spark Framework. The implemented Spark application is based on a completely different approach which consists, in fact, in distributing the processing and the data on several nodes each of which carries out specific tasks in order to execute the FP-growth algorithm in parallel on different machines of the cluster. The distribution mechanism of computing and storage solves the problem of limiting available resources while speeding up the execution speed and the cost of processing. 


\section{Author details}

Karim Dahdouh*, Ahmed Dakkak, Lahcen Oughdir and Abdelali Ibriz Engineering Sciences Laboratory, FPT, Sidi Mohamed Ben Abdellah University, Taza, Morocco

*Address all correspondence to: karim.dahdoh@gmail.com

\section{IntechOpen}

(c) 2020 The Author(s). Licensee IntechOpen. This chapter is distributed under the terms of the Creative Commons Attribution License (http://creativecommons.org/licenses/ by/3.0), which permits unrestricted use, distribution, and reproduction in any medium, provided the original work is properly cited. $(\mathrm{cc}) \mathrm{BY}$ 


\section{References}

[1] Bruillard E. Les Machines à Enseigner. Paris: Hermès; 1997

[2] Guri-Rosenblit S, Gros B. E-learning: Confusing terminology, research gaps and inherent challenges. International Journal of E-Learning \& Distance Education/Revue Internationale Du e-Learning et La Formation à Distance. 2011;25(1). Available from: http://www. ijede.ca/index.php/jde/article/view/729

[3] Udupi PK, Malali P, Noronha H. Big data integration for transition from E-learning to smart learning framework. In: 2016 3rd MEC International Conference on Big Data and Smart City (ICBDSC). Muscat, Oman: IEEE; 2016. pp. 1-4. DOI: 10.1109/ICBDSC.2016.7460379

[4] Birjali M, Beni-Hssane A, Erritali M. Learning with big data technology: The future of education. In: Abraham A, Haqiq A, Hassanien AE, Snasel V, Alimi AM, editors. Proceedings of the Third International Afro-European Conference for Industrial Advancement — AECIA 2016. Vol. 565. Cham: Springer International Publishing; 2018. pp. 209217. DOI: $10.1007 / 978-3-319-60834-1 \_22$

[5] Logica B, Magdalena R. Using big data in the academic environment. Procedia Economics and Finance. 2015;33:277-286. DOI: $10.1016 /$ S2212-5671(15) 01712-8

[6] Cox M, Ellsworth D. Applicationcontrolled demand paging for out-ofcore visualization. In: Proceedings. Visualization '97 (Cat. No. 97CB36155). Phoenix, AZ, USA: IEEE; 1997. pp. 235244. DOI: $10.1109 /$ VISUAL.1997.663888

[7] Ghemawat S, Gobioff H, Leung S-T. The Google File System. ACM Édition; 2003. Available from: https:// static.googleusercontent.com/media/ research.google.com/fr//archive/gfssosp2003.pdf
[8] Hadoop. Apache Hadoop. Apache Software Foundation; 2019. Available from: http://hadoop.apache.org/

[9] Chakhari A. La digitalisation est une guerre mondiale armez-vous. 2015. p. 70

[10] Gartner. Big Data: The Next Frontier for Innovation, Competition, and Productivity. McKinsey Global Institute; 2011

[11] NIST Big Data Public Working Group Definitions and Taxonomies Subgroup. NIST Big Data Interoperability Framework. Definitions. NIST SP 15001. Vol. 1. National Institute of Standards and Technology; 2015. DOI: 10.6028/ NIST.SP.1500-1

[12] Grandmontagne Y. Les $5 \mathrm{~V} \mathrm{du}$ Big Data-IT Social | Média des Enjeux IT \& Business. Innovation et Leadership. 2014. Available from: https://itsocial.fr/articles-decideurs/ les-5-v-du-big-data/

[13] Dahdouh K, Dakkak A, Oughdir L, Messaoudi F. Big data for online learning systems. Education and Information Technologies. 2018;23(6):2783-2800. DOI: 10.1007/ s10639-018-9741-3

[14] Dean J, Ghemawat S. MapReduce: Simplified data processing on large clusters. Communications of the ACM. 2008;51(1):107

[15] Apache Spark. 2019. Available from: https://spark.apache.org/

[16] ESTenLigne Platform. 2018. http:// elearn.est-usmba.ac.ma/

[17] Ibriz A. Une Démarche Innovante de Conduite de Projet Elearning: C.D.I.O. In: 2ème Congrès International du Génie Industriel et du Management Des Systèmes (CIGIMS). 2015 
[18] Ibriz A, Abdellatif SAFOUANE. L'Innovation Pédagogique dans les EST du Maroc: Le model et la Conduite d'un cas réussi à travers le Projet ESTenLigne. In: Colloque Eomed. 2014

[19] Ecole Supérieure de Technologie. 2018. Available from: http://www.estusmba.ac.ma/

[20] Instituts Universitaires de Technologie. 2018. Available from: http://www.iut.fr/

[21] Oughdir L, Ibriz A, Harti M. Modélisation de l'apprenant dans le cadre d'un environnement d'apprentissage en ligne. In: TELECO2011 \& 7ème JFMMA Mars 16-18, 2011-Tanger MAROC. 2011

[22] Benslimane M, Kamar O, Mehdi T, Mohammed B. Proposal of an approach of online course design and implementation: A case study of an algorithmic course. 2016;7:7

[23] Ibriz A, Benslimane M, Ouazzani K. Didactics in online learning technical courses: A case study based on activity theory. International Journal of Computer Science and Information Technologies. 2016;7:849-854

[24] Dahdouh K, Oughdir L, Dakkak A, Ibriz e A. Smart courses recommender system for online learning platform. In: 2018 IEEE 5th International Congress on Information Science and Technology (CiSt). Marrakech: IEEE; 2018. pp. 328-333. DOI: $10.1109 /$ CIST.2018.8596516

[25] Rakesh A, Srikant R. Fast algorithms for mining association rules. In: Proceedings of the 20th VLDB Conference Santiago, Chile; 1994. p. 13

[26] Larose DT. Data Mining and Predictive Analytics. Hoboken, New Jersey: Published by John Wiley \& Sons, Inc.; 2015. p. 827
[27] Li H, Yi W, Zhang D, Zhang M, Chang e EY. Pfp: Parallel Fp-growth for query recommendation. In: Proceedings of the 2008 ACM Conference on Recommender Systems-RecSys '08. Lausanne, Switzerland: ACM Press; 2008. p. 107. DOI: $10.1145 / 1454008.1454027$

[28] The Hadoop Distributed File System (HDFS). 2018. Available from: https:// hadoop.apache.org/docs/r3.1.1/hadoopproject-dist/hadoop-hdfs/HdfsDesign. html

[29] Apache Hadoop YARN. 2019.

Available from: https://hadoop.apache. org/docs/r3.1.1/hadoop-yarn/hadoopyarn-site/YARN.html 
Section 2

New Technologies in Learning and Teaching 



\title{
Chapter 3
}

\section{Using Tablets for Technology Integration in Classroom Differentiation}

\author{
Irfan Simsek and Tuncer Can
}

\begin{abstract}
Differentiation works on both individual and social levels; the immediate outcomes in the classroom have an influence on the whole life of the society. The learning process could be differentiated in terms of content, process, and product by taking students' readiness, interest, and needs into account. Our research has shown that using tablets in classrooms provides a useful implementation tool for differentiation. However, attitudes and beliefs of teachers are as important as experimental studies to understand the advantages of using tablets to ensure the differentiated curriculum and its implementation. Participants' ideas on using tablets in classrooms for differentiating the classroom were documented in a bootcamp that includes ICT, English, Math, and class teachers who use tablets, ICT experts, and academicians. Questions included topics like the need for differentiation, the advantages and disadvantages of using tablets for implementing the differentiated curriculum, and the teachers' attitudes on using tablets. They pointed out that differentiation via technology is able to meet the different needs of students. They reported that technology degradation and tablets were useful tools for differentiation. However, they all agreed that a successful organization was needed to be able to include technology to the existing practice and curriculum.
\end{abstract}

Keywords: differentiation, using tablet, technology integration, TPACK, TABLIO

\section{Introduction}

Today's modern world caters for a great variety in applications and practices for education. The development of technologies and the Internet has also diversified the opportunities for students and teachers in this context. The students who are attending the schools are more diverse and come from various segments of the societies. This is more demanding on the side of the schools and teachers, and one size fits them all does not work in this respect. The awareness of the learner differences has risen among all societies and educational circles, and thus curricula have been changing more rapidly. In Turkey, for example, the curricula for all levels have been changed almost every 4 years now. Previously, the curricula changes were taking place in almost every 10 years [1].

The changes of curricula are necessary because the diversity of the students and the learning styles of those students need to be recognized. However, the recognition of the learning preferences is not enough in itself and requires taking more action. 
Thus, the concept of differentiation brings about an immediate answer for recognition and could readily play an important role in actionizing a proactive execution of this action. Most of the time, students and teachers are aware of the diversity taking place in the classroom, but the teachers cannot act on that due to reasons like heavy content, centralized curriculum, and school culture. They need a solid ground rooted in pedagogy to be able to address this caveat. Differentiation can bring a relief to those teachers and students. According to [2] "a key goal of differentiated instruction is maximizing the learning potential of each student” (p. 3). Differentiation could be implemented not only on an individual or classroom level but also on a curriculum level. Curriculum differentiation, which is defined as "the process of modifying or adapting the curriculum according to the different ability levels of the students in one class" [3], involves the modification of the content and presentation of information as well as variation in practice and performance on the side of the students.

The introduction of the Internet into the classrooms has enabled the use of new technologies and in particular mobile technologies like tablets in the classroom. The use of tablets in the classroom has also brought about new opportunities to recognize the differences of the students in the learning process. The awareness of this on the teacher's side is a key component in using tablets in classrooms for differentiating their classrooms and curriculum. The teachers should have a positive attitude toward technology integration and then be aware of the advantages and disadvantages of using tablets for implementing the differentiated curriculum. The variety of apps that could suit each student in the classroom and meet the different needs of different students make the technology integration and the tablets useful tools for differentiation.

\section{Technology integration in education}

The twenty-first century, which is defined as the age of technology, brought many requirements in the name of meaningful and permanent learning and thus necessitated new structures within the educational systems. It is aimed to design the environments where education is carried out with appropriate and various technologies and to enable students and teachers to use these technologies both in the classroom and outside the classroom.

It is easy to defend the effective use of technology in the world as technology both assists learning environments and also supports alternative learning-teaching approaches. In this context, computers, tablets, smartphones, video conferencing devices, etc. gain different usage opportunities in educational environments every day. Of course, using these technologies in learning environments to improve the quality of education can be made possible only by planning activities that support the productivity of students, not only with technology but also with pedagogy. Mishra and Koehler's technological pedagogical content knowledge (TPACK) model provides a road map for the effective integration of technology and pedagogy in learning environments [4-6].

In an era of highly valued technological knowledge, it is important that teachers develop an integrated knowledge of teaching, content, and technology, called Technology Pedagogy and Content Knowledge (TPACK); as suggested by [7], TPACK (Figure 1) is becoming a required area of expertise for teachers in new learning environments in the twenty-first century.

With the transfer of technology into the classroom environment, the teachers' TPACK knowledge has developed to ensure meaningful and permanent learning and the ability to use technology within the classroom.

The introduction of technology into schools as a product only does not provide an effective use of technology. It is important that teachers, students, parents, and the management use the technology for real aims and the technology fosters 


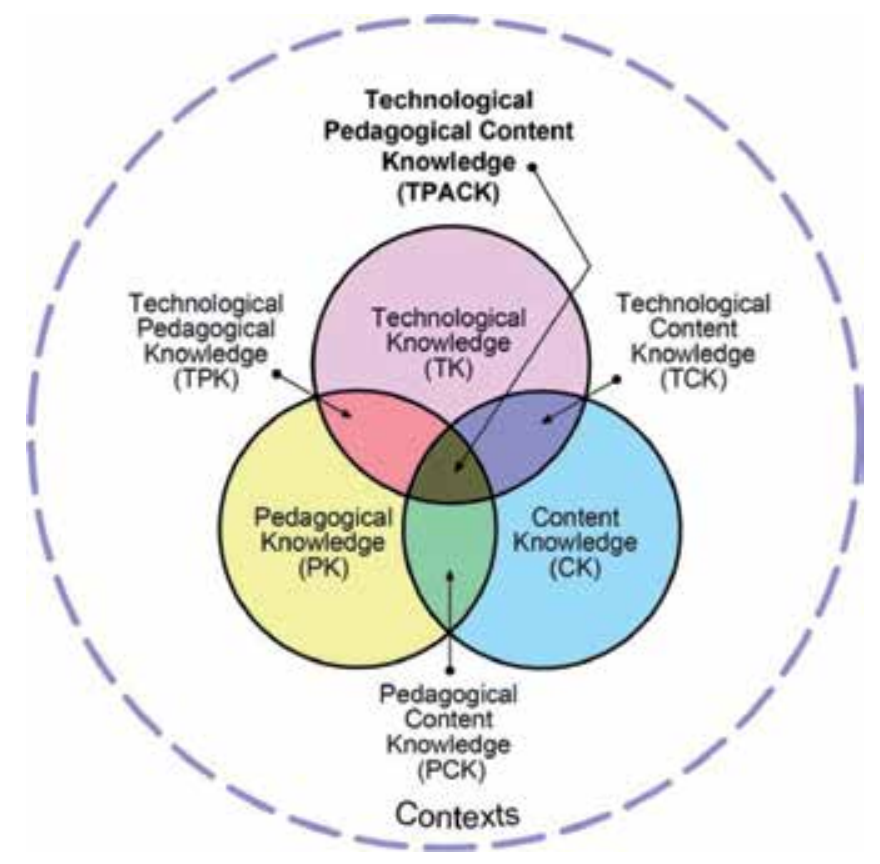

Figure 1.

TPACK framework (tpack.org).

learning in the process, that it is included in the school culture, and that it can be a premise for further innovations [8]. This is possible only with the integration of technology. To [9] technology integration is to improve students' thinking ability, whereas to Griffin it is the use of instructional technologies consciously and purposefully in the development and transfer of teaching process [10].

As the use of technology becomes widespread in institutions, better services are provided, more productive studies are carried out, and as a result more quality products are introduced; thus, technology has become an indispensable element of life as a center of attention in all segments [11]. To emphasize the necessity of technology integration in education, Alkan has defended that in order to provide quality education services to individuals, it is necessary to meet the different needs and demands of the society, using human resources effectively and ensuring equal opportunities in education as well as the use of educational technologies in the classroom [12]. However, Yıldırım argues that there should be widespread cooperation between researchers, decision-makers, and practitioners in terms of improving the learning process for the use of technology in the classroom [13].

According to [14] integrating technology into the school curriculum requires taking a number of elements into account. These elements can be summarized as the needs of learners, the availability of resources, the identification of instructional needs and technology design for technology, and the provision of technical support and guidance in the use of technology for teachers. Based on the studies, two main objectives in technology integration can be proposed for the effective use of technology in schools: one is to teach how to use technology and how to access information on the computer. The other goal is to use information technology (IT) and its facilities effectively. According to [15], in order to achieve these objectives, educators should consider the contextual factors that influence the findings of the studies in the field of educational technology, student achievement, and learning objectives. In addition, today's teachers have stated that they frequently encounter computer-based technologies in the schools they work for or in the programs they 
prepare for teaching $[16,17]$. The field of differentiation could also benefit from the body of information presented by the proponents of TPACK and technology integration. The knowledge from these fields can enrich the opportunities for classroom differentiation and add invaluable depth to differentiation activities. In addition, teachers who want to apply the principles of differentiation in their classrooms could find such in-depth model for the integration of technology degradation and tablets for differentiation in their classroom in the SAMR model.

\section{SAMR model}

Ruben R. Puentedura developed the SAMR model — which is the acronym made up from substitution, augmentation, modification, and redefinition-in 2006 as part of his work with the Maine Learning Technology Initiative [18]. The SAMR model consists of the following four classifications of technology use for learning activities [19]:

Substitution: the technology provides a substitute for other learning activities without functional change.

Augmentation: the technology provides a substitute for other learning activities but with functional improvements.

Modification: the technology allows the learning activity to be redesigned.

Redefinition: the technology allows for the creation of tasks that could not have been done without the use of the technology (Figure 2).

According to the SAMR model, these two dimensions (substitution and augmentation) play an enhancement role in teaching and learning processes. But when ICTs are used to transform (modify and redefine) the teaching and learning processes, we significantly realize a redesign of tasks. This model clearly describes how technology can sequentially be integrated in education without skipping any stage of development.

The SAMR model is not a pedagogical method but a tool that guides pedagogues and shows what kind of assignments they should give in their learning process. It reveals the ways to integrate the techniques to ensure in-depth learning in
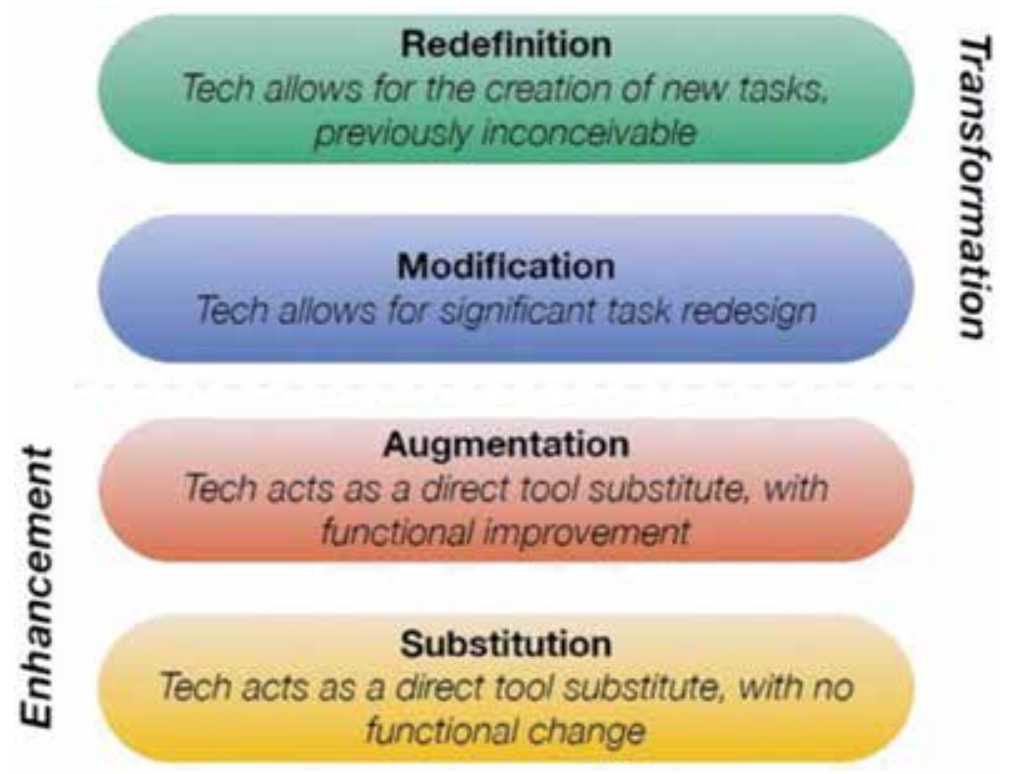

Figure 2.

SAMR model (eagleschools.net). 


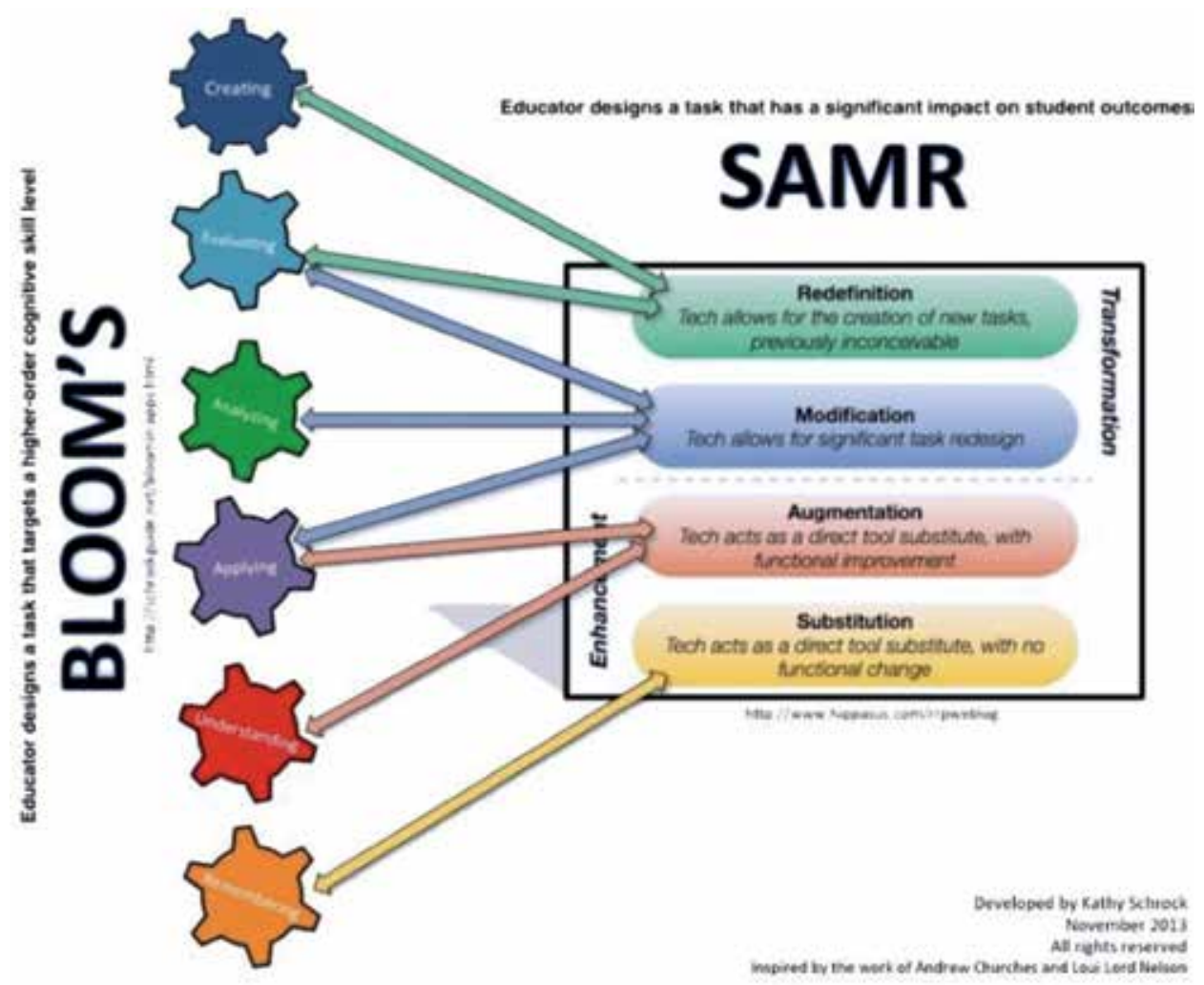

Figure 3.

SAMR model and Bloom's taxonomy (schrockguide.net).

environments where all students have access to computers and how the expectations from the students in these classrooms should change with the digital technology [20]. Teachers can integrate the technology for differentiation and find various applications for the individual needs of their students (Figure 3).

\section{Differentiation}

Tomlinson and Eidson define differentiation as "a conceptual approach to teaching and learning that involves careful analysis of learning goals, continual assessment of student needs, and instructional modifications in response to data about readiness levels, interests, learning profiles, and affects" [2]. The definition stresses the importance of continuous engagement with the students in the learning process as well as their cognitive and affective states. In their concept map, the TABLIO Project funded by the European Union has pointed out that differentiation aims for the inclusion of all students; the inclusion brings in a higher motivation to learn and to participate in a lifelong learning and for achieving learning outcomes more efficiently [21]. They believe that the objectives of differentiation are self-realization and self-actualization between the cognitive, emotional, and social levels and striving for harmonious and pluralistic citizens for the society and humanity. In this context, differentiation serves more than just the recognition of student differences and needs but a holistic aim. Thus, differentiation works on both individual and social levels; the immediate outcomes in the classroom affect the whole life of the society. Due to these reasons, differentiation should be considered to be a necessary aspect of all education. [22] proposes that there are certain benefits to differentiated 
instruction such as effectiveness for high-ability students as well as students with mild to severe disabilities, taking on more responsibility for their own learning, more engagement in learning, and reportedly fewer discipline problems in classrooms. On the other hand, some drawbacks include ever-increasing workload while planning and executing and lack of professional development resources.

According to [22] differentiation could be reflected into the curriculum in many ways. These would include the differentiation of the instruction and presentation by changing the content to be learned. They can also differentiate the learning process in which students are participating. The outcome or the product of the learning process could also be differentiated as well as the classroom environment. IIn this effort, though, students' readiness, interests or learning profiles could also play a defining role. To [22] "in differentiated classrooms, teach provide specific ways for each individual to learn as deeply as possible and as quickly as possible, without assuming one student's road map for learning is identical to anyone else's (p. 2).” The TABLIO Project [21] has also pinpointed those aspects but added that differentiation also requires cooperation from stakeholders between the microlevel (classroom level), meso-level (school level), and macro-level (policy level). They have also stated that the differentiation can appear in two main types: organizational differentiation and educational differentiation. Organizational differentiation can be actionized in many ways like grouping strategy of the classroom, individualized programs for special needs, extracurricular acceleration programs, and remedial programs. On the other hand, educational differentiation works on a classroom level. The classroom has two important players, the students and the teachers. Student's readiness, interests, and learning profile should be taken into consideration if differentiation is to be achieved for students. Teacher-oriented differentiation works on content, process, and product aspects. There is a reciprocal influence of teacher-oriented and learner-oriented differentiation techniques. As seen above, the teacher can plan differentiation on students' needs, abilities, and interests and also by incorporating many other aspects like content, process, and product. Thus, the teachers can achieve effective curriculum differentiation as a whole. According to [23], curriculum differentiation emphasizes the need to modify and match curriculum objectives and teaching methods to the "pupil's individual abilities, educational needs and learning styles" (p. 1).

Applying differentiation in education for major gains requires the collaboration among many stakeholders. The first and foremost of those stakeholders is in macro-level, also defined as policy level. This is the national and/or regional policy makers' level. The educational documents and aims should reflect and include differentiation as an application in the learning process. Politicians and the Ministry of Education should support the idea and should also work toward the implementation and the evaluation of the learning process. Inspectors and teacher trainers can also work to transfer and promote the idea of differentiation into schools and classrooms and then proceed with the meso-level support. Mesolevel means the practices and the policies in schools among principals and teachers. These parties should also recognize the need and understand the concept of differentiation; this can be defined as the school level as well. Microlevel requires not only the teacher and the student but also other classroom assistants and most importantly the parents to be engaged in the process of differentiation. Initially all of these levels should actively participate in the process of differentiation and also in negotiation to make the process more transparent and effective for all parties.

When the idea and the policies require the teachers to apply differentiation, they could start from organizational differentiation. Organizational differentiation is about implementing individualized programs for special needs, gifted students, and other 
groups with different needs like learning disabilities, some disorders, and various disabilities. In this way the teachers can help students with special needs succeed personally in school and in their community. Students with these kinds of special needs are likely to benefit from additional educational services such as different approaches to teaching, the use of technology, a specifically adapted teaching area, or a resource room. Teachers can also design remedial programs and extracurricular acceleration programs in small groups such as developmental education, basic skills education, compensatory education, preparatory education, and academic upgrading as well as sports, music, arts, academic clubs and many other after-school activities [21].

Educational differentiation necessitates taking both students' readiness, interest, and profiles and teachers into account. Students' readiness is about students' previous knowledge or skills. Students' interest areas could be used to increase the motivation toward learning and create links between the content and the student; finally students' learning profiles are their preferred way of learning.

When teachers are considered in the differentiation process, what they can differentiate first is content. Content-oriented differentiation reflects the ways of modifying the content and also varying methods of presentation. Content is dependent on subject, text, and age of the learners. Content information should be provided through a variety of sensory inputs, e.g., audio, visual, or kinesthetic. To differentiate the content, [22] recommends designing activities around Bloom's taxonomy including remembering, understanding, applying, analyzing, evaluating, and creating. Some students can prefer to learn in certain ways. Thus, delivering the content materials by taking the learning preferences such as visual, auditory, and kinesthetic into account makes up a successful process differentiation. The process-oriented differentiation could be achieved by letting students explore the content in pairs, in small groups, or individually. The students should be given multiple options for taking in information and making sense of concepts to be learned. In the end of the learning process, students are expected to produce outcomes to evaluate their takeaway from the content. This product could be differentiated as well. These products could be in the form of tests, projects, reports, portfolio, performance assignments, concept maps, structured grids, self-evaluation, or peer evaluation.

Terwel views schools as places where the task of guiding students to learn to think for themselves and creating conditions for developing this "disciplined intelligence" as a habit of mind are emphasized. This of course necessitates different approaches to the function of the curriculum that emphasizes one fit for all. Thus, offering different curricula to different groups of students is becoming more and more common in modern education. In Germany and in many other European countries, students from the age of 10 are selected into different school types or streams according to ability and career perspectives. Streaming, tracking, and ability grouping are the most persistent issues in curriculum theory and practice [24]. Furthermore, in the context of gifted students, [25] identified four ways that the curriculum can be modified to address the needs of learners:

\section{- Acceleration: adjusting the pace of learning}

- Enrichment: allowing for more depth and exploration within the content area

- Sophistication: bringing more complexity and abstraction to the subject

- Novelty: providing for learning opportunities not generally included in the curriculum, often through self-directed, interest-based projects 


\section{Pedagogical design principles on classroom differentiation with tablets}

Tablets could be a very practical way for differentiation in the classroom. Pedagogical implications relating to the tablets are that they can work on all content, process, and product differentiation phases. The apps that can be used on tablets are various, and this very nature of the tablets enables a diverse use in the classroom. Differentiation needs to be proactive and should allow many stakeholders in the process to be successful. Differentiation with tablets is student-centered in nature, and being aware of the many differences in the group could be considered a significant influencer in achieving inclusion of all students. Thus, differentiation entails quality rather than quantity. This is not a static concept but rather an organic, dynamic process.

The tablets could be used to differentiate the content by using a varied set of learning materials, such as various apps for various presentation types. It will also be wise to use materials that are meaningful for the students and are also reflecting authenticy. Student-generated content as learning materials for other students or classes could also help in varying the content and to break the course book domination. When process is taken into account, the teachers should approach the students with a coaching attitude and should support their students where needed. Moreover, peer teaching can also be part of the classroom as well as streaming, and different grouping techniques could be used variously. Teachers can vary the learning environment by changing places around the school as well as outside the classroom in real-life environments and even virtual environments. Students should be stimulated to assess themselves and their peers; the teachers should also give timely and concrete feedback to students and therefore integrate ICT tools as a solution. Product differentiation across the learning process could encompass the use of alternative assessment techniques in addition to traditional assessment techniques in order to adapt more to individual needs, changes, and differences. The products need to enable the students to use higher-level thinking skills. These can be made apparent by using transparent evaluation rubrics. The final products of the lessons should reflect students' different characters, needs, levels, and preferences, and the teachers should be prepared to allow for a variety and perform summative and formative assessments interchangeably. Teachers should take advantage of the available ICT tools for assessment as well. Teachers should be aware of differences between students based on special needs, gender, culture, linguistic preferences, strengths and weaknesses, confidence, self-awareness, and self-efficacy [21].

When tablets or other mobile devices are planned to be used for differentiation in the classroom, teachers should be aware that implementing those devices requires some considerations to be taken. The first of those could be the security of the devices; the use of mobile devices for differentiated learning should comply with the policies, legalities, guidelines, protocols, and structures that are aimed at protecting the health and well-being of both the learner and the teacher. Both the students and the teachers should be media and digital literate, and if they are not, they should be given previous training. In all levels, teachers should inform the parents and the school management and get permissions for profiles and other online accounts and shares. The teachers should provide secure online and digital environments. If a school decides to use tablets, a clear policy on privacy, security, and storing/deleting user content has to be ensured. A multi-platform approach should be adopted, and apps that function platform independently should be favored.

When apps are selected to be used, there has to be previous consideration on app availability and access; the choice of the right app for learning should be influenced by the differentiated needs of the learners. It is suggested to use the apps that work well 
on all devices. Flexible approach to apps is also advisable as when an app is getting oldfashioned, teachers should consider a change. Initially free apps should be preferred, and if they do not meet the differentiation needs, paid apps can be selected as well. A group of teachers can come together to decide what the common educational needs are and adapt the apps that will be used. A "line of apps" could be an interesting approach in order to have alignment within a grade and across grades. The school can provide the tablets and the apps as well as BOYD approach. The Internet and Wi-Fi infrastructure should be reliable and robust. Students and teachers should take account of the restrictions associated with individual mobile devices such as screen size, memory to save apps, and outputs such as images and infrastructural limitations, e.g., bandwidth, availability of Wi-Fi, etc. There has to be clear statements about what student may and may not do with the tablet, during classes, but also in between classes [21].

\section{Differentiation examples}

The differentiation scenarios have been designed according to the deficiencies teachers who attended the 3-day TABLIO Project Bootcamp have observed in their classrooms, schools, and curriculum. The practical workshops included three fullday meetings with classroom, English, and mathematics teachers. The first meeting introduced the TABLIO Project concept map about the integration of tablets for differentiation. The second meeting was held a month later and required the teachers to work in groups and design their own lesson and action plans based on their needs and contexts. The last meeting that was held a month later was about reporting, evaluation, and reflection on their experience with their lesson plans. The differentiation scenarios which the classroom, English, and mathematics teachers have designed and organized during the TABLIO Project Bootcamp have been included in this section.

\subsection{Differentiation examples for classroom teachers}

\subsubsection{Learning objectives}

Topic: fractions

- The teacher shows the whole, half, and quarter with suitable models and explains the relationship between whole, half, and quarter.

- The students use fractional representations of all half and quarter models.

- The students identify simple, compound, and integer fractions and models.

- Students show the whole, half, and quarter with suitable models and explain the relationship between whole, half, and quarter.

- Students compare and sort the unit fractions.

- Students make adding and subtracting with fractions with equal denominators.

\subsubsection{Student profiles}

Grade 2, Grade 3, and Grade 4 students.

Group work will be done since there is no tablet in each class. 


\subsubsection{Process differentiation: learning activities}

- An animation prepared with "Scratch" will be used in the teaching process.

- "Fraction for Kids" and "Simply Fractions 2" will be used as an activity. Both applications can work without an Internet connection.

- "Kahoot!" and "Learning Apps" applications will be used in the evaluation process.

Space adventure animation will be prepared with "Scratch" by coding. In the animation, two characters are going into space. There is a problem about the food. They have little bread and try to share the bread. In this process, the characters who use the concepts of full, half, and quarter will try to teach these concepts. At the same time, concepts such as equality and justice will be emphasized.

In the practice phase, Kahoot!, Plickers, and Learning Apps will be used to reinforce the concepts of full, half, and quarter.

During the evaluation process, a test created by the teacher on Kahoot! will be used to measure the learning outcomes. The teacher will make observations during the application and perform video recordings. The teacher will note down the important events and situations.

Applications that are going to be used during the application will be announced to the parents via WhatsApp, and the apps will be uploaded to the tablets in advance. Applications vary depending on the versions or brands of some tablets. It is important for the teacher to make checks before the class to avoid any problems during the course. During the teaching-learning process, videos that are uploaded to the "Padlet" will be monitored. Then, the link for the "Padlet" will be shared with the QR code. The animation that is prepared with Scratch will be watched in the class. "Dot Day" coloring page 2 will be used in the Quiver application (I say - you guess). The special information given in the videos will be repeated. Because of slow Internet speed, "Fractions for Kids" and "Plickers" (instant student evaluation) will be used for individual study. "Learning Apps" will be used as a group work in the classroom with the multi-connection tool. The game pins and extensions of "Kahoot!" and "Learning Apps" work will be announced to parents for use at home and to perform evaluation again. Students will be asked for a product like movie posters, etc. (any application that the students prefer can be used) during the evaluation process. The products that are delivered to the teacher will be shared on "ClassDojo" as an example to other students and parents. Each student will be asked to express his/her understanding. The goal here is not to prepare a homework but to learn in a fun way and selfrealize themselves.
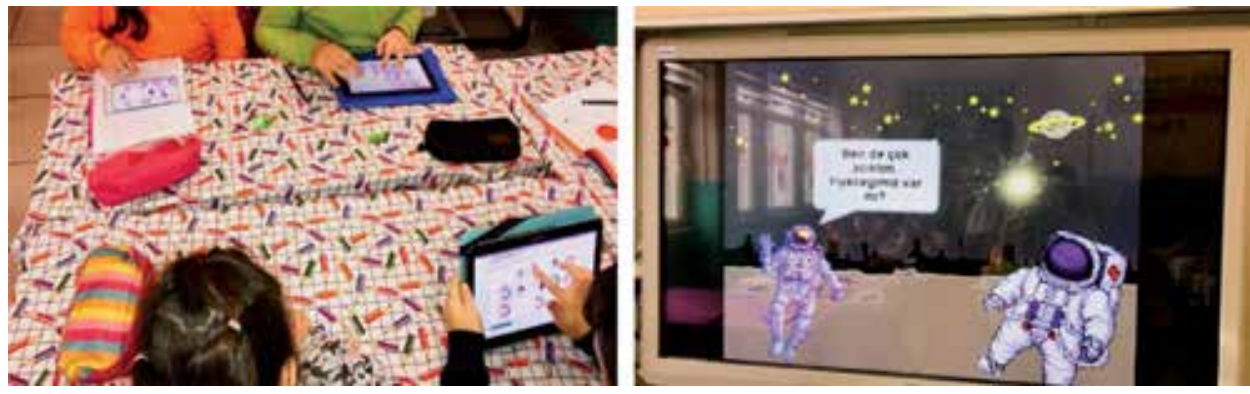
6.1.4 Content differentiation: teaching materials and educational technologies

- Technological devices: tablet

- Tablet applications:

○ Scratch

○ Fraction for Kids

○ Simply Fractions 2

○ Kahoot!

$\circ$ Learning Apps

$\circ$ Padlet

○ Plickers

$\circ$ Quiver

$\circ$ Inigma

6.1.5 Content differentiation: accessibility and availability

Applications (Fraction for Kids, Simply Fractions 2) are downloadable and executable to Android devices.

Fraction for Kids and Simply Fractions 2 applications are available without an Internet connection.

The course content produced with the Scratch application will be output as video.

Kahoot!, Flickers, and Learning Apps are applications that can be used on all devices because they are applications that are open on the web.

The applications are designed so that the elementary school students can easily adapt and use them.

\subsubsection{Product differentiation: evaluation and progress control}

Kahoot! will be used during the evaluation phase. The students' achievement as a group will be determined with the Kahoot!, and additional activities will be done with the groups that cannot reach the desired level.

Evaluation will also be done using videos and "Learning Apps." The videos will be used as a tool for the students to transfer their learning as individual homework.

\subsection{Differentiation example for English teachers}

\subsubsection{Learning objectives}

1. To increase the participation of students in speaking activities

2. Minimizing errors in pronunciation 
3. To address the concerns of shy students in the field of speaking

4. To reach the synthesis step by using higher cognitive skills

5. Integrating existing knowledge into everyday life by speaking

\subsubsection{Student profiles}

Primary, secondary, and high school students. Not every student has a tablet. Therefore, group studies can be done. Each tablet has access to the Internet.

\subsubsection{Process differentiation: learning activities}

1. Brainstorming: students read the code with the $\mathrm{QR}$ code and connect to Menti. com as a group. As a group, they create a word cloud.

2. The following activities are used at different age and language levels:

a. Students use the cards (color classification) to stand up and produce a sentence.

b.Students are divided into groups by the group organizing application or ClassDojo.

c. Students use QR code to connect to Padlet and color their sentences and write anonymous sentences without writing their names.

3. For the elementary-secondary school level, the "Toontastic 3D" and for high school level "Voki" are used to create the digital stories, and the students voice over their characters/avatars.

4. Students share their video products on "Padlet" page by linking with a "QR code reader."

5. Students should watch and comment on at least one video on "Padlet" (these can be evaluated as an instant feedback or homework according to the atmosphere of the class).

6. Assessment and evaluation of the content can be done by using "Plickers" application. $5 \times 3$ (true-false and multiple choice and visual use and question type) is prepared with five questions in three different areas.

7. Students are asked to use their favorite word in a sentence to express and illustrate how they feel on a Dot Day page by using "QuiverVision" app. The application also offers them the opportunity to record in their own voice; the students experience their products in a concrete way.

8. High school students complete the activity with the "Flipgrid" app. By using their favorite word in a sentence, they record their voice or video recording into the application.

9. Using the "QuiverVision” Dot Day app, students are expected to write a sentence using place prepositions and phrases and then visualize it. Then, the products are animated, and the students record their voice. 
Using Tablets for Technology Integration in Classroom Differentiation DOI: http://dx.doi.org/10.5772/intechopen.85713
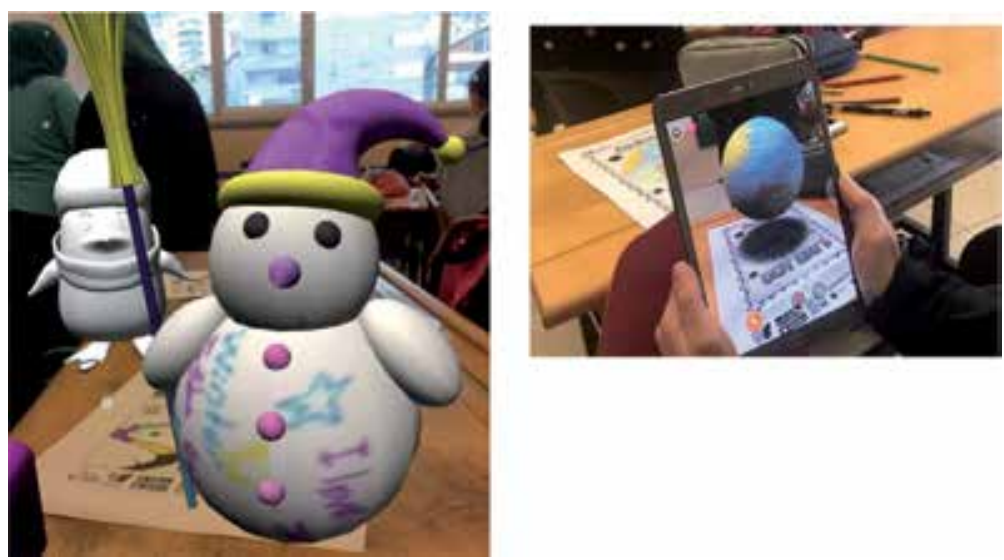

6.2.4 Content differentiation: teaching materials and educational technologies

- Worksheets

- Computer

- Projection

- Wi-Fi

- Smart board

- Tablet

- Tablet applications

○ QR code creator

○ QR code reader

○ Mentimeter

○ Padlet

○ Toontastic

○ Volki

○ Flipgrid

○ Quiver

○ Plickers

○ Wordwall

- ClassDojo

$\circ$ VoiceTooner 


\subsubsection{Content differentiation: accessibility and availability}

Applications are compatible with different operating systems (iOS and Android), and students can use them easily when they have Internet and tablets.

\subsubsection{Product differentiation: evaluation and progress control}

Applications created with "Toontastic" or "Voki" are shared in the classroom with the "Padlet" app, and students are allowed to comment and like. In this evaluation, it is aimed not to repeat the mechanical errors.

"Quiver" or "Flipgrid" can also be used for the evaluation phase.

Students can use "Toontastic" to produce a film of their own and to practice language more self-confidently.

\subsection{Differentiation example for mathematics lesson}

\subsubsection{Learning objectives}

- Students can understand that the integer fraction is the sum of a natural number and a simple fraction.

- Students can convert an integer fraction into a compound fraction and a compound fraction into an integer fraction.

- Students can make calculations of simplification and expansion on integer fractions and compound fractions.

- Students can perform addition and subtraction of fractions with or without equal denominators.

\subsubsection{Student profiles}

Differentiation scenarios were prepared for the 4 th, 5 th, and 6 th grade students. Students are experiencing problems in Grades 5 and 6 because they cannot conceptualize the concept "full-half-quarter" that they learned in the Fractions Unit in the 4th Grade. Not every student has a tablet. Therefore, group work can be done. Each tablet has access to the Internet.

\subsubsection{Process differentiation: learning activities}

1. With the "Edpuzzle" program, students are given quizzes. Students watch a question-and-answer video, and students' quiz results are presented as a graphic.

2. Stories are combined in the "Storybird" editing program and turned into a book.

3. The mind map of differentiated education is created with the "Xmind" or "MindMeister" programs. Students create a concept map on fractions.

4. An activity is gamified and applied within the class.

5. An animation is created on "Morpho" program.

6. Course feedback is taken with the "Plickers" program. 
7. Objects are shown in augmented reality via “Quiver” program.

8. Students draw a 3D object on the subject with the "GeoGebra" program.

9. The word cloud of the delivered lesson is prepared with "Tagul word cloud art creator" program.

10. Storyboard stories about the subject are prepared in the graphic design tool "Canva."

11. Stories are combined in the "Storybird" editing program and turned into a book.

12. The story is combined with the LEGO educational tools and turned into a cartoon with the "LEGO Stop Motion" program; thus it is conceptualized.

13. The story is improvised in the classroom. Students are videotaped. The captured video is turned into a film with the "Apple iMovie" program.

14. Virtual materials are prepared and animated with augmented reality application "HP Reveal," and interactive panels are created. Filmed video is prepared and recorded in HP Reveal application.

15. The augmented reality projects are saved as links with the "QR code reader" program. With "HP Reveal” projects and "QR code reader," a treasure hunt game is prepared, and the event is created, where students can play outside the classroom.

16. The subject of the lesson is animated with "Powtoon."

17. A "YouTube channel" is created. The story created with "Powtoon" is shared in the "Youtube channel."

18. Students watch the story shared on the "YouTube channel," and they are asked to draw conclusions from the video. In order to get the feedback about the story, students are asked to brainstorm in the "Padlet" program that is used to create the online virtual board.

19. To reinforce the subject, students are asked to prepare an online presentation on "Prezi."

20.Class evaluation is performed with "Kahoot!"

21. A quiz is given to students with the "Edpuzzle" program. Students watch a question-and-answer video, and students' quiz results are presented as a graphic.

22. A 3D code game is created on the Code Game Lab program developed by Microsoft. Students from different grade levels are asked to try the coding game related to the subject, and feedback is requested. A report of whether the desired goal has been reached is created.

23. A 3D animation about the subject is created on "SketchUp."

24. A site with Blogger is created. Applications that are learned and acquired information are shared. 
25. A 3D design work is carried out on the subject with 3D modeling program "Tinkercad" application.

26. The 3D design project is printed from the 3D printer. 3D designs made within the school are offered for sale. The income of the projects sold is donated to the Spinal Cord Paralytics Association.

Each teacher selects one or more of the programs above on the basis of the subject and performs their applications in the classroom.

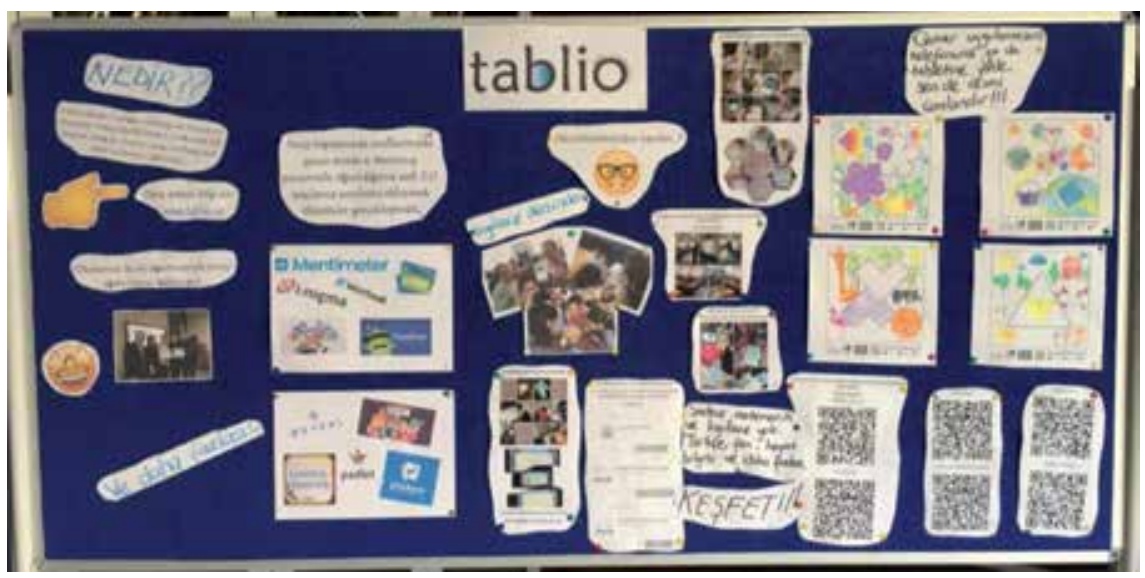

6.3.4 Content differentiation: teaching materials and educational technologies

- Technological devices: table, PC, and smartphone

- Tablet applications:

$\circ$ Xmind

○ Tagul

$\circ$ Morpho

○ Plickers

$\circ$ Quiver

○ GeoGebra

○ LEGO Stop Motion

○ iMove

○ HP Reveal

○ QR code reader

o Powtoon

○ Padlet 

- Prezi
$\circ$ Kahoot!
$\circ$ Edpuzzle
○ Kodu Game Lab
○ SketchUp
$\circ$ Weebly
○ Tinkercad

\subsubsection{Content differentiation: accessibility and availability}

The platforms to be used were chosen as teacher, student, and course oriented. Because each student has different interests, the applications are selected with "what kind of a lesson students want" point of view of and from among the ones that they will enjoy according to their age level. An enjoyable lesson should be considered as an efficient lesson. Platforms that can be used in future life and contribute to their individual lives have been selected.

\subsubsection{Product differentiation: evaluation and progress control}

Each teacher will make an assessment of how successful the learning of the subject is through the use of digital platforms, graphics, and feedback:

- The success of the lesson outcomes will be assessed by the questions and answers in the "Edpuzzle" program; the students' answers to the questions will be turned into graphs and charts.

- Students will be asked to take a working video for themselves and share them with their friends so that both subject gains and technology skills will be measured.

- The students are asked to form a group of 5 with their friends and to create a story about fractions and to visualize this story using the "Storybird" program. Stories are combined in the "Storybird" editing program and turned into a book. Thus, both the topic gains and the skills of using technology will be measured.

\section{Conclusion}

This chapter aims at bringing the use of tablets and classroom differentiation together. Recognizing students' needs and making use of the best resources to enable the students achieve the best they can for their society is the aim of the differentiated instruction. The integration of technologies into the classroom practice has become a mainstream approach in many educational contexts now, and making use of those new approaches for differentiation should add a depth to the activities. According to Hilton [26], both of the "educational technology integration models, SAMR and TPACK, provide important directions for ways that teachers can think specifically about how to integrate technology into their classrooms to maximize their use of resources and the learning possibilities of their students." In this respect, the learning process can be 
enriched by differentiation and integrating technology into the classroom. The learning process could be differentiated in terms of content, process, and product by taking students' readiness, interest, and needs into account. Teachers who apply differentiated instruction should be aware of what kind of opportunities the mobile technologies like tablets could bring to their classrooms. The lesson design principles for successful integration of tablets for differentiation have been developed in the course of the TABLIO Project, and these principles have been presented to ICT, English, math, and class teachers from Turkish schools during a boot camp. Our experience has shown that using tablets in classrooms provides a useful implementation tool for differentiation. These teachers developed lesson plans and applications to differentiate their classrooms and reported beneficial results and comments from their students. They pointed out that differentiation via technology is able to meet the different needs of different students. They reported that technology degradation and tablets were useful tools for differentiation. However, they all agreed that a successful organization was needed to be able to include technology to the existing practice and curriculum. Integration of technology into education is one of the multiple paths to reach a learning goal that addresses students' learning styles, interests, needs, and readiness levels; thus, the teacher can engage all students in differentiated instruction that is appealing, developmentally appropriate, and motivational [27]. In fact, technology integration serves as differentiation globally for education and locally for the classroom.

\section{Acknowledgements}

This study includes some of the activities carried out within the scope of the TABLIO Project funded by the EU Erasmus+ KA2. Please visit http://tablio.eu for more details.

\section{Notes/thanks}

We would like to thank the teachers who joined TABLIO Bootcamp in Istanbul and prepared differentiation scenarios:

Differentiation Example 1 available from https://youtu.be/gwrb5AYfbRA

Differentiation Example 2 available from https://youtu.be/uri9FKe4r2w

Differentiation Example 3 available from https://youtu.be/W_MSZQqSap8

Differentiation Example 4 available from https://youtu.be/B5OIJ1xLlYU

\section{Author details}

Irfan Simsek* and Tuncer Can

Hasan Ali Yucel Faculty of Education, Istanbul University-Cerrahpasa, Istanbul, Turkey

*Address all correspondence to: irfan@istanbul.edu.tr

\section{IntechOpen}

(C) 2020 The Author(s). Licensee IntechOpen. This chapter is distributed under the terms of the Creative Commons Attribution License (http://creativecommons.org/licenses/ by/3.0), which permits unrestricted use, distribution, and reproduction in any medium, provided the original work is properly cited. (cc) BY 


\section{References}

[1] Hamurcu H. Comparative examination of the primary school science curricula in Turkey (curricula of 1992, 2001, 2005, 2013 and 2017). Journal of Education and Learning. 2018;7(2):261-279

[2] Tomlinson CA, Strickland CA. Differentiation in Practice: A Resource Guide for Differentiating Curriculum, Grades 9-12. Alexandria, VA, USA: ASCD; 2005. ISBN: 978-1416600503

[3] UNESCO. Changing Teaching Practices: Using Curriculum Differentiation to Respond to Student Diversity. Paris: UNESCO; 2004

[4] Hofer M, Grandgenett N. TPACK development in teacher education: A longitudinal study of preservice teachers in a secondary MA Ed program. Journal of Research on Technology in Education. 2012;45(1):83-106

[5] Harris J, Mishra P, Koehler M. Teacher's technological pedagogical content knowledge and learning activity types: Curriculum-based technology integration reframed. Journal of Research on Technology in Education. 2009;41(4):393-416

[6] Graham CR. Theoretical considerations for understanding technological pedagogical content knowledge (TPACK). Computers \& Education. 2011;57(3):1953-1960

[7] Mishra P, Koehler MJ. Technological pedagogical content knowledge: A framework for teacher knowledge. Teachers College Record. 2006;108(6):1017

[8] Çakır R, Yıldırım S. Bilgisayar öğretmenleri okullardaki teknoloji entegrasyonu hakkında ne düşünürler? İlköğretim Online. 2009;8(3):952-964

[9] Hew KF, Brush T. Integrating technology into K-12 teaching and learning: Current knowledge gaps and recommendations for future research. Educational Technology Research and Development. 2007;55(3):223-252

[10] Samancioğlu M, Summak MS. Öğretmenlerin derslerde teknoloji kullanımlarını etkileyen faktörler: Kişisel bilgisayar kullanımı ve öğretim yaklaşımları. Atatürk Üniversitesi Sosyal Bilimler Enstitüsü Dergisi. 2014;18(2):195-207

[11] Başak MH, Ayvacı HŞ. Teknoloji entegrasyonunun eğitim alanında uygulanmasına yönelik bir karşılaştırma: Türkiye-Güney Kore örneği. Eğitim ve Bilim. 2017;42(190):465-492

[12] Alkan C. Bilgisayar Destekli Öğrenme Modülleri. Ankara: Anı Yayıncilı; 1991

[13] Yildirim S. Current utilization of ICT in Turkish basic education schools: A review of Teacher's ICT use and barriers to integration. International Journal of Instructional Media. 2007;34(2):171-186

[14] Cradler J. Implementing Technology in Education: Recent Findings from Research and Evaluation Studies. 1996 [Accessed: 05 December 2018]

[15] Melmed A, editor. The Costs and Effectiveness of Educational Technology: Proceedings of a Workshop. DRU-1205-CTI. Santa Monica: RAND Corporation; 1995

[16] Christiensen R. Effects of technology integration education on the attitudes of teachers and students. Journal of Research on Technology in Education. 2002;34(4):411-433

[17] Vrasidas C, McIsaac MS. Integrating technology in teaching and teacher education: Implications for policy and 
curriculum reform. Educational Media International. 2001;38(2/3):127-132

[18] Puentedura R. Transformation, Technology, and Education [Blog post]. 2006. Available from: http://hippasus. com/resources/tte/

[19] Hamilton ER, Rosenberg JM, Akcaoglu M. The substitution augmentation modification redefinition (SAMR) model: A critical review and suggestions for its use. TechTrends. 2016;60(5):433-441

[20] Romrell D, Kidder L, Wood E. The SAMR model as a framework for evaluating mLearning. Online Learning Journal. 2014;18(2):1-15

[21] TABLIO. Tablets for Classroom Differentiation and Inclusion [Internet]. 2016-2019. Available from: http://tablio.eu

[22] Tomlinson CA. How to Differentiate Instruction in Mixed-Ability Classrooms. Alexandria, VA, USA: ASCD; 2001. ISBN 978-0871205124

[23] Bird G, Alton S, Mackinnon C. Accessing the Curriculum: Strategies for Differentiation for Pupils with Down Syndrome. DSE Enterprises; 2000. Available at: http://www.downsyndrome.org/information/education/ curriculum/

[24] Terwel J. Curriculum differentiation: Multiple perspectives and developments in education. Journal of Curriculum Studies. 2005;37(6):653-670

[25] Gallagher J, Gallagher S. Teaching the Gifted Child. 4th ed. Boston: Allyn and Bacon; 1994

[26] Hilton JT. A case study of the application of SAMR and TPACK for reflection on technology integration into two social studies classrooms. The Social Studies. 2016;107(2):68-73
[27] Taylor BK. Content, process, and product: Modeling differentiated instruction. Kappa Delta Pi Record. 2015;51(1):13-17 


\title{
Chapter 4
}

\section{The Usefulness of Original Teaching Materials for Motivation}

\author{
Koji Uenishi
}

\begin{abstract}
This chapter investigates the potential usefulness of original teaching materials in order to enhance Japanese university students' awareness, especially intrinsic motivation when learning English, including cross-cultural understanding, usefulness, and pleasure. Specifically, the extent to which the teaching materials are favored by students and the difference of learner awareness among the four texts are explored. In reading classes non-English-major students were taught English for one semester using the author's textbook, based on his own experiences overseas including 'misadventures'. At the end of each unit, a questionnaire was administered. The collected data were analyzed using two-way ANOVAs and Pearson product-moment. Data analysis suggests that almost all students in the two classes examined enjoyed learning from the teaching materials, had a strong feeling of the importance of English learning, and had a strong awareness of developing English ability after studying each unit.
\end{abstract}

Keywords: original materials, student motivation, teaching content, two-way ANOVAs, Pearson product-moment

\section{Introduction}

With regard to English learning in tertiary education, we educators and researchers need to continually evaluate our approaches. University students who will use English as a tool in society after graduation need to improve their English proficiency, which might lead to their increased motivation to learn English at university.

In general, however, students lack motivation to learn English on a bachelor program, and most do not feel language learning to be meaningful. Most student motivation relates to credit gains for their general English classes. Especially, by the time they become sophomores, students' attitudes toward English study tend to become diverse; in fact, some students appear demotivated with regard to learning English and others are just losing interest in English. However, among sophomores some students have studied very seriously by setting TOEIC Test goals or developing their English proficiency in order to study abroad.

It appears vital for teachers to create a class to motivate English language students. In this chapter, one useful method to overcome this is considered, while teaching students who are less motivated or demotivated into English learning, in order to help them discover the significance of studying English in class. An attempt is made to implant feelings of English usefulness and pleasure in learning English into the students via the use of original materials which might motivate students to learn the language. 


\section{Earlier research}

There have been numerous studies on English learning motivation. Particular attention has been paid to intrinsic motivation and extrinsic motivation. These types of motivation are distinguished in self-determination theory (e.g., [1, 2]). Intrinsic motivation is responsible for learners taking an interest in English learning and wanting to communicate with English speakers in English. Alternatively, extrinsic motivation, coming from external sources, leads to learners towards qualifications or passing examinations [1]. It is often said that such motivations do not conflict with each other, but form a diverse continuity [3].

Some research on intrinsic motivation has been conducted by introducing presentations into group activities in class. As a result, enhancement of intrinsic motivation has been shown to be successful (e.g., [4]). Hayashi [5] explores the relations of intrinsic and extrinsic motivations to learner activities by classifying learners into three groups based on their autonomy, concluding that regardless of their autonomy, learners have a tendency towards 'enjoyable' activities in class. Iwanaka [6] confirms that it might be possible to enhance learner motivations toward class activities, English classes and English learning by satisfying three psychological needs of 'competence', 'relatedness' and 'autonomy'. The above was conducted in order to enhance intrinsic motivation through various learner activities.

Miura [7] conducted a 7-year longitudinal research on students' learning motivation from junior high to university, and suggested that university students tend to feel less motivated with regard to language learning after entering university even though their motivation tended to increase at the third year of junior high and senior high schools.

Hamada's [8] quantitative research on junior and senior high school students' awareness shows that course books were the strongest demotivator. Sakai and Kikuchi [9] collected high school student learning motivation data and found three important motivation factors: learning contents and materials, lack of motivation, and test scores, especially for less motivated learners.

Tanaka [10] conducted motivation research focusing on English learning materials, especially overseas dramas and movies, and likewise he found these to have the positive effect of enhancing intrinsic motivation. Use of DVDs has a great influence on motivation for learning English.

Furthermore, enhancement of student motivation of English learning using movies in class has been attempted (e.g., [11, 12]). For example, in Yoshimura's paper after understanding the outline of the story, students do the tasks (e.g., dictation and reading aloud) while watching part of the movies. As a result, it is reported that students were more motivated into English learning.

Based upon his data results, Hamada [13] lists the following effective methods in preventing demotivation:

\section{Practice listening by shadowing}

2. Communicative tasks

3. Group/pair work

4. Less use of grammar translation style

\section{Presentation}

6. Teachers' uniqueness 
The last category, Teachers' uniqueness, includes teachers' creative ideas such as their experiences abroad and their use of quizzes in English on current world news [13]. This category can be said to be related to the materials the teacher uses. When it comes to English reading class especially, the teaching content has a crucially important effect on student learning motivation.

\section{Objectives and methods}

\subsection{Research objectives}

The current research investigates university students' intrinsic motivation to learn English and explores the extent to which the content of teaching materials is received favorably by non-English-major students, and the relationship between the original materials and student awareness of English learning. In particular, focusing on the four countries/areas introduced in class, learner affectivity about the content was compared and discussed. The specific research questions are:

1. To what extent are particular teaching materials favored by students?

2. Does learner awareness vary according to the content of the teaching materials (amongst four countries or regions)?

3. How do students feel about the teaching materials?

\subsection{Research methods}

The subjects were 67 students who were not majoring in English (non-English major students). Students were mainly sophomores in Communication IIIB (a receptive-skills class), and the classes were taught using the author's original textbook, Ryu's Misadventures Abroad.

In the reading class, the author's textbook, based upon overseas experiences, was introduced in order to enhance student motivation into English learning. At the end of each unit a questionnaire was administered to explore learner awareness on the teaching materials and language learning. To obtain answers from the subjects, the questionnaire used a 6-point Likert scale. The questionnaire items were classified into four categories based upon the content of each questionnaire.

Then, the collected data were analyzed using Two-way ANOVAs and Pearson product-moment correlation. In the last item of the questionnaire the students were asked to freely describe impressive or interesting parts relating to the teaching content.

\subsection{Class content}

The research was designed to encourage students to take a greater interest in English learning, become more motivated to learn it, and enhance their English proficiency through use of materials based on the teacher's travel experiences, including 'misadventures'. The textbook introduced is the teacher's original, Ryu's Misadventures Abroad, which constitutes 24 chapters, covering eight countries or regions. However, as students have 15 classes in one semester, they could only cover 12 chapters (four countries or regions). Below are the nations or regions they read about, and some of the problems Ryu encountered: 
Vietnam: The main character visits a local village on the outskirts of Hanoi by bus. The roads in the rural areas were not developed and he is annoyed by the bumpy roads. He is warmly welcomed by the local people in the traditional or conventional way of treating guests. After that, he goes to Khanh Street in the city and has a Vietnamese boy polish his shoes. Then he visits another city, Hue, to participate in a teaching workshop as well as do some sightseeing. During his stay there, a restaurant called Hot Tuna catches his eye and he has pumpkin soup and steamed thin rice with meat and shrimp. On another day, he leaves the wharf for one of the sightseeing spots, Big Dong, in a small boat and sees two rowers wearing conical-shaped hats in the boat. On the way to Big Dong, the rowers suddenly quit rowing the boat on the quiet water and urge him to purchase the decorated fabrics taken out of a box. At last, he unwillingly agrees to purchase some silk goods.

Florida: The main character takes Japanese teenagers to Florida as a leader of the short-term overseas study program. He is curious about colloquial expressions in English, and he feels very happy to learn them there. One day, they visit Cocoa Beach and he goes to a restaurant and spends his time sitting back and relaxing there. Then, he is very impressed to see a sea lion, an otter and a walrus perform skillfully with a man and a woman in Sea World, and he also enjoys a 30-minute virtual trip to the Bermuda Triangle. Another day, while walking around the natural zoo, Busch Gardens, with other leaders, they first stop by the Budweiser Brewery and then go to see the Bird Show and Dwarf Village. He happens to see a ventriloquist talking to a stuffed animal puppet. The next day, in spite of the stormy weather outside in the morning, they go bowling in a bowling alley. Then, they see the 'Alligator Show' but he can see only half of it because he has to take care of one female student for the rest of the show. She feels sick when seeing the snakes and she develops a serious condition, hyperventilation.

Thailand: The main character visits the Snake Farm on the premises of a hospital called Thai Red Cross Hospital. The snake show is held twice a day, but the show is not a real performance by snakes since it just displays a wide range of snakes to visitors. After that, he visits several famous Buddhist temples and also sees a lying golden Buddha as well. He has an elderly monk predict his future. Then he visits the ancient temples in Ayutthaya by taxi. However, he has to negotiate with a cab driver about the taxi fare, and the driver's eager invitation urges him to show a flexible attitude toward the fare and finally he decides to use the taxi with no typical taxi sign on it. He is amazed to see almost all of the Buddha statues are without their heads because of repeated violent battles or irreparable damage.

Canada: The coordinator shows the main character around the town of Gibsons in his car, which has an odd odor, similar to rotten crabs. He enjoys the spectacular view along the coast and joins a big festival called Sea Cavalcade. While talking to his host father, he learns some idiomatic expressions. Also, he recognizes Japanese people's typical characteristic of being reserved and modest. He attends a magnificent ceremony at a Protestant church on Sunday with his host parents and listens to the preacher's sermon and then their lodger's long-suffering story. One day he walks on the long path, and on their way to a famous spot, Whirlpool, he stops by Brown Lake for a while to enjoy the fantastic scenery and to take photos of the beautiful lake surrounded by luxuriant cedars. The next day he enjoys fishing for trout at a fish farm, paying $\$ 2.00$.

The following teaching methods were used in class.

1. Vocabulary check (10 words)

2. Reading the passages and checking phrases 


\section{Listening section (4 questions)}

\section{Listening to the teacher's explanation}

\section{Reading comprehension (4 questions)}

\section{Speaking section: Filling in the blanks in two dialogues}

\section{Doing role play using the above dialogues}

Regarding the vocabulary check, students check not only the vocabulary in the section, but also difficult and unknown words in passages. Next, they read a slightly longer passage (800-1000 words). The passage comes with one or two photos, which hopefully can lower students' resistance to reading the long text. If necessary, the teacher makes some comments on the photo(s) before reading and sometimes tells further interesting stories with additional colored photos.

With regard to the listening section in the passage, students use the headset in the CALL classroom, listen to the CD individually and answer the questions. This can be very useful especially for slow learners because they can listen and answer at their own pace. Also, this type of longer text might be difficult for slow learners to read. Then, moving on to reading comprehension, students answer Japanese questions on the content of the passage in order to deeply understand it. Additional explanation based upon the writer's actual experiences further motivates learners and results in a more positive attitude towards English learning.

In another activity, students fill in blanks in the dialogues created based on the text, and after checking answers, they play the roles of Ryu and another person from the text. One aim of this activity is to deepen their understanding of the content while reading the passage again in order to fill in the blanks. The other aim is to enable them to have a 'virtual reality' experience of an overseas trip by doing the pair work activity as if they actually were Ryu traveling abroad.

The final section is a speaking section in which students fill in the blanks in the story dialogue. Based on the story content, the conversation between Ryu and another person develops. In short, Regarding Ryu's overseas experience, the other person asks Ryu questions about it and Ryu answers the questions.

\section{Results and discussion}

\subsection{Research question (1)}

In this section RQ (1) “To what extent are particular teaching materials favored by students?" is discussed (Table $\mathbf{1}$ ). As for the responses to questionnaire items among all students, first several remarkable items in the questionnaire are described. The mean scores of Item 5 (English will be useful in the future), Item 11 (The vocabulary section was effective) and Item 13 (The reading comprehension was effective) showed very high numerical values, 4.926, 4.881, and 4.956 on the 6 -point Likert scale, respectively (Table 2). Table 3 shows that among the items, Items 11 and 13 belong to Category 4 (Effectiveness of questions) and these high numerical values show how useful the questions to understand the texts, along with the other two ones (Items 12 and 14). Also, Item 5 shows a very high numerical value, which means students feel the usefulness of English in the future through their English classes. 


\begin{tabular}{ccccc}
\hline Class & $\boldsymbol{N}$ & $\boldsymbol{M}$ & $\boldsymbol{S D}$ & $\boldsymbol{S E}$ \\
\hline BS1 & 120 & 4.591 & 0.807 & 0.074 \\
\hline BS2 & 148 & 4.395 & 1.046 & 0.086 \\
\hline BS: combined faculties. & & & & \\
\hline
\end{tabular}

Table 1.

Descriptive analysis.

\begin{tabular}{cccccccc}
\hline & $\mathbf{1}$ & $\mathbf{2}$ & $\mathbf{3}$ & $\mathbf{4}$ & $\mathbf{5}$ & $\mathbf{6}$ & $\mathbf{7}$ \\
\hline$M$ & 4.358 & 4.612 & 4.038 & 4.139 & 4.926 & 4.645 & 4.311 \\
\hline & 8 & 9 & 10 & 11 & 12 & 13 & 14 \\
\hline$M$ & 4.591 & 4.091 & 4.512 & 4.881 & 4.536 & 4.956 & 4.391 \\
\hline
\end{tabular}

Table 2.

Total responses to questionnaire items (mean scores).

\begin{tabular}{ccc}
\hline & Classification & Item \\
\hline C1 & Cross-cultural understanding & 1,2 \\
\hline C2 & Motivation into English learning & $3,4,6$ \\
\hline C3 & Pleasure of textbook content & $7,8,10$ \\
\hline C4 & Effectiveness of questions & $11,12,13,14$ \\
\hline
\end{tabular}

Table 3.

Classification of items.

Further, the mean value of Item 6 (I became keen to develop comprehensive English ability better) was high, 4.645. This means that many students had a strong awareness of their developing English ability after finishing each unit. These results imply that the teaching materials, focusing on the writer's troubles while traveling abroad, motivated the students to learn English and encouraged them to understand the textbook using the questions.

To reiterate, the questionnaire items were classified into four categories based upon the content of each questionnaire (Table 3), and the relationship among the categories was analyzed using Pearson product-moment and discussed (see Table 4).

Reliabilities amongst the whole data were relatively high, since the range of Cronbach's Alpha was from 0.907 to 0.731 . Therefore, for all the scales, reliability is considered acceptable. Table 5 shows that the mean scores of four categories are higher than 4.229 on the 6-point scale. This means that the teaching contents including questions on the texts are meaningful and useful for learner motivation and understanding the passages.

\begin{tabular}{ccccc}
\hline & C1 & C2 & C3 & C4 \\
\hline C1 & 1 & $0.713^{* *}$ & $0.827^{* *}$ & $0.613^{* *}$ \\
\hline $\mathrm{C} 2$ & 1 & $0.745^{* *}$ & $0.533^{* *}$ \\
\hline $\mathrm{C} 3$ & & 1 & $0.672^{* *}$ \\
\hline $\mathrm{C} 4$ & & & 1 \\
\hline$p<0.01$ & & & \\
\hline${ }^{* *} p$ & & & \\
\hline
\end{tabular}

Table 4.

Correlative relationship (total). 
The Usefulness of Original Teaching Materials for Motivation

DOI: http://dx.doi.org/10.5772/intechopen. 85440

\begin{tabular}{ccccc}
\hline & $\boldsymbol{N}$ & $\boldsymbol{M}$ & $\boldsymbol{S D}$ & $\boldsymbol{S E}$ \\
\hline $\mathrm{C} 1$ & 268 & 4.465 & 0.895 & 0.055 \\
\hline $\mathrm{C} 2$ & 268 & 4.229 & 0.981 & 0.060 \\
\hline $\mathrm{C} 3$ & 268 & 4.351 & 1.011 & 0.062 \\
\hline $\mathrm{C} 4$ & 268 & 4.651 & 0.716 & 0.044 \\
\hline
\end{tabular}

Table 5.

Descriptive analysis (categories).

Table 4 demonstrates the strong correlation between Category 3 (Pleasure of textbook content) and two other categories: Category 1 (Cross-cultural understanding) and Category 2 (Motivation into English learning). These results suggest that learner awareness of the enjoyment of reading the passages in the textbook relates to their positive attitudes toward learning English and understanding of foreign cultures. In short, there is a possibility that when the teacher provides students with an interesting textbook or enjoyable content, including adding short stories with colored photos shown on the large screen in the CALL classroom, and they enjoy learning English, they might deepen their understanding of the content and be motivated into English learning. Also, it is considered that in order to have a better understanding of the content, students can use each PC in the CALL classroom to enhance their motivation of English learning. In addition, there is a strong correlation between $\mathrm{C} 1$ and $\mathrm{C} 2$, indicating that understanding foreign cultures might relate to English learning motivation and that any incorporation of foreign cultures, including overseas experiences, into class might influence student motivation.

\subsection{Research question (2)}

In this section RQ (2) "Does learner awareness vary according to the content of the teaching materials (amongst four countries or regions)?” is discussed (Table 6).

Two-way ANOVAs were conducted regarding learner awareness and classes, and the interactions between them were identified $(F(3)=6.445, p<0.000)$. In order to identify the differences among the groups, the data were analyzed using multiple comparison tests (Bonferroni). As shown in Table 7, the results indicate significant differences between the two groups regarding C1 (Cross-cultural understanding), C2 (Motivation into English learning), and C3 (Pleasure of English learning), but there were no significant differences when it came to C4 (Effectiveness of questions). On the whole the high mean scores of all categories show that learners

\begin{tabular}{lccccc}
\hline Class & C & $\boldsymbol{N}$ & $\boldsymbol{M}$ & $\boldsymbol{S D}$ & $\boldsymbol{S E}$ \\
\hline 1 & $\mathrm{C} 1$ & 120 & 4.554 & 0.830 & 0.076 \\
\hline 1 & $\mathrm{C} 2$ & 120 & 4.319 & 0.826 & 0.075 \\
\hline 1 & $\mathrm{C} 3$ & 120 & 4.531 & 0.903 & 0.082 \\
\hline 1 & $\mathrm{C} 4$ & 120 & 4.604 & 0.713 & 0.065 \\
\hline 2 & $\mathrm{C} 1$ & 148 & 4.392 & 0.941 & 0.077 \\
\hline 2 & $\mathrm{C} 2$ & 148 & 4.155 & 1.088 & 0.089 \\
\hline 2 & $\mathrm{C} 3$ & 148 & 4.205 & 1.072 & 0.088 \\
\hline 2 & $\mathrm{C} 4$ & 148 & 4.689 & 0.718 & 0.059 \\
\hline
\end{tabular}

Class 1: BS in 1st semester; Class 2: BS in 2nd semester.

Table 6.

Descriptive analysis (total). 


\begin{tabular}{cccccccc}
\hline & L1 & L2 & M1 & M2 & SE & $\boldsymbol{F}$ & $\boldsymbol{P}$ \\
\hline C1 & 1 & 2 & 4.554 & 4.392 & 0.056 & 2.923 & 0.004 \\
\hline C2 & 1 & 2 & 4.319 & 4.155 & 0.056 & 2.955 & 0.004 \\
\hline C3 & 1 & 2 & 4.531 & 4.205 & 0.056 & 5.865 & 0.000 \\
\hline C4 & 1 & 2 & 4.604 & 4.689 & 0.056 & 1.531 & n.s. \\
\hline
\end{tabular}

Table 7 .

Multiple comparison tests among categories (total).

tended to be highly motivated and enjoyed the teaching content. Nevertheless, this shows that students in the first semester class understood foreign cultures more deeply and learned English in a more enjoyable manner than those in the second semester class.

The obtained data were analyzed using two-way ANOVAs in order to identify any differences between countries in each category. As mentioned in the Research Methods, Communication III classes in Liberal Arts Education were selected by sophomores, plus some juniors. Groups 1 and 2 were combined classes including the Faculties of Letters, Integrated Arts \& Sciences, Economics and Law.

Table 8 shows that the mean scores of all categories tend to be high. As for each category, the total data obtained from the BS 1 and 2 classes were analyzed using the

\begin{tabular}{|c|c|c|c|c|c|c|c|}
\hline & L1 & L2 & M1 & M2 & $S D$ & $F$ & $P$ \\
\hline \multirow[t]{6}{*}{ C1 } & Vietnam & Florida & 4.4403 & 4.4030 & 0.0373 & 0.4748 & n.s. \\
\hline & Vietnam & Thailand & 4.4403 & 4.4478 & 0.0075 & 0.0950 & n.s. \\
\hline & Vietnam & Canada & 4.4403 & 4.5672 & 0.1269 & 1.6144 & n.s. \\
\hline & Florida & Thailand & 4.4030 & 4.4478 & 0.0448 & 0.5698 & n.s. \\
\hline & Florida & Canada & 4.4030 & 4.5672 & 0.1642 & 2.0892 & n.s. \\
\hline & Thailand & Canada & 4.4478 & 4.5672 & 0.1194 & 1.5194 & n.s. \\
\hline \multirow[t]{6}{*}{$\mathrm{C} 2$} & Vietnam & Florida & 4.0697 & 4.3234 & 0.2537 & 3.2288 & 0.008 \\
\hline & Vietnam & Thailand & 4.0697 & 4.1990 & 0.1294 & 1.6461 & n.s. \\
\hline & Vietnam & Canada & 4.0697 & 4.3234 & 0.2537 & 3.2288 & 0.008 \\
\hline & Florida & Thailand & 4.3234 & 4.1990 & 0.1244 & 1.5827 & n.s. \\
\hline & Florida & Canada & 4.3234 & 4.3234 & 0.0000 & 2.0152 & n.s. \\
\hline & Thailand & Canada & 4.1990 & 4.3234 & 0.1244 & 1.5827 & n.s. \\
\hline \multirow[t]{6}{*}{$\mathrm{C} 3$} & Vietnam & Florida & 4.4179 & 4.3781 & 0.0398 & 0.5065 & n.s. \\
\hline & Vietnam & Thailand & 4.4179 & 4.2488 & 0.1692 & 2.1525 & n.s. \\
\hline & Vietnam & Canada & 4.4179 & 4.3582 & 0.0597 & 0.7597 & n.s. \\
\hline & Florida & Thailand & 4.3781 & 4.2488 & 0.1294 & 1.6461 & n.s. \\
\hline & Florida & Canada & 4.3781 & 4.3582 & 0.0199 & 0.2532 & n.s. \\
\hline & Thailand & Canada & 4.2488 & 4.3582 & 0.1095 & 1.3928 & n.s. \\
\hline \multirow[t]{6}{*}{$\mathrm{C} 4$} & Vietnam & Florida & 4.6306 & 4.7463 & 0.1157 & 1.4719 & n.s. \\
\hline & Vietnam & Thailand & 4.6306 & 4.5448 & 0.0858 & 1.0921 & n.s. \\
\hline & Vietnam & Canada & 4.6306 & 4.6828 & 0.0522 & 0.6648 & n.s. \\
\hline & Florida & Thailand & 4.7463 & 4.5448 & 0.2015 & 2.5641 & n.s. \\
\hline & Florida & Canada & 4.7463 & 4.6828 & 0.0634 & 0.8072 & n.s. \\
\hline & Thailand & Canada & 4.5448 & 4.6828 & 0.1381 & 1.7569 & n.s. \\
\hline
\end{tabular}

Table 8.

Multiple comparison tests. 
multiple comparison test, Bonferroni. Significant differences were found between Vietnam and Florida/Canada regarding C2 (Table 8). This implies that, regarding motivation into English learning, students were much more motivated into English learning by the texts of Florida and Canada than the text, Vietnam.

\subsection{Research question (3): free description}

After learning about each country/region, students were asked to freely describe the parts they found particularly interesting or impressive about the country/area. The main free comments collected after reading the story of each country were categorized and are shown in Table 9.

When it comes to the total average number of each category, the comment described most was 'Understanding foreign culture'. Table 9 shows that on the average 18.75 out of 67 students commented on it. It is considered that, through the units (four countries/regions) they studied, they recognized they could learn about different aspects of those nations and broaden their minds in many respects.

The second most frequent comment in the free description concerned the fact that they were impressed with the story of the writer's actual experiences and failures. As for 'Story of real experience/failure', the average number of students writing the comment was 12.75 out of 67. In case of Vietnam and Thailand the total numbers of students were 24 and 19, respectively, and they were much larger than those for the other two nations. Especially in Vietnam, the writer had a terrible and embarrassing experience of being unwillingly forced to purchase the decorated fabrics by rowers on the boat. While reading the passages, students might have felt as if it were their own affair and they probably thought it could happen to anybody as well. It is considered that the content of the story enthralled the students in class.

Also, regarding the third most frequent comment, 'the content was interesting/a lot of fun', the total average number of their comments was 10.5 out of 67, and the numbers of comments for the four countries/regions were almost the same (Table 9). As mentioned above, it seems that it is related to the writer's terrible experience and the students have been attracted by the writer's urgent situation in the story of Vietnam and Thailand. On the other hand, in Canada the writer visits the places where they have local events like a parade, and in Florida he visits an amusement park and sightseeing spots with beautiful nature to enjoy some activities.

Further, in the story of Canada there were far more students who wrote the different types of comments as follows:

\begin{tabular}{lccccc}
\hline Comments & Vietnam & Florida & Thailand & Canada & AVG \\
\hline Understanding different culture & 13 & 16 & 21 & 22 & 18.75 \\
\hline Story of real experience/failure & 24 & 6 & 19 & 2 & 12.75 \\
\hline (The content) interesting & 13 & 10 & 12 & 7 & 10.5 \\
\hline Want to go & 6 & 8 & 11 & 3 & 7 \\
\hline Enjoy reading & 3 & 2 & 2 & 6 & 3.25 \\
\hline Vocabulary/communication & 0 & 5 & 3 & 6 & 2.75 \\
\hline
\end{tabular}

Table 9.

Free description (total). 
It felt like hell getting into a car which smelled like rotten crab.

It was impressive for me to read the story in which trout thought a fake bait would be real, and they bit it.

I was impressed with the story in which local people reclaim a person from alcoholism. (Translated into English by the author)

The variety of feelings and thoughts in the above arise from the rich cultural content itself of the country. With regard to the first of the above comments, eleven students made a similar comment and seemed to have had more impact from the story or enjoy reading it.

Regarding the story of Florida, one student commented like this: In English study real overseas experiences are easy to understand and learn. This comment gives the teacher more courage and motivation to teach English using this kind of content based on a true story containing an actual experience.

\section{Conclusions}

The teaching materials, the contents of which include traveling abroad and encountering various kinds of trouble, were utilized in class, and the extent to which the teaching contents (the four countries/regions) favored by students and the relevancy between the teaching content and student awareness were explored. The current chapter has evaluated the use of travel abroad materials, including whether experiences might relate to enhancing learning motivation.

The mean scores of all categories were high, and they imply that specific areas (i.e., Vietnam, Florida, Thailand, and Canada) were preferred. The scores for Category 4 were especially high, which means that the teaching contents, including questions on the texts are meaningful and useful for learner motivation and understanding of the passages. Also, It is considered that explanation of the original colored photos shown on the screen and the listening activity for further understanding of the content using the PC in the CALL classroom at their own pace can also enhance students' learning motivation.

Also, learner awareness of the enjoyment of reading the passages in the textbook relates to their positive attitudes toward learning English and understanding of foreign cultures. There is a possibility that when the teacher provides students with an interesting textbook or enjoyable content and they enjoy learning English, they might deepen their understanding of the content and be more motivated into English learning.

\section{Survey for English Classes}

How did you feel about the English class? What do you think about the class in which Ryu's Misadventures Abroad is used? For further improvement of the class, please feel free to answer the following questionnaires. Below is the evaluation standard: 6 (strongly agree), 5 (agree), 4 (somewhat agree), 3 (somewhat disagree), 2 (disagree) and 1 (strongly disagree).

1. I could gain an understanding of foreign cultures.

2. I could gain an understanding of foreign countries (sightseeing spots, local people, etc.) 
The Usefulness of Original Teaching Materials for Motivation

DOI: http://dx.doi.org/10.5772/intechopen. 85440

3. I became keen to study English more.

4. I want to read English sentences more.

5. English will be useful for me in the future.

6. I became keen to develop comprehensive English ability better.

7. It was fun to read this textbook.

8. I find reading about overseas experiences interesting.

9. I felt learning vocabulary is difficult.

10. The textbook content is interesting.

Do you think English Questions were effective to understand the passages?

11. The vocabulary section was helpful.

12. The listening section was helpful.

13. The reading comprehension was helpful.

14. The speaking section (fill-in-the-blanks type) was helpful.

15. Please freely describe your feelings and thoughts about any particularly impressive or interesting content in this unit.

\section{Author details}

\section{Koji Uenishi}

Institute for Foreign Language Research and Education, Hiroshima University, Japan

*Address all correspondence to: uenishi@hiroshima-u.ac.jp

\section{IntechOpen}

(C) 2019 The Author(s). Licensee IntechOpen. This chapter is distributed under the terms of the Creative Commons Attribution License (http://creativecommons.org/licenses/ by/3.0), which permits unrestricted use, distribution, and reproduction in any medium, provided the original work is properly cited. (cc) BY 


\section{References}

[1] Deci EL, Ryan RM. Intrinsic Motivation and Self-Determination in Human Behavior. New York: Plenum; 1985

[2] Ryan RM, Deci EL. Overview of selfdetermination theory: An organismic dialectical perspective. In: Deci EL, Ryan RM, editors. Handbook of SelfDetermination Research. New York: University of Tochester Press; 2002. pp. 3-33

[3] Lin YG, McKeachie WJ, Kim YC. College student intrinsic and/or extrinsic motivation and learning. Learning and Individual Differences. 2003;13:251-258

[4] Tanaka H, Hiromori Y. Eigo gakushuusha no naihatsuteki doukizuke wo takameru kyouiku kainyuu to sono kouka no kenshou [Educational practical intervention to enhance English learners' intrinsic motivation and verification of the effects]. JALT Journal. 2007;29:59-80

[5] Hayashi H. Eigo gakushuu no tanosisa juuyousei jikkou ni tsuiteno gakushuusha kannhikaku-doukiduke no kanntenn kara [Enjoyment, importance, and execution of study activities in relation to learners' autonomy: Motivational perspectives]. Language Education \& Technology. 2009;46:191-212

[6] Iwanaka T. Gakushuu iyoku no koujou ni kouken suru kyoushitsu katsudou-kouryo subeki mittsu no sinnriteki yokkyuu- [Classroom activities contributing to enhancement of learning motivation-three psychological needs to consider-]. JACET-CSCRB. 2011;8:1-16

[7] Miura T. A retrospective survey of L2 learning motivational changes. JALT Journal. 2010;32(1):29-53
[8] Hamada Y. Demotivators for Japanese teenagers. Journal of PAAL. 2008;12(2):1-23

[9] Sakai H, Kikuchi K. An analysis of demotivatiors in the EFL classroom. System. 2009;37:57-69

[10] Tanaka H. Doukizuke ga hikui gakushuusha no doukizuke wo takameru jissennteki kenkyuu [Practical research to enhance low-motivated student motivation]. JACET ChugokuShikoku Chapter Research Bulletin. 2009;6:69-82

[11] Fujiyama K. Eiga wo katsuyoushita eigo gakushuu no doukiduke-kousen deno torikumi wo chuushin ni [English learning motivation by use of moviesfocusing on practice at technical college]. Hikaku Bunka Kenkyuu [Comparative Culture Journal]. 2015;117:129-138

[12] Yoshimura K. Using movies as teaching materials to enhance student's motivation and encourage out-ofclass study in junior college English education: A report of learning English conversation through movies. Bulletin of Kagoshima Women's College. 2017;53:69-82

[13] Hamada Y. What demotivates and what prevents demotivation? Annual Research Report on General Education, Akita University. 2011;13:56-67 
Section 3

\section{New Tendencies for the Technology in Education}





\title{
Factors Affecting the Utilization and Adoption of Technology in Education
}

\author{
Aliyu Mustapha, Abdulkadir Mohammed, \\ Abdullahi Raji Egigogo, Abdullahi Abubakar Kutiriko \\ and Ahmed Haruna Dokoro
}

\begin{abstract}
Education is vital in any type of society for the conservation of lives of its associates and the preservation of the public formation. The rationale of this chapter is not only to reveal the role of technology in education but also to reveal the factors affecting the proper utilization and adoption of technology in education. Prior studies carried out by researchers confirm that technology utilization and adoption in education undeniably helps teachers and learners in the teaching and learning process. This chapter serves as a stepping stone to support teachers to do better in utilizing and adopting technology in education to a certain extent as an alternative of overlooking their thoughts, efforts and desires in blindly trying to vie with the swift change of technology in education in this epoch. Hence, this chapter discusses technology in education, the roles of technology in education, factors associated with technology utilization and adoption in education and the factors that limit the proper utilization and adoption of technology in education.
\end{abstract}

Keywords: adoption, education, technology, utilization

\section{Introduction}

The world today is going computerized; virtually everything today is automated from manual business to e-business, from manual banking to e-banking. Even the education system is also experiencing the effect of technology. Today, the admission process into tertiary institutions is now done electronically. This is to mention but few groundbreakings into the world of technology today. Technology has come to help a man in his strenuous tasks by automating the head-aching process originally done manually by man. Equally, due to the vast role played by the technology in education in making teaching and learning uncomplicated, its significance is gradually raising in the education sector because as technology steps forward, the benefits it put forward for learners in all facet of education. According to [1], the utilization of technology in learning has get to staggering levels. Subsequently, the significant statistics are as follows: 
1.89 and $60 \%$ of conventional and private universities offer online courses respectively.

$2.50 \%$ of college presidents envisage that in the next decade, a good number students will have taken courses online.

$3.62 \%$ of college presidents also forecast that in the next decade, more than half of the textbooks used will be digital.

$4.57 \%$ of college graduates have used a Smartphone, tablet or laptop to some degree during classroom instruction. Even though, most institutions do not have clear policies regarding the use of such gadgets; for most institutions, it is up to the teacher to manage such uses.

As new cohorts of people are exposed to highly developed technologies, applications in educational settings also grow. This flow of technology necessitates competent and talented teachers so as to sustain this emergent demand in technology. Thus, this chapter looks at the factors affecting the utilization and adoption of technology in education.

\section{Technology in education}

A technology that is utilized in the classroom is incredibly advantageous in supporting the learners appreciate the lessons being taught. For instance, given that there are a number of visual learners, projection screens attached to computers can be situated in classrooms to permit the learners to glimpse their notes as distinctive to sitting down and paying attention to the teacher. A good number of technologies are used to harmonize the class set of courses. These technologies put as one offered resources to students in the form of study questions, assessments and activities that may perhaps be of assistance to the students to go on with the learning process once they are not in the classroom [2].

In the present day, technology has been integrated into the school curriculum, as a result, students get used to computers to come up with exhibitions. Additionally, they make use of the internet to conduct an investigation on a category of problems intended for their compositions and critiques [3]. This proffers the certainty that, upon graduation, the learners will not beget any challenges while working with technology in the workplace, because it has the capacity to assist them in making stronger and feasible activities when correlated to an individual who has no access to technology in school. [4] corroborated that with the progressive advancements in the technological world, students are acquiring a refined path to such learning openings. Regularly, amazing and ground-breaking technology is taken into the market and the demand of the existing technology is adapted which makes it available to a great extent in the educational setting even to those schools that might not have a lot of monetary support accessible to them.

Technology has considerably developed to help the youngsters who are hitherto to start school [5]. Contrastingly, many people belief that technology "spoils" kids. For example, as objected to sitting down and learning to grasp when to calculate, they will decide on to arrange a calculator. Notwithstanding the experience, this has being contentious; though it remain to be a critical ingredient of today's social order. By adding it into schools, learners will be outfitted with scientific tools and knowledge so as to make a changeover from 
school to the workplace. Without hesitation, technology has today become critical and mandatory not only in education but in each and every aspect of our lives because it offers more knowledge to learners and also making them ambitious in the labor market.

\section{Roles of technology in education}

Many diverse roles of technology in education are promising; these range from using technology as a tool to support the conventional way of teaching to fully technological driven. In view of the above piece of information, many students derived gratification from the use of technology in education. It is vital to bring to light the roles of technology in education as highlighted by $[6,7]$;

i. Technology allows students to learn in a serene environment.

ii. It acknowledges the study of a "classroom experience" without interrupting the established measure of communication.

iii. It facilitates students thought based on strengths and weaknesses.

iv. It aids the teacher to evaluate skills in a consistent and objective manner.

v. It authorizes the duplication of inherent classroom order of events that may be seldom faced in material life.

vi. It enables assessment of intricate to long-term classroom and synergies across-institutional.

\section{Factors associated with technology utilization and adoption in education}

The performance of technology is a multifaceted route that depends on its distinctiveness, the connections among human resources and educational settings. The following factors are identified to influence technology utilization in education.

\subsection{Teacher's factor}

A recurrently mentioned set of factors affecting the utilization of technology in education is linked with the teacher. The teachers' thoughts on the way to and proficiency with technology have regularly been acknowledged as the key factor connected with the utilization of technology [8]. If not a teacher cling to affirmative thoughts to technology and not expected of using it in teaching. Teacher's instructive attitude and teaching philosophy put into practice are in addition factors that appear to persuade the proper utilization uses of technology in education.

\subsection{Organization factors}

The purpose of school as an institute is not to unravel a distinct predicament although to lighten the pressure on the school caused by stress working outside of or overriding the power of customary control. Similarly, they obviously and 
unavoidably oppose modification that will set demands on the existing practices. This implies that what emerges as a clear-cut enhancement to outsiders can to an organization be felt as deplorably upsetting if it means that societies are obliged to modify its ethics and practices for execution. The prologue of technologies necessitates a stern modification in the program of study, teaching practices, reallocation of wherewithal, and possibly reorganizing the basic composition of school. More to the point, this innate opposition to modification, organizations are assumed to contain a formation that averts widespread utilization of computers.

\subsection{Technology factors}

Technology itself is also among the spring of set of factors that affect its usage by teachers. Today, some contradictory thoughts on the significant effects of technology ought to be utilized in education. This directs the teachers to a state of uncertainty regarding the apt educational ethics of technology. Furthermore, the continuously varying technologies make it complex for teachers to live with the latest trends in technology. This is because, on a daily basis, new hardware and software are becoming available and the teachers find it hard and daunting to continue following this mysterious beast in technology. Thus, the nature of unpredictability makes technology less alluring for most teachers because of its undependable and can break down at any time but teachers, who have only a limited amount of time in front of students, cannot spend the time troubleshooting problems they may or may not be able to solve. Thus if not there is a strong need for the use of technology and reliable support, teachers may opt not to use it in their teaching.

\section{Factors that limit the proper utilization and adoption of technology in education}

In thoughtful piece of writing on the factors that limit the proper utilization of technology in education are:

1. Inadequate classroom space that will accommodate a large number of computers.

2. Teachers' distaste to take the students to computer laboratory.

3. Lack of expedient access to computers at home.

4. Inadequate infrastructure.

5. Pitiable planning.

6. Inadequate healthy human infrastructures that sustain technology advancement in the classroom.

However, more problems, though, recline beyond physical or technological compositions in the constitution of education because the formation of education developed in the preceding years is relatively contrary with the utilization of new technologies. The analysis of education as the transfer of knowledge and facts from the teachers to learners has a gigantic position for the learners to use innovative technologies to achieve significant everyday jobs. 


\section{Conclusion}

As a driving force of gigantic transformation, technology has omen the current understanding by helping the teachers and learners to achieve the best in its utilization and adoption in education. These transformations will have a momentous ripple result on education. Over the next period of 10 years, highly developed technologies will put education in the reach of many more individuals in the world over and will permit larger interest in teaching methodologies. As this chapter indicates, these far-reaching technological transformations will in effect change the skill-sets of the upcoming employees. Consequently, the general public around the world will need to reflect on how to make the judicious use of these novel prospects and accordingly guarantee to facilitate competition in education worldwide.

\section{Author details}

Aliyu Mustapha ${ }^{1 *}$, Abdulkadir Mohammed ${ }^{1}$, Abdullahi Raji Egigogo $^{2}$, Abdullahi Abubakar Kutiriko ${ }^{3}$ and Ahmed Haruna Dokoro ${ }^{4}$

1 Industrial and Technology Education Department, Federal University of Technology Minna, Niger State, Nigeria

2 Cyber Security Science Department, Federal University of Technology Minna, Niger State, Nigeria

3 Department of Informatics, Kings College London, London, United Kingdom

4 Department of Computer Science, Gombe State Polytechnic Bajoga, Nigeria

*Address all correspondence to: aliyu21m@gmail.com

\section{IntechOpen}

(C) 2020 The Author(s). Licensee IntechOpen. This chapter is distributed under the terms of the Creative Commons Attribution License (http://creativecommons.org/licenses/ by/3.0), which permits unrestricted use, distribution, and reproduction in any medium, provided the original work is properly cited. (cc) BY 


\section{References}

[1] Mahato S. Use of educational technology at Sidho Kanho Birsha university. International Journal of Advanced Research, Ideas and Innovations in Technology. 2017;3(1):419-422

[2] Mustapha A. The importance of Technology in Teaching and learning. In: Artois M, editor. Teaching with Technology: Perspectives, Challenges and Future Challenges. New York: Nova Science Publishers; 2018

[3] Brandstrom C. Using the Internet in Education-Strengths and Weaknesses. A Qualitative Study of Teachers' Opinions on the Use of the Internet in Planning and Instruction. 2011. Available from: http://www.diva-portal.org/ smash/get/diva2:438827/FULLTEXT01. pdf [Accessed: 28 August 2017]

[4] Toyama K. There Are No Technology Shortcuts to Good Education. 2011. Available from: http://edutechdebate. org/ict-in-schools/there-are-notechnology-shortcuts-to-goodeducation/ [Accessed: 05 November 2017]

[5] Leslie MB, Jason TD, Virginia EV. Observations of children's interactions with teachers, peers, and tasks across preschool classroom activity settings. Early Education and Development. 2012;23(4):517-538

[6] Akinsola M, Animashun I. The effect of simulation-games environment on student achievement in and attitudes to mathematics in secondary schools. Turkish Online Journal of Educational Technology. 2007;6(3):113-119

[7] Mustapha A. Effects of simulation on the achievement, retention and skill performance of motor vehicle mechanic in Niger State technical colleges [unpublished med thesis]. Minna:

National Open University of Nigeria; 2016
[8] Mundy M-A, Kupczynski L, Kee R. Teacher's perception of technology use in school. SAGE Open. 2012;2(1):1-8 


\title{
Educational Technology at the Study Program of Educational Physics at the University of Maribor in Slovenia
}

\author{
Milan Svetec, Robert Repnik, Robi Arcet and Eva Klemenčič
}

\begin{abstract}
Physics is an experimental scientific discipline and needs to be introduced as such in schools. However, in recent decades, we witnessed intensive advancement in the field of computers, sensors, and measurement devices and also educational technologies, animations, and simulations, which one can use in teaching Physics. With ICT integration in education, we can supplement, but not substitute, different teaching methods, which include experiments. The modern teacher of Physics needs to be well trained in the use of all kinds of educational technologies, in particular in the field of experimental work. In this contribution, we analyze the study program of educational Physics at the University of Maribor in Slovenia, where we focus on achieving adequate competences for appropriate use of ICT in teaching theoretical topics as well as executing experiments.
\end{abstract}

Keywords: educational technology, experimental work, smart phone applications

\section{Introduction}

Information and communication technology (hereinafter referred to as ICT) is one of the most important and irreplaceable technologies of the twenty-first century. Among others, the rise of new technologies leads to important changes in the field of education. Educational systems in most EU countries [1, 2], including Slovenia, face a major problem of how to include the rapidly changing ICT field systematically and on a daily basis into teaching and learning. Consequently, in recent years, many studies of ICT integration [3-6] and its potential in the educational field were published.

ICT in education has a double role. Technology brings new tools that improve the teaching and learning process, but at the same time, ICT is a part of the curriculum with the goal of preparing students for life by providing them with all the necessary skills and knowledge. Note, that by word "student," we mean everyone who is studying at any educational level. We need to be aware that technology itself cannot be effective every time and does not necessarily improve students' knowledge. Teachers must have a good sense for planning when to include ICT, to what extent, and how to actively involve students. We must emphasize that science subjects require the development of experimental research skills and abilities, which cannot 
be fully developed, or even replaced with even the most sensible inclusion of ICT. Experiments should not be substituted but supplemented by ICT tools. It is important that Physics teachers are digitally literate and well trained in the use of all kinds of educational technologies, particularly in the field of experimental skills. In our opinion, only a smart combination of educational technologies can improve the understanding of students. Furthermore, it can lead to the development of not only digital and science competences but also entrepreneurship competences. The EntreComp study [7] defines entrepreneurship as a transversal key competence that act upon opportunities and transform ideas into value for others.

In our contribution, we use qualitative research methods based on a documentary research method and experience-based analysis. We analyze the study program of educational Physics at the University of Maribor in Slovenia with a focus on achieving adequate competences for appropriate ICT integration in teaching theoretical topics and experimental work.

\section{Information and communications technology}

New technologies based on ICT are appearing in different areas. In the field of education, ICT ignites important changes. Availability of ICT is an indicator showing the progress and development of a society. ICT literacy has become one of the most significant life skills or competences and has been influencing many areas in life. An individual wanting to function in society in a socially acceptable manner must, therefore, be digitally literate. Gerlič et al. [8] claims that a digitally competent individual using ICT is more successful, creative, and innovative, handles valid and reliable data, and is aware of legal and ethical principles of safe and responsible use of technology.

Digital literacy can be defined as the ability to use digital environments to acquire important knowledge. A digitally literate individual can:

- recognize IT needs;

- effectively acquire necessary data;

- be critical to information and sources;

- incorporate gathered data into its own skill set;

- use the information to achieve set goals; and

- follow ethical rules and legal regulations regarding acquiring and use of information [9].

ICT development is extremely fast, and the field is constantly changing and upgrading. At first, ICT applies only to hardware, but today it also covers applications (software), networks (Internet), and services. One of the most important ICT resources recently is mobile technology (smartphones, tablet PCs, handheld devices, etc.), which has developed rapidly over the past decade. Its significance has been increasing mostly due to mobility. With the help of the Internet, the user can communicate and quickly access various content and information at any time. ICT has become accessible and available immediately and almost everywhere. This in itself offers not only many advantages but also disadvantages, which is seen as excessive stress and abuse of information technology. 
A large variety of things that people used to do by thinking, technology does for them today. Spitzer [10] warns about the phenomenon of the so-called digital dementia-the sneaking of mental abilities due to the use of digital technology. For children, Spitzer even recommends all schools should ban all forms of digital technology. However, this is highly unlikely. We should not abandon digital technology as it does serve several educational benefits. Instead, we need to learn how to use it responsibly to get the best out of technology and look after the mental health of both the younger generation and ourselves. As Tearle [11] concludes, although ICT requires additional work for a teacher, it enables positive learning outcomes.

\section{Incorporating ICT in the educational process}

Educational systems in most EU countries, including Slovenia, are facing a major challenge of how to include the rapidly changing ICT field systematically into teaching and learning. Because changes in education occur gradually and introducing new approaches is relatively slow, there is a discrepancy between general use of ICT in everyday life and its use in education $[1,12]$.

By incorporating ICT in education, one can notice improvement of the teaching and learning process. Furthermore, as ICT is a part of the curriculum, students gain skills and knowledge that are important also in everyday life [13]. In addition, ICT can be a tool to develop other key competences. In order to utilize all ICT advantages, we need to familiarize students with the basic skills to work with ICT, starting with the early years of study. Content should be included in school subjects in the most suitable manner allowing for the use of technology. Therefore, word processing should be included in mother language and spreadsheets in mathematics when learning about functions or data presentation. We believe regular inclusion of current technology in the teaching process would accustom students to the practical use of technology.

The updated curricula in Slovenia recommend the use of ICT in the educational process. ICT is used in class by teachers according to their personal preferences, which depends on their skills and attitude toward technology. Therefore, for the development of digital competences of students, it is relevant that teachers possess sufficient skills and competences to incorporate ICT in their teaching practices on a daily basis.

Gerlič [8] gives five main advantages of the use of ICT in the learning process, as follows:

- increased motivation of students (ICT provides interactive and multimedia lessons which draw students' attention);

- easier and improved access to information (teachers can prepare materials and tools in advance and students can access them using computers and the Internet);

- support of modern teaching approaches (problem lessons, teamwork lessons, and cooperative learning);

- greater teacher efficiency (ICT helps teachers access various sources to form lesson plans).

- improved information literacy (ICT helps improve teacher and student information literacy). 
ICT gives students many positive changes that influence their motivation and activity during lessons. We need to be aware that technology cannot be effective every time and does not necessarily improve students' knowledge. Sensible use of technology requires a lot of knowledge and preparation. Teachers must have a good sense for planning, when, how, and why include ICT and to what extent. In addition, teachers must have skills in the didactically reasonable use of ICT during lessons [14, 15]. Science subjects require the development of experimental research skills and abilities (observing, classifying, developing experimental techniques, comparison, etc.), which cannot be fully developed or even replaced with even the most sensible inclusion of ICT. Therefore, just using ICT in the classroom does not automatically mean an increased contribution of ICT to the lesson and the students' knowledge.

\section{ICT deployment in Slovenian schools}

In Slovenia, the systematic ICT deployment in education started in 1994 with the project called $\mathrm{RO}-$ Computer Literacy. The program was designed to encourage schools to increase the number of computers, hardware, and software equipment, and thus affect the motivation of the lessons. The implementation of this project took place during the years from 1994 until 2000. With the introduction of ICT, curricula, textbooks, and didactic materials were updated. In addition, it was crucial to educate teachers. Initially, teachers attended general introductory seminars in order to update with technology, which was later used in a variety of administrative matters and lesson planning. Later, they began not only to educate teachers in the use of ICT in these areas but also in their individual subject areas.

The Ministry of Education, Science and Sport assured one of the major breakthroughs of the system from 2006, based on the upgraded Action plan for the follow-up leap of the IT implementation in schools. With the resources of The European Social Fund, The Ministry of Education and Sport carried out a variety of public tenders and direct projects in public institutions (National Education Institute Slovenia and ARNES) under the name of e-education.

Within the "e-education," educational consultancy support and technical assistance to schools were developed and implemented, as well as the development and implementation of the standard called "e-competent teacher and principal". The proposal of the standard called "e-competent teacher," which contains six fundamental e-competences, was not formally introduced [16].

The six fundamental e-competences are as follows:

1. Knowledge of and ability to critically use the ICT.

2. The ability of communication and cooperation at a distance (teachers, educators, and other educational professionals, parents, and students).

3. The ability to search, collect, process, and evaluate (critical assessment) data, information, and concepts.

4. Safe use and compliance with the legal and ethical principles of information use and information publication.

5. Designing, creating, updating, and posting products (materials).

6. The ability to design, implement, and evaluate teaching and learning with the use of ICT. 
In addition to the aforementioned project "e-education," a few other projects in the field of ICT deployment were carried out between 2007 and 2013 with cofinancing from the European Social Fund: e-competences for teachers in bilingual schools; Production of multimedia and interactive e-learning materials; e-books; a project called e-schoolbag; and a project called IR optics.

After all these projects, it was found that the use of ICT in the classroom in Slovenian schools is in accordance with the average use of ICT in classrooms of EU countries $[1,2]$. Slovene teachers participated in several trainings regarding the use of ICT, which were beyond the development phase of the "basic training." Now, most of the training is in the area of pedagogical use of ICT.

In January 2016, the Ministry of Education, Science and Sport adopted Strategic guidelines for further implementation of ICT in the Slovenian education until 2020 [17]. This document presents current initiatives and policies in Slovenia and the European Union. In addition, it defines the vision of providing an open, creative, and sustainable learning environment supported by innovative use of ICT. The aim of ICT integration is to improve the effectiveness and quality of obtained knowledge and skills of key competences that one needs for successful integration into society.

Other objectives are to provide a higher level of utilization of ICT skills within the whole educational system and thereby contribute to the development of key competences. The latter also includes participants in the adult education and thereby represents the provision of comprehensive development of the competences of educators, teachers, coordinators, principals, and teachers in higher education (formal education and further training) with effective forms of training. This leads to the strengthening of the professional community, with the active exchange of good practices, or through mutual learning and providing quality services (counseling, assistance). This should also be pursued through the provision of various forms of training (seminars, workshops, consultancy, etc.) of educators, teachers, higher education faculty, and professional staff and principals for better and more efficient education with the support of ICT.

In addition to ICT deployment and developing digital literacy, the Ministry of Education, Science and Sport run the project called "Strengthening the competence of entrepreneurship and promoting a flexible transition between education and the environment in gymnasiums," which started in 2018 and will finish in 2022. The main objectives of the project are to establish, implement, and evaluate the model to develop entrepreneurship competences among students. The latter can be achieved by introducing flexible forms of learning, cross-curricular connections, studentcentered learning, authentic problem solving, and innovative use of ICT.

\section{The use of ICT in education}

The use of ICT in the educational process can be divided into three major areas. The primary scope encompasses activities through which learners become familiar with the operation and use of ICT (general educational area-ICT literacy), or they upgrade their knowledge or decide about a vocational route (specific professional education area). The secondary area encompasses the ICT integration in the educational process itself. In this case, ICT acts as a teaching resource or device in a variety of learning activities, which are linked to the direct educational process in the individual subjects. It can take part in all or only in certain stages of the learning process, such as introductory stage, processing new learning contents, practice exercises, revision, knowledge testing, and decision-making on the workflow. The tertiary area covers activities that accompany the educational process: business and 
technical-organizational elements characteristic of the educational system (administration, organization, information, and communication). Nowadays, the use of ICT in this area is indispensable. The information system of education that allows internal, local, national, and transnational networking through ICT is becoming an increasingly important factor in the development of the tertiary area.

The critical review of ICT integration in education is done by Livingstone [18], who presents both obstacles and challenges that schools face, and improvements in learning outcomes.

\section{1 e-learning}

ICT has brought new opportunities for the acquisition and creation of knowledge. It has become a vital element of the modern processes of education. In general, the term e-learning refers to the possibility or the use of ICT in education [19]. Gerlič et al. [8] cites three different approaches of the use of ICT in learning and teaching. The first approach, a classic or traditional education, takes place in the classroom. The teacher uses technology as mere interpretation assistance to achieve greater student motivation. Students use classical textbooks, workbooks, and e-materials. The second approach, e-education, is carried out with the help of ICT in synchronous or asynchronous form. Synchronous learning means that communication between participants takes place at the same time. This allows two-way communication between teachers and students (audio-video conferencing, chat rooms, the Internet, or classical telephony, etc.). In the case of asynchronous forms, the educational process is delayed, participants are not logged on to the network at the same time, and their communication takes place time independently (e-mail, Internet forum, e-materials, etc.). The third approach represents a combination of the above forms of teaching (blended learning). This means that the concepts of learning and teaching are characterized by different styles of learning or teaching methods and using physical and virtual learning media, through which a diverse range of learning outcomes and educational didactic effects are achieved.

Finally, the so-called m-learning or mobile learning has occurred. It refers to the use of more advanced, mobile technologies [20,21]. m-learning is part of e-learning, and the essential difference between them is in mobility. This type of technology is accessible in every step of the way and allows us to communicate with other users, logging onto the World Wide Web, it enables the use of a wide range of services and applications, and is, at the same time, is easy to use [22].

\subsection{ICT teacher}

The use of ICT in the educational process has its own advantages [23, 24]. Nevertheless, the quality of the lessons still depends primarily on the teacher, who forms learning objectives, content, forms of work, etc. The classic role of the teacher as the transmitter of knowledge is diminishing, while the role of the teacher as a facilitator, who directs and encourages the acquisition of new knowledge, is increasing. The teacher's guiding of information, obtained by a student with the help of ICT, improves quality of knowledge and helps students to create a holistic image of the world and themselves. At the same time, it represents the foundation for learning and education development.

When using ICT, it is crucial that teachers are critical to the devices they use. They need to use ICT intelligently and in particular in accordance with the educational objectives and the modern pedagogical principles. Use of ICT increases teacher productivity and saves time mainly for the following: 
Educational Technology at the Study Program of Educational Physics at the University... DOI: http://dx.doi.org/10.5772/intechopen.85081

- daily lesson planning and updating,

- adapting to individual student's needs,

- presentation of learning content,

- the creation and maintenance of the evaluation,

- the creation of a wide variety of exam questions, and

- keeping reports, records, and archives with the possibility of rapid data acquisitions and additions.

Furthermore, teachers examining different ways of incorporating ICT in the education process in order to increase the effectiveness of their work are also developing their entrepreneurship competences.

The use of ICT during the teaching process is closely related to the teachers' self-assessment of their own ICT competences, their assessment of the suitability of ICT use, and to the accessibility of ICT in an individual school. The more teachers feel confident about their ICT skills and competences, the more they are willing to undergo further training in the field and to incorporate ICT-related activities in their teaching at all levels of education. A survey from 2011, Condition and Trends in the Use of ICT in Education, shows that teachers' problems due to lack of experience on the application of ICT occur less often than the European average. At the same time, however, teachers believe that they are poorly trained to deal with ICT and need additional professional education. The computer is mostly used in class by younger teachers; the frequency of use declines with the growing age of a teacher [25-27].

Jimoyiannis and Komis [28] disclose that teachers recognize positive educational benefits of the use of ICT, especially from the science teacher's respective. On the other hand, they also highlight problems regarding ICT integration in education in terms of effectiveness and organization.

Gerlič believes it is particularly necessary to motivate and properly train teachers and not only to provide adequate software and hardware. Future teachers should be properly trained for the meaningful use of ICT in education during their studies. The latter is also studied by Drent and Meelissen [29]. They point out that a lack of ICT competence among teachers can often represent an obstacle. In their study, they conclude that the innovative use of ICT demands personal entrepreneurship competences. In addition, the innovative use of ICT enhances the learning process of students and affects the development of entrepreneurship competences among students themselves.

\subsection{Guidelines for using ICT in Physics lessons}

In the ICT deployment in Slovenian schools, the curriculum of individual subjects had been changed and supplemented. Therefore, in up-to-date curricula, it is recommended the implementation of ICT in the pedagogical process. The Physics curriculum in Slovenia allows great opportunities for meaningful inclusion of ICT in class.

The curriculum refers to reasonable use of the World Wide Web and computerbased measurement with interfaces and sensors. A computer with an interface and a set of sensors should become a measurement system for data acquisition and processing and a tool for analyzing and presenting measurements. Computer 
simulations and animations could be a useful complement to Physics lessons, especially when the nature of the phenomenon is such that it cannot be shown by an appropriate experiment. Teaching can be enhanced using a computer classroom and appropriate software, selection of e-materials, animations, and access to the World Wide Web.

Curricula also point out that the use of information technology can only complement experimentation rather than to substitute it. Computer simulation does not achieve the motivational or didactic effect of a well-demonstrated experiment.

The curriculum does not restrict the way ICT is used but encourages it. Thus, ICT can be used in lessons in many ways:

- electronic answering machines can be used to check and evaluate knowledge (Student Response System Socrative, Clicker, Plickers, Microsoft Interactive Classroom, Turning Point, Google Drive, Moodle, etc.)

- web classrooms can be used to track work done, collect students' materials, check knowledge, collaborate work, etc. (Moodle, Google Classroom, etc.) and

- use of e-materials in combination with doing a worksheet when adopting a new subject matter (e-textbooks., sio.si, e-va.e-um.eu, nauk.si, etc.)

In the field of Physics, there are many examples of the use of ICT in teaching in the Slovene language, as well as some sets of e-materials that cover curriculum content, but we must consider the fact that they were created at different times and that the curricula had already changed in the meantime. In the proceedings of the international conference Sirikt, which is the largest in our area in the field of the use of ICT in education in Slovenia, there are many examples of the use of ICT in teaching Physics. There is also a lot of contributions published in the magazine Physics at School.

By examining the meaningful use of ICT in the classroom, we cannot ignore a collection of manuals published by the public institution of The National Education Institute of Slovenia: Modernization of lessons in High School practice-PHYSICS, mechanics, heat, oscillation (Part 1); Updates of lessons in Elementary School practice-PHYSICS and Challenges of developing and evaluating knowledge in High School practice-PHYSICS, electricity and magnetism, wave, modern physics (Part 2).

\subsection{Models in natural science teaching}

Čepič emphasizes the importance of experimentation and demonstration when she interprets three various models of the description of a scientific phenomenon: the theoretical model, the computer model, and the experimental model. Of course, all the models mentioned concern the planned simplification and neglect of the various circumstances of the scientific phenomena examined in exchange for the possibility of organized methods of exploration and experimentation [30].

In the theoretical model, one describes natural events using abstract mathematical description that allows for quantitative predictions and hypothesis testing using measurements. Theoretical models are always used by students whenever their task is something to calculate. Using ICT, we can create a computer model with various simulations or animations of natural science phenomena. Thus, students acquiring some experience, associated with natural phenomena, do not observe this phenomenon directly. We must be aware that the computer model is the preprogramed flow of the test resulting from the theoretical model. The maximum value of computer 
models is the point of view of the symbolic representation of phenomena that we cannot see and the possibility of integrating developments at the sub microscopic level. In experimental models using devices and tools, we can present complex natural phenomena in the classroom. Such model successfully develops skills and competences in experimental research. Students can do practical work by gaining practical experience in new areas while leading them to an understanding of complex phenomena of nature. Virtual experiments using ICT (computer, mobile device) are also considered to be part of an experiment in the broader view. The results of such experiments are predefined with the program itself and do not allow any experimental error in terms of improper implementation of the experiment, overlook the circumstances of the actual experiment, the imprecise measurement, and others.

The study conducted by Jimoyiannis and Komis [31] confirms the positive outcome of the use of ICT and computer simulation in physics class. Additionally, it shows that the use of ICT can improve students understanding of the examined topic of the trajectory motion.

It is important that simulations and animations do not replace experiments. Computer models should be applied rationally and especially as a complement to experiments. Students, who discover natural phenomena only through ICT, will never acquire experimental skills.

\section{Study program of educational physics}

We have determined that sensible and rational use of technology requires a lot of knowledge on the teacher's part. Besides mastering ICT, a teacher should be able to make sensible use of information technology during class.

The modern Physics teacher needs to be well trained in the use of all kinds of educational technologies, particularly in the field of experimental work. It is therefore important for students during their studies to achieve adequate competences for an appropriate use of ICT in teaching theoretical topics as well as in executing experiments.

According to Gerlič, it is of great relevance that study programs for teachers should include subjects and content covering the competences and skills listed below:

General ICT and Computer Sciences (regardless of their specialization, students must acquire basic knowledge and skills in ICT and Computer Sciences, in using information systems and the computer in class, as well as for school administration. Students of Science, Mathematics, Craft, and Technologies also need basic skills in the field of designing simple educational software; they need an in-depth insight into computer networks, the multimedia, conference systems, distance learning, etc.).

Specific competences for the use of a computer in the field of their specific subject (students are familiarized with the use of the computer and information systems in the field of their specific subject).

Specialized didactics competences (within the course of specialized didactics, students of any subject specialization are familiarized with the possibilities of ICT use in their chosen subject field) [32].

We analyzed the study program of educational physics at the University of Maribor in Slovenia. The study program Physics teacher follows the principles of the Bologna process and includes modern study content, various organizational approaches, and modern work methods, which ensure greater connectivity between theory and practice. This means that during their studies, students have more practical training and they start with it sooner, which ensures a better integration of 
students in the school environment and gives them a better insight into what they will have to do after finishing their studies at the university.

\subsection{Subjects in the field of ICT}

The student of the Physics teacher program has several subjects with ICT content [33]. Information and Communications Technology and The Computer in Physics are taught in the first year. Both are core subjects. Students acquire knowledge in the theoretical and practical field of use of ICT in education and the profession. Students can work independently and creatively to solve practical problems in education and studies and can use computer tools to process and display the results of measurements. Working with a computer is particularly important for all lab work and writing physical texts.

Among the subjects that are optional, some subjects develop competences in the ICT field in depth. In the fourth year, students can choose the subject e-education and information technology in Physics and in the fifth year, e-learning and Computer-aided Laboratory Work.

Given the rapid development of ICT technology, it may be better if those subjects would not be of the optional type.

In ICT-based subjects, students can develop some of the entrepreneurship competences, for example as defined by EntreComp [7] mobilizing resources and mobilizing others. They also get acquainted with ICT tools that can enhance motivation and the active role of students.

\subsection{Subjects in the field of physical experiments}

Because Science subjects require the development of experimental research skills and abilities, let us now look in which subjects' students of the Physics Teacher Program acquire the necessary competences for experimental work.

Subjects are spread across the entire study path. In the first year of the study, students have Physical Experiments 1, in the second year Physical Experiments 2, in the third year Physics Experiments 3 and Physical Experiments 4, and in fourth year Physical Measurements.

Students in these subjects refresh and extend their knowledge obtained from attending lectures, especially topics that are essential for the successful and correct execution of laboratory work. Students also acquire experience and laboratory skills that are essential for autonomous execution of demonstrative physics experiments. They learn how to use their theoretical and practical knowledge, as well as information offered from secondary sources to master problems that might occur during experimental work and report on their findings.

In the subject Physical experiments 1, students take laboratory work with topics from mechanics. Experiments are in the following topics: Kinematics, Dynamics, Hydrostatics, and Hydrodynamics [34].

In the subject Physical experiments 2, students take laboratory work in thermodynamics and electromagnetism. Experiments are done in the following topics: Clausius-Clapeyron equation, Thermal expansion, Ideal gas equation, Specific heat of metals and liquids, Heat of fusion, and Heat of vaporization [35].

In the subject Physical experiments 3, students take laboratory work in oscillations and waves and in wave and geometrical optics. Experiments are done in the following topics: Undamped and damped oscillations, forced oscillations and resonance, Electrical oscillation circuit, Traveling and standing waves, Lenses and mirrors, Systems of lenses, Diffraction and interference, Spectroscopy, and Blackbody radiation [36]. 
In the subject Physical Experiments, four students take laboratory work in the field of Modern Physics. Experiments are done in the following topics: Experiments with Roentgen rays, Experiments with microwaves, Franck-Hertz experiment, Photo-effect, Measurement of the Planck constant, Gaussian distribution, Measurement of the ideal gain of a heat engine, Diffusion of liquids, Magnetic resonance spectroscopy, Gamma ray spectroscopy, Michelson interferometer, Diffraction of beta rays in an electromagnetic field, and Absorption of beta and gamma rays [37].

In the subject Measurements in Physics, students acquire basic theoretical and practical knowledge in the field of measurements. Among the contents are the following topics: Description of the measurement of the scalar and vector quantities, Tensors and transfer function, feedback to the system, thermic noise. Basic electrical circuits, Measurement of the constant quantity, statistics, tests, least squares method, Respond of the system to the periodical disturbance, Measurement of the time and frequency, feedback loop, and standards, Sensors of displacement, and Temperature sensors [38].

Within described subjects, students develop entrepreneurship competences, which are reflected in creativity, valuing ideas, mobilizing resources, taking initiative and planning, and management skills. The development of entrepreneurship competences can be supported by the way experimental laboratory work is carried out. For example, instead of executing an experimental work step by step in accordance with instructions, we could only present to students what we want for them to measure or which information they have to obtain by experiment.

\subsection{Subjects in the field of didactics}

Students of the Physics teacher program learn about the possibilities of using a computer in the classroom with specific didactics subjects. The following didactics subject matter is linked indirectly to the study program on ICT and experimental work: Didactics of physics 1 with practicum; Didactics of physics 2 with practicum; Pedagogical practice for teaching physics 1; Pedagogical practice for teaching physics 2.

The objectives of these subjects are the acquisition of teaching experience in the development of Physics teacher skills and technology. In addition to the first experiences with lessons planning, students also learn about the possibilities of using ICT in the classroom and deepen their knowledge in the field of physical experimentation at school. Students develop skills of safe design, execution of experimental exercises, and competence in writing and verbal expression to the professional and lay audiences. They are able to prepare the self-developed practice exercise in a manner, which is suitable for its inclusion in the teaching of physics. They are skilled to execute measurements in various physical fields of school Physics and to use the computer with interface and sensors within these measurements.

Having thoroughly reviewed the study program, we can conclude that the young Physics teacher acquires enough knowledge to use ICT in class, especially in the field of experimental work. It goes without saying, however, that the educational program cannot provide all the competences needed by a young teacher for practical work. Certain competences can only be acquired through experience and additional training.

\section{Conclusions}

In Slovenia, several projects in the field of ICT were implemented at the national level $[16,17]$. Upon the completion of all these projects, it was found that [2] the 
use of ICT in the classroom in Slovenian schools is in accordance with the average use of ICT in classrooms of EU countries. In the final report of the survey of ICT in education prepared for the European Commission [12], Slovenia ranks among top countries regarding the percentage of students that are in digitally supportive schools, and have high access to ICT and high-speed Internet. Furthermore, the study indicates that Slovenia has the highest percentage of students that are taught by digitally supportive teachers. One of the main obstacles in some countries is insufficient ICT equipment $[3,6]$, which, regarding this study, cannot be true for Slovenia.

Several studies confirm $[4,24]$ that integration of ICT in education brings new opportunities and tools that improve the teaching and learning process. As Livingstone [18] points out, ICT enables mobilization of resources, collaborative learning, and can improve motivation and learning outcomes. The abilities of mobilization of resources and collaborative learning are in the EntreComp framework [7] two of entrepreneurship competences.

Besides mastering ICT, a teacher should be able to make sensible use of information technology in class. Education in the field of training Slovene teachers for the use of ICT was beyond the development phase of "basic training." Nevertheless, Gerlič [32] addressed shortcomings regarding some training programs of teachers which do not include contents of information and computer science. Nowadays, most training programs focus on the area of didactic use of ICT $[8,13]$.

The updated curricula in Slovenia recommend the use of ICT in the educational process. Teachers use ICT in teaching at their own discretion, depending on their knowledge and attitude to technology [14, 15, 24-26]. Sang et al. [27] shows that ICT integration in education correlates with teacher attitudes and beliefs, which is confirmed by the study of Jimoyiannis and Komis [28]. The Physics curriculum allows many opportunities for a meaningful integration of ICT into teaching $[30,31]$.

The modern Physics teacher needs to be well trained in the use of all kinds of educational technologies and ICT, particularly in the field of experimental work. It is therefore important for students, during their studies, to achieve adequate competences for appropriate use of ICT in teaching theoretical topics as well as in executing experiments. These competences are digital competence, mathematical competence, and basic competences in science and technology. In addition, we think during studies, students can work on various activities that lead to the development of entrepreneurship competences. One of such activities could be an innovative and smart use of ICT that results in increasing the time efficiency and improving learning outcomes at the same time. Furthermore, ICT provides development of other entrepreneurship competences such as mobilizing resources and others, financial and economic literacy, planning and management, working with others, and learning through experience.

Based on the study program review [33-38], we can conclude that the young Physics teachers acquire enough knowledge to use ICT in class and to do experimental work. Students have several mandatory subjects with ICT content, in which they acquire knowledge in the theoretical and practical field of ICT use in education and the teaching profession. In specialized didactics subjects, students learn about the different possibilities of the pedagogical use of ICT in class.

Because Science is primarily concerned with the development of experimental and research skills, students have many subjects in this field across the entire study course. In these subjects, students refresh and extend their knowledge obtained from attending lectures and also acquire experience and laboratory skills that are essential for autonomous execution of demonstrative physics experiments. 
Of course, the educational program cannot provide all competences needed in practice by a young teacher. Certain competences can only be acquired by experience and additional training. The fact is that the teacher will have to regularly acquire new competences in the rapidly changing ICT field by consistently undergoing additional training. In this contribution, we present one example that is m-learning. With the rapid development of mobile technology over the past decade, most students have smartphones, but they use them more or less exclusively for entertainment. Despite the fact that smartphones are powerful devices, students do not consider using them for educational purpose. With a multitude of built-in sensors, a smartphone can easily become a measuring device for physics experiments. The teacher should be able to take advantage of all the potential that these devices possess in the educational process. In most schools, the use of smartphones is prohibited. In our opinion, the attitude toward the use of smartphones will have to change over time, if we want students to be prepared for life and use these devices sensibly.

Regardless of all the positive outcomes, we must be aware that excessive use of technology also brings negative consequences that are reflected in addiction, excessive stress, and abuse of information technology. But the fact remains that digital technology offers many benefits in education. We need to learn how to use it responsibly so that we can get the best out of technology and look after the mental health of both, the younger generation and ourselves.

\title{
Acknowledgements
}

This work was supported by financial support from the Ministry of Education, Science and Sport (project "Krepitev kompetence podjetnosti in spodbujanje prožnega prehajanja med izobraževanjem in okoljem v gimnazijah - PODVIG," translated: Strengthening the competence of entrepreneurship and promoting a flexible transition between education and the environment in gymnasiums).

This research was supported by the Slovenian Research Agency (Grant P1-0403).

\section{Conflict of interest}

The authors declare no conflict of interest.

\section{Author details}

\author{
Milan Svetec, Robert Repnik*, Robi Arcet and Eva Klemenčič \\ Faculty of Natural Sciences and Mathematics, University of Maribor, Maribor, \\ Slovenia
}

*Address all correspondence to: robert.repnik@um.si

\section{IntechOpen}

(C) 2019 The Author(s). Licensee IntechOpen. This chapter is distributed under the terms of the Creative Commons Attribution License (http://creativecommons.org/licenses/ by/3.0), which permits unrestricted use, distribution, and reproduction in any medium, provided the original work is properly cited. (cc) BY 


\section{References}

[1] Pelgrum WJ. Obstacles to the integration of ICT in education: Results from a worldwide educational assessment. Computers \& Education. 2001;37:163-178. DOI: $10.1016 /$ S0360-1315(01)00045-8

[2] Wastiau P, Blamire R, Kearney C, Quittre V, Van de Gaer E, Monseur C. The use of ICT in education: A survey of schools in Europe. European Journal of Education. 2013;48(1):11-27. DOI: 10.1111/ejed.12020

[3] Becker HJ. Access to classroom computers. Communications of the ACM. 2000;43(6):24-25

[4] Cooper B, Brna P. Supporting high quality interaction and motivation in the classroom using ICT: The social and emotional learning and engagement in the NIMIS project. Education, Communication and Information. 2002;2:113-138

[5] Godfrey C. Computers in school: Changing technologies. Australian Educational Computing. 2001;16(2):14-17

[6] Ertmer PA. Addressing first- and second-order barriers to change: Strategies for technology integration. Educational Technology Research and Development. 1999;47(4):47-61

[7] Bacigalupo M, Kampylis P, Punie Y, Van den Brande G. EntreComp: The Entrepreneurship Competence Framework. Luxembourg: Publication Office of the European Union; EUR 27939 EN;; 2016. DOI: 10.2791/593884

[8] Gerlič I, Krašna M, Pesek I. Information and Communication Technologies in Slovenian Elementary Schools: Situation and Prospects. Maribor: Faculty of Natural Sciences and Mathematics; 2013 Informacijsko komunikacijske tehnologije $\mathrm{v}$ slovenskih osnovnih šolah: stanje in možnosti. Maribor: Fakulteta za naravoslovje in matematiko; 2013. (in Slovene)

[9] Stopar K, Kotar M, Pejova Z, Knap N. Criteria and Indicators of Information Literacy in Higher Education. Ljubljana: Association of Librarians' Societies of Slovenia; 2010. Merila in kazalci informacijske pismenosti v visokem šolstvu. Ljubljana: Zveza bibliotekarskih društev Slovenije; 2010. (in Slovene)

[10] Spitzer M. Digital Dementia: How We Make Our Children and Ourselves Out of Mind. Ljubljana: Mohorjeva Založba; 2017 (Digitalna demenca: kako spravljamo sebe in svoje otroke ob pamet. Ljubljana: Mohorjeva založba; 2017. in Slovene)

[11] Tearle P. A theoretical and instrumental framework for implementing change in ICT in education. Cambridge Journal of Education. 2004;34(3):331-351. DOI: 10.1080/0305764042000289956

[12] Survey of Schools: ICT in Education. [Internet]. 2013. Available from: https:// ec.europa.eu/digital-single-market/ sites/digital-agenda/files/KK-31-13-401EN-N.pdf [Accessed: 22 December 2018]

[13] Brečko BN, Vehovar V. Information and Communication Technology in Teaching and Learning in Slovenian Schools. Ljubljana: Pedagogical Institute; 2008. Informacijskokomunikacijska tehnologija pri poučevanju in učenju v slovenskih šolah. Ljubljana: Pedagoški inštitut; 2008. (in Slovene)

[14] Higgins S, Moseley D. Teachers' thinking about information and communications technology and learning: Beliefs and outcomes. Teacher Development. 2001;5(2):191-210 
[15] Hermans R, Tondeur J, Braak J, Valcke M. The impact of primary school teachers' educational beliefs on the classroom use of computers. Computers and Education. 2008;51(4):1499-1509

[16] Kreuh N, editor. Bilten e-šolstvo: Pot do e-kompetentnosti. Ljubljana: Miška; 2012. 28 p. (The way to e-competence). (in Slovene)

[17] Strateške usmeritve nadaljnjega uvajanja IKT v slovenske VIZ do leta 2020 (Strategic guidelines for the further introduction of ICT in the Slovenian schools by 2020). [Internet]. 2016. Available from: http://www.mizs.gov. si/fileadmin/mizs.gov.si/pageuploads/ StrateskeUsmeritveNadaljnjega UvajanjaIKT1_2016.pdf [Accessed: 21 December 2018]

[18] Livingstone S. Critical reflections on the benefits of ICT in education. Oxford Review of Education. 2012;38(1):9-24. DOI: 10.1080/03054985.2011.577938

[19] Welsh ET, Wanberg CR, Brown KG, Simmering MJ. e-learning: Emerging uses, empirical results and future directions. International Journal of Training and Development. 2003;7:245-258. DOI: 10.1046/j.1360-3736.2003.00184.x

[20] Korucu AT, Alkan A. Differences between m-learning (mobile learning) and e-learning, basic terminology and usage of $\mathrm{m}$-learning in education. Procedia Social and Behavioral Sciences. 2011;15:1925-1930. DOI: 10.1016/j. sbspro.2011.04.029

[21] Ally M, Prieto-Blazquez J. What is the future of mobile learning in education? Mobile Learning Applications in Higher Education [Special Section]. RUSC. 2014;11(1):142151. DOI: $10.7238 /$ rusc.v11i1.2033

[22] Zalar K. Primeri uporabe in primernost mobilnih naprav za izobraževanje (Examples of use and mobile devices educational suitability). [Internet]. 2016. Available from: http://pefprints.pef.uni-lj.si/1132/1/ Diploma_Ksenija_Zalar.pdf [Accessed: 24 December 2018]. (in Slovene)

[23] Zhang D, Zhao JL, Zhou L, Nunamaker JF. Can e-learning replace classroom learning? Communications of the ACM. 2004;47(5):74-79

[24] Valtonen T, Kukkonen J, Kontkanen S, Sormunen K, Dillon P, Sointu E. The impact of authentic learning experiences with ICT on pre-service teachers' intentions to use ICT for teaching and learning. Computers \& Education. 2014:1-24. DOI: 10.1016/j. compedu.2014.09.008

[25] Akbaba S, Kurubacak G. Teachers' attitudes towards technology. Computers in the Social Studies. 1999;7(2):833-836

[26] Myers JM, Halpin R. Teachers' attitudes and use of multimedia technology in the classroom: Constructivist-based professional development training for school districts. Journal of Computing in Teacher Education. 2002;18(4): 133-140

[27] Guoyuan S, Martin V, Braak J, Tondeur J. Student teachers' thinking processes and ICT integration: Predictors of prospective teaching behaviors with educational technology. Computers \& Education. 2010;54:103-112. DOI: 10.1016/j. compedu.2009.07.010

[28] Jimoyiannis A, Komis V. Examining teachers' beliefs about ICT in education: Implications of a teacher preparation programme. Teacher Development. 2007;11(2):149-173

[29] Drent M, Meelissen M. Which factors obstruct or stimulate teacher educators to use ICT innovatively? Computers \& Education. 
2008;51:187-199. DOI: 10.1016/j. compedu.2007.05.001

[30] Čepič M. Modeli v poučevanju naravoslovja. In: Moravec B, editor. Posodobitve pouka v osnovnošolski praksi. Ljubljana: Zavod RS za šolstvo; 2014. Models in science teaching. In:Moravec B, editor. Updates of teaching in elementary practice: Ljubljana: Institute of education of the Republic of Slovenia; 2014. p. 31-37. (in Slovene)

[31] Jimoyiannis A, Komis V. Computer simulations in physics teaching and learning: A case study on students' understanding of trajectory motion. Computers \& Education. 2001;36:183-204

[32] Gerlič I. Organizacija: Uporaba Informacijske in Komunikacijske Tehnologije v Slovenskih šolah. (Organization: Use of Information and Communication Technology in Slovenian Schools). 2005;8:383-385 (in Slovene)

[33] Subject Teacher: IZO FIZcurriculum 2018-2019. [Internet]. 2018. Available from: https://www.fnm.um.si/ index.php/2018/02/09/predmetniucitelj-izo-fiz-predmetnik-2018-2019/ [Accessed: 17 December 2018]

[34] Physics experiments 1. [Internet]. 2018. Available from: https://www. fnm.um.si/wp-content/uploads/ predmetniki/1_stopnja/predmetniucitelj/izofiz/2018-2019/EMAG_IZOFIZ_Fizikalni_eksperimenti_1.pdf [Accessed: 17 December 2018]

[35] Physics experiments 2. [Internet]. 2018. Available from: https://www. fnm.um.si/wp-content/uploads/ predmetniki/1_stopnja/predmetniucitelj/izofiz/2018-2019/EMAG_IZOFIZ_Fizikalni_eksperimenti_2.pdf [Accessed: 17 December 2018]

[36] Physics experiments 3. [Internet]. 2018. Available from: https://www. fnm.um.si/wp-content/uploads/ predmetniki/1_stopnja/predmetniucitelj/izofiz/2018-2019/EMAG_IZOFIZ_Fizikalni_eksperimenti_3.pdf [Accessed: 17 December 2018]

[37] Physics experiments 4. [Internet]. 2018. Available from: https://www. fnm.um.si/wp-content/uploads/ predmetniki/1_stopnja/predmetniucitelj/izofiz/2018-2019/EMAG_IZOFIZ_Fizikalni_eksperimenti_4.pdf [Accessed: 17 December 2018]

[38] Measurements in Physics. [Internet]. 2018. Available from: https:// www.fnm.um.si/wp-content/uploads/ predmetniki/1_stopnja/predmetniucitelj/izofiz/2018-2019/EMAG_IZOFIZ_Fizikalna_merjenja.pdf [Accessed: 17 December 2018] 


\title{
Endorsement of Individualized Instruction and Learning Performance through Mobile-Based Learning Management
}

\author{
Anil Shukla and Kshama Pandey
}

\begin{abstract}
In the ever changing world, higher education demands to have a competitive and inspiring learning environment that facilitates technology enhancement to make m-learning easy and individualised to all. Mobile learning has a significant impact on learning environment shifting. M-learning makes easy individualised instructions that enhance learning performance of learners. Mobile-based learning management system (LMS) has the ability to deliver highly relevant, resources individualized for each child's learning style and other individualised needs. In this chapter, there is an attempt to discuss the various endeavours and significance of mobile-based learning management system. It also reflects how M-based LMS facilitates individualised instruction that enhances learning performance.
\end{abstract}

Keywords: mobile-based learning management system, individualised instruction, learning performance

\section{Introduction}

The present scenario of the technology has changed world's learning pattern. After integration of communication-based technology into the classrooms, contemporary education has accelerated. With the growing acceptance of using mobile devices, m-learning has become significant in teaching and learning process. M-learning or mobile learning is learning across multiple contexts, through social and content interactions, using personal electronic devices. For distance education, m-learners use mobile device educational technology at their convenience.

M-learning services can be provided through the learning management systems (LMSs). With the mobile learning management system, many opportunities have been facilitated to advance course efficacy. After completion of courses, instructors can refer messages, reminders, homework, and some other supporting materials to students using mobile platforms.

This chapter focuses on the following objectives:

1. To study the meaning and concept of mobile based learning management system. 
2. To study the relationship between individualized instruction and learning performance.

3. To explore the individualized instruction and learning management system with reference to learning management system.

4. To study the perception of administrators towards LMS.

\section{Methodology of the study}

A descriptive survey method has been used. Thirty principals have been selected through the purposive sampling method from different teacher training institutes affiliated with MJP Rohilkhand University, Bareilly. Self-developed semi-structured interview has been employed to collect the data. Percentage analysis has been calculated for qualitative analysis. For theoretical background, the present study has been based on secondary data collected from articles, publications, and Websites.

\subsection{What is mobile-based LMS?}

For learning, an instructor uses LMS to deliver online courses and learning materials for learners. For management, an LMS helps instructor to organise and manage his students as well as the course itself through a mobile device. In teaching practices through mobile-based learning, a teacher educator can build and create their own cloud-based LMS with the help of any available LMS service providers. LMS can combine texts, videos, images, practice questions, assessment, and feedback.

In its first step, a teacher educator needs to create interactive learning content with the integrated Web authoring tool and publish as HTML5, which is supported on various smartphones and tablets. Then it is required to schedule and publish events on a site and allow the pupil teachers to register for the events from a mobile device. Hence, they may be able to browse events on a calendar or sort events by location.

\subsection{Significance of mobile-based LMS}

In this modern world, pupil teacher training needs to be easy and accessible. Learning management is the capacity to design pedagogic strategies that achieve learning outcomes for students [1]. The learning management concept was developed by Richard Smith of Central Queensland University (Australia) and is derived from architectural design (an artful arrangement of resources for definite ends) and is best rendered as design with intent. Typically, mobile responsive LMS has an ability to offer an innovative approach for teacher educators as well as pupil teachers to create and deliver e-lesson plans and also monitor their teaching and learning process and assess their overall performance and completion of the required courses.

Teacher educators can also create new topics, add comments, and share documents under existing topics within multiple learning forums. A learning management system may also provide pupil teachers with the ability to use interactive features such as threaded discussions, video conferencing, and discussion forums to reach their full potential. Discussions can rectify and enhance the learning experiences by enabling pupil to share their practices and insights with peers. Instructors can moderate the post to avoid unsolicited e-mails. Instructors should also create 
and manage pupil teachers' login account/profile and control what they should access on the mobile portal. Teacher educators can generate and deliver online quizzes or assessments comprising various question types to keep track of each learner's teaching and learning performance. It is the responsibility of each teacher educator to get feedback from pupil teachers. In this way, pupil teachers can also use LMS for their practice teaching in simulated mode through mobile. They have lot of opportunities to improve their new teaching skills by getting feedback from their peers and their instructors.

\subsection{Features of mobile-based learning management system}

- Synchronized online and mobile learning: with this feature of MLMS, during practice teaching, pupil teachers may able to initiate an e-learning module at his desk, pause, and pick it up where he left off on his mobile device.

- Mobile virtual classroom: pupil teachers may participate fully in practice teaching with slide viewing, HD video, and voice with a single click.

- Social learning: with the help of mobile device, pupil teacher can work together with the online community to explore and observe content. Pupil teachers can also participate in discussions, provide ratings and comments, and connect with experts while practice teaching.

- My learning plan: pupil teachers have speedy access to their learning proposal, assisting them stay on top of their practice teaching. Supervisors also have mobile access to the 'My Team' dashboard, so they know who is on target and who may necessity assistance, and they can reach out directly from their phones by sending messages, setting up a meeting, or even starting a meeting directly from their mobiles.

- Intelligent recommendations on the go: pupil teachers can analysis recommendations from The Intelligent Mentor (or 'TIM') when it is appropriate during practice teaching for them.

- Apple and Android applications: native applications are available for Apple and Android phones and tablets.

- Enterprise class security: mobile devices make practice teaching easy and secure with LMS-based single sign-on for both online and mobile access. For sensitive content, teacher educators have the choice to have it robotically deleted after a set period of time. Automatic time-outs, remote wipe, and access PINs for the devices are supplementary safekeeping features.

\section{Mobile-based LMS and individualized instruction}

In previous days of the one-size-fits-all curriculum, today's schools are becoming diverse. Many teachers find that their class rooms are populated by English language learners, gifted students, students with disabilities, and students who are culturally diverse [2]. Teacher educators observe that only a minor subgroup of any class was acquainting the resources they presented. Hence, one of the utmost benefits of using technology in classrooms is the ability to deliver highly relevant, pertinent resources individualized for each child's learning style and other 
individualised needs. Mobile devices such as laptops, personal digital assistants, and mobile phones have become a learning tool with great potential in both classrooms and outdoor learning.

Mobile learning has a characteristic of not being dependent on time and space [3]. Properly, the use of a mobile-based LMS has potential to allow teacher educators to help each pupil teacher to develop their own pace of instruction. Mobilebased LMS can create an effective system of individualized instruction that is reasonable, replicable, and accessible. A mobile-based LMS makes learning stressfree for teacher educators to involve pupil teachers' at all different levels. Pupil teachers can open their own learning folders and access individualised, higher level lesson units.

\subsection{What is individualized instruction?}

Learners are very different in their academic needs, backgrounds, and abilities. For this motive, it is imperative to come across them where they are so that we can make best use of their learning potential. One way to do this is to utilize individualized instruction.

Individualized instruction refers to the practice of strategies, resources, and assessments to meet the necessities of one particular learner. It makes sure that a scholar is receiving the appropriate guidance, flexibility, and learning support to magnify opportunities for academic progression. A learner's profile gives educator information that shows both a learner's strengths and weaknesses.

\subsection{Purposes of individualized instruction strategy}

Individualised instruction is based on the assumption that every individual has specific needs, and therefore, it involves different tasks for each learner and supports at individual level. Individualized instruction incorporates such teaching strategies that connect with individual student's learning strategies. The ultimate goal is to facilitate a learning environment that will make best use of the potential for student success. Individualised learning has following purposes:

- To enrich and improve listening pattern: since most of the teaching is done through lecturing, the role of students is to listen and if felt essential take note of them. The learning of the leaners is critically reliant on their listening practice and sense of hearing, thus facilitate them in improving their listening pattern.

- Empowers the pupil teachers to elucidate a lesson or demonstrate a technique to small groups of students at a time: this method offers the benefit for the pupil teachers in teaching or elucidating a lesson or to demonstrate a technique to their small group of learners.

- Individualizing instruction permits each pupil teacher to augment individualised instruction through the curriculum at his or her own pace: in this instruction method, teacher educators need to know the capacity of pupil teachers' pace of learning and content of learning. It is less important to cover the content from the curriculum. Vigorous significance is that the learner becomes able to learn through curriculum in his own way.

- Long-term retention as they note down what they frequently comprehend while the pupil teacher is teaching in the class, students are actively engaged in taking note of what they really understand instead of what the pupil teacher explains. 
They usually note down what they comprehend and are frequently recorded in their own words. So, this supports them to keep in mind the information for an elongated period of time.

- Importance is given to a learner as a specific not as group, class, and so on: the strategy is more related to how much a particular pupil teacher is capable to learn, retain, and his or her achievement not as a group, class, and team. According to the present education scenario, 'no child is left behind' so it is important for a pupil teacher to keep attention on a child as an individual.

\subsection{Impact of mobile-based learning management systems on learning performance}

New communication technology, particularly LMSL, is assumed to be effective in boosting interaction between the pupil teacher and the learner, and refining learning performance. MLMS may vary as per need and requirements of learner and learning environment. But it has some common features and purposes. A good MLMS can improve learning performance of a pupil teacher in different ways as follows:

- Ability to create self-registration: for a large number of learners, pupil teachers need to learn an automated self-registration feature. Otherwise, registering a small class can be done manually. LMSL can make possible for pupil teachers to create self-registration for learners.

- Capability to construct a portal for course materials: LMSL can provide a single location of past and current course materials. This feature makes it easier to retrieve data, reuse materials, or organize courses for students. Students may be able to navigate their vital goal and augment their learning performance.

- Proficiency to generate a knowledge base or self-service portal: learners and educators needed assistance to use the MLMS. A self-service section should address FAQs or collate best practices and case studies. This feature of MLMS generates curiosity to explore knowledge and manage their study as they want.

- Expertise to assemble course materials by categories: learners may be able to organize the courses by topics, subjects, authors, or curriculum order. Learners and educators also develop expertise to sort the materials as they required.

- Ability to create groups or teams: this feature lets them conduct group classes, which may be valuable for group orientations or team workshops.

- Ability to join a course funnel: with this feature of mobile-based LMS, learners can choose the programs where they needed improvement across curricula or courses.

- Reduce stress for quizzes and tests: mobile-based LMS provides exercise platform for learners. Pupil teachers assess students' performance or competency before, during, or after the course program. This feature improves learning performance and reduces stress for quizzes and tests.

- Ability to export/import resources: learners become able to swap course materials, reports, and registries to popular document files like PDF, TXT, JPEG, CVS, and DOC in case they need to use other curriculum. 


\subsection{Mobile-based learning performance}

Mobiles with their increasing usage have created a learning culture that fits the pressure-filled environment of modern, hi-tech, fast-paced workplaces. Individualised learning is gradually recommended as an effectual approach for raising learners' inquisitiveness and motivation. It supports learners to advance their ability to work anywhere and anytime, and an unpredictable environment makes them more critical thinkers and curious learners. Although mobile technology is a suitable support for this learning process, there is a need of practical strategies for educational practitioners' who can impart mobile learning as a tool to improve learning performance among learners. Integrating performance-centred learning and m-learning, results in a performance-centred mobile learning (PML) approach, in which students receive performance support via a mobile device (Mileva), mobile-based individualised instructions have following ubiquitous potentials:

i. Eradicate lessening errors: in teaching learning environment, learners need to be very accurate and any slight mistake can create enormous problems. Mobile devices can be the best tool to support them accurately with their need at any point and time. They can also seek real-time support from the MLMS when needed.

ii. Bring up-to-date about latest information: in the hi-tech industry, new features are added with the knowledge world frequently. When the pupil teachers are about to meet a prospect, they need to have considerable information about the new learning apps. Such latest updates can be accessed easily through mobile devices. The learners can easily access the information and apply it across the curriculum effectively.

iii. Become proficient at complex processes: when any institute implements mobile-based LMS in their organization, the end-users may find it difficult to use the software, despite end-user training. Teacher educators and pupil teachers are not familiar to new work processes. So they are cautious and do not perform the task well with the new software. In such scenarios, they can develop learning performance and deliver it through mobile devices. The learners can also resolve any complications themselves while working on the mobile-based LMS.

iv. Offline support: mobile learning not only deals with online support and access to information but also makes available offline support to teacher educators as well as pupil teachers. Mobile devices have the endowment of storing vast volumes of data offline due to the recent technological expansions. This feature is utmost advantageous to learners who belong to remote areas with limited Internet connectivity.

v. Bottom line: mobile learning can deliver what the learning environment needs, when they need it, wherever they are. This mobile-based LMS is aware of what pupil teachers are doing and where they are. It also enables interventions regarding teaching and learning. They can get instant assistance on their device.

\section{Obligatory teaching skills with MLMS}

Teaching is a type of communication process, may it be verbal or nonverbal. In this process, the communication should be clear and accurate. A teacher educator 
adapts various ways of teaching according to the needs of pupils. In this digital world, maximum educators possess the digital skills desirable to function in academic life. There are the basics such as managing the e-mails, using the learning management system (LMS), and uploading papers to plagiarism checkers, among others. Yet some faculties still struggle with basic LMS functions [4].

The rapid penetration of mobile-based learning into our learning environment creates challenges both for teacher educators and pupil teachers to face. The skill level needed to be updated with the changes in technology is expanding. The working modes of teacher educators have been transformed since the introduction of learning management systems (LMS). Whether courses are taught entirely online or whether a blended approach is used, most university instructors must design and develop online materials, and create and maintain course Websites [5], and LMSs have become the predominant means of communication with students for many instructors. Some important features of a mobile-based LMS include: grading, discussion forums, online assessment, plagiarism checkers, community portals, posting and uploading of assignments, and tracking of usage statistics.

A pupil teacher, therefore, is able to work with mobile-based learning management system. They should also be able to create an appropriate learning environment, and evaluate the performance of the students accordingly. They should learn how to create courses within the mobile-based learning management system. They should have opportunity to post assignments, monitor learners' progress and work, and post content (video, documents, links and more) and to flip their class-rooms. Mobile-based LMS includes some inbuilt applications like word processor; spread sheet and slide show presentations that allow the creation of different course content and various assessment tools. Thus, pupil teachers learn and practise all these skills, to make their teaching effective.

\subsection{Results and discussion}

Findings concluded through interview revealed that LMs is positively related with individualised instruction and learning performance. Results are shown in Table 1.

\begin{tabular}{|c|c|c|c|}
\hline S. No. & Item & Frequency (n) & Responses (\%) \\
\hline 1 & $\begin{array}{c}\text { Individualized instructions increase learning } \\
\text { performance. }\end{array}$ & 25 & 83 \\
\hline 2 & LMS can enhance learning performance. & 24 & 80 \\
\hline 3 & LMS can facilitate individualized instructions. & 21 & 70 \\
\hline 4 & $\begin{array}{l}\text { LMS increases student engagement with technology; } \\
\text { creating extra learning opportunities. }\end{array}$ & 22 & 73 \\
\hline 5 & $\begin{array}{l}\text { LMS has potential to increase access technology } \\
\text { for students. }\end{array}$ & 15 & 50 \\
\hline 6 & LMS has ability to improve student success. & 18 & 60 \\
\hline 7 & $\begin{array}{l}\text { LMS introduces greater peer support options for } \\
\text { students. }\end{array}$ & 23 & 76 \\
\hline 8 & $\begin{array}{l}\text { LMS provides additional resource for students } \\
\text { and academics. }\end{array}$ & 16 & 53 \\
\hline 9 & LMS increases students' responsibility. & 15 & 30 \\
\hline 10 & LMS enhances interactivity among learners. & 19 & 63 \\
\hline 11 & LMS enhances reflective engagement among learners. & 20 & 66 \\
\hline 12 & LMS provides feedback for learners as well as educators. & 25 & 83 \\
\hline
\end{tabular}

Table 1.

Types of LMS. 
Results revealed that administrators have positive approach towards LMS. They supposed that LMS has a great potential to enhance techno-centric learning environment. LMS can improve entire learning environment but need to update pedagogy and instructional approach as per learners' demand. Therefore, it is imperative to develop mobile-based pedagogy and teaching skills so that learners, educators, and administrators can be benefitted from mobile-based learning management system. On the bases of findings, some considerations have been discussed here with reference to mobile-based teaching skills and LMS.

\subsection{Refining mobile-based teaching skills with learning management system}

Time is shifting fast and technology is crossing ahead even quicker. Today's pupil teachers are tech-savvy. They like visuals, colours, animation, and real-life videos. The introduction of mobile learning has given a new height to learning in the field of teacher education. They can now better assimilate new knowledge through mobile apps, which are known to be more operative in keeping active interest even in the most boring topics. One smart feature of mobile based LMS that make convenience of recording a lesson taught in a class, develop quizzes, etc. and then sharing it with other sections of the school. If a student has been absent for a particular lecture, he/she can conveniently watch the lecture video and complete his notes later, without depending on his classmates.

There are many ways, in which teaching practice of pupil teachers is carried out. And if, the practice teaching of pupil teachers is done, with the help of mobilebased LMS (learning management system), then, it could positively enhance the teaching skills of pupil teachers.

During teaching practice, the teachers are pupil teachers; they are laying their foundation to become teachers. And if, from the very beginning, we contribute in enhancing their teaching skills, with the help of mobile-based learning management system, then it would lead to a line of good and effective teachers.

With mobile learning management system, pupil teachers can get connected to its fellow pupil teachers, and all together can work on each other's strength and weakness, leading to their improvement of teaching skills. In practice teaching, pupil teachers traditionally observe the other pupil teacher and give various suggestions; in mobile-based learning management system, suggestions can be given through while connecting to each other.

Thus, mobile-based learning management system can be helpful in enhancing the teaching skills of pupil teachers.

\subsection{Dimensions of mobile-based teaching skills}

One of the most neglected areas of m-learning is the digital skills of teacher educators. Like face-to-face teaching learning process, mobile-based teaching needs a strong formation in content, instruction, and assessment. But since they are teaching using the technology, they also need formation in other areas (managing online learners and technology skills). These areas include:

- M-content knowledge: in mobile-based learning, teacher educators must know their content and must know how to help learners develop an understanding of content in a learning environment. Often, it assumes that all $\mathrm{m}$-learning is a self-study process in which content assists as instructive materials and that learners can learn key content concepts on their specific way simply by watching a video or reading text. In such an environment, m-instructors emphasise on communication, record keeping, and administrative tasks. 
They also need to have content knowledge, but most of all, they need to know how to help learners develop a deep understanding of m-content and know how to use $\mathrm{m}$-content through individualised instructional strategies in a technology-mediated environment.

- Blend pedagogy, individualised instruction, technology, and content: M-learning is usually skirmish to find well-qualified instructors who understand how the individualised instruction, intersection of technology, pedagogy, and content can deliver meaningful learning experiences for pupil teachers; who reveal skills of self-regulation that enhance their efficacy as $\mathrm{m}$-facilitator; and who understand the importance of and have the skills to provide active facilitation and technology-mediated support [6].

M-facilitator also knows to modify the individualised instructional practices and pedagogical techniques for the m-learning environment. Teacher educators should prepare m-learning facilitator (pupil teacher) to teach in the medium in which they will instruct.

Medium-based individualised instruction (i.e. training online instructors to teach online via an online program) can help pupil teachers develop the necessary skills to foster interaction and communication with and between learners during practice teaching through m-learning. M-facilitator should also know how to implement telecommunication tools in support of individualised instructional method that can enhance pupil teachers' knowledge acquisition.

M-learner and facilitator can blend pedagogy, individualised instruction, and curriculum as per need and requirement of m-learning environment. M-facilitator has also the required skills as online instructor. Burns (2013) also states that introduce online instructors to frameworks of knowledge, such as technological pedagogical content knowledge, which emphasize connections among technologies, curriculum content, and specific pedagogical approaches so that instructors can blend technology, pedagogy, and content to produce effective, discipline-based teaching via technology.

- Create an online presence: in m-learning environment, the facilitators demonstrate a vigorous and multidimensional role. They should be well aware of innovation in the field of m-learning. They should also take care of novices and potentially disorienting experience. Facilitator should ensure the presence of learners in online learning environment. Facilitators must work to establish a welcoming presence, set a tone that encourages reflection and inquiry, broaden and deepen online communication, assess both individual and group learning and interactions, make critical judgments about whether and how well participants are gaining content-specific knowledge, encourage those who fall behind in posting, know when and when not to intervene, and summarize participant learning [6].

Teacher educators should provide robust and skilled assistance of knowledge for their pupil teachers and make them able to manage their content as they required. They are also responsible to facilitate them in m-learning process, especially when learners are new in m-learning.

- Energetic communication skills: online discussion through m-learning provides a platform for individual learners to come into a collaborative learning community. Without such discussions, the learning opportunity becomes a solo endeavour, and opportunities for deeper learning are lost [6]. Instructors can provide various opportunities for pupil teachers to sharp their online 
communication skills. They can also suggest those best learning strategies for online participation. Instructors can become a bridge between the learner and the virtual world.

- Ability to manage learners (in online classes): M-learner should know to the complete his task independently and regulate his time and learning style. He should also learn to work in an open environment. It is the responsibility of teacher educators to motivate their learners, assist with counselling, offer justin-time support, assess and monitor their performance, and provide individualised instruction to improve learning performance and teaching skill.

M-instructors need to offer adequate support and facilitation via the technology available (computer, mobile phone, tablets, laptop, e-mail, etc.) on an on-going basis. This assistance makes them intuitive and develops interest to learn and explore new knowledge.

\subsection{Requisite of mobile-based LMS and teaching skills}

Mobile-based LMS has been required to associate some of the issues with m-learning as given below:

1. Teachers must be proficient in digital skills.

2. Parents must be aware of the importance of m-learning at home.

3. Community and stakeholders should be ready to accept m-learning.

4. Schools must consider improving their existing infrastructure.

\subsection{Mobile-based LMS and teaching skills}

Mobile learning has long been applied in the teaching and learning processes with promising advantages. Utilizing the right combination of mobile learning features influences the students' learning approach, increases their interest, enhances their performance, and affects the learning environments. MLMS can develop communication skills. It is a pivotal teaching skill. Mobile-based LMS fosters communication skills among learners. This may include discussion forums, realtime messaging, videoconferencing, e-mail, and announcement posts. The second teaching feature is accessibility. MLMS allows students to access their assignments and course content from home. Additionally, the technology promotes globalization with open, flexible learning environments. So it may be concluded that teaching MLMS has the capacity to learn without border.

Learning management systems permit teachers and pupil teachers to post supplementary content and resources to enrich the curriculum, providing learning opportunities without the constraint of classroom schedules or limited class time. Pupil teachers also regulate their teaching skills across the practice teaching.

Mobile-based LMS develop the flexibility in teaching and learning among pupil teachers, because they learn at different rates, and mobile-based learning management systems offer the flexibility needed to meet their distinctive learning needs. Pupil teachers can revert and review content as needed, or spend additional time researching a topic of interest. This self-directed learning makes them self-regulatory, and pupil teachers can develop more control over their practice teaching. 
Endorsement of Individualized Instruction and Learning Performance through Mobile-Based... DOI: $h$ ttp://dx.doi.org/10.5772/intechopen.88152

\subsection{Future prospects of mobile-based learning management system with reference to pupil teachers}

With regard to access to computers, large-scale one-to-one computing programs have been implemented in many countries globally, such that elementary- and middle-school students and their teacher educators have their own mobile devices. In addition, in terms of promoting innovation in education via information technology, not only does mobile computing support traditional lecture-style teaching, but through convenient information gathering and sharing, it can also promote innovative teaching methods such as cooperative learning, exploratory learning outside the classroom, and game-based learning. Therefore, mobile technologies have great potential for facilitating more innovative educational methods. Simultaneously, these patterns in educational methods will likely not only help subject content learning but may also facilitate the development of communication, problemsolving, creativity, and other high-level skills among students.

Thus, mobile-based learning management system can be helpful in enhancing the individualised instruction, learning performance, and teaching skills of pupil teachers.

\section{Author details}

Anil Shukla ${ }^{1}$ and Kshama Pandey ${ }^{2 *}$

1 M.J.P. Rohilkhand University, Bareilly, Uttar Pradesh, India

2 Department of B.Ed./M.Ed., Faculty of Education, M.J.P. Rohillkhand University, Bareilly, Uttar Pradesh, India

*Address all correspondence to: kshamasoham@gmail.com

\section{IntechOpen}

(C) 2020 The Author(s). Licensee IntechOpen. This chapter is distributed under the terms of the Creative Commons Attribution License (http://creativecommons.org/licenses/ by/3.0), which permits unrestricted use, distribution, and reproduction in any medium, provided the original work is properly cited. (cc) BY 


\section{References}

[1] Galbraith and Comp. Learning management. 2018. Available from: http://www.galbraithco.com/ index.php/about/competencies/ item/7-learning-management

[2] Voltz D, Sims MJ, Nelson B. Connecting Teachers, Students, and Standards. North Beauregard St. Alexandria: ASCD; 2010

[3] Nurhayati OW, Teguh M. Mobilebased learning design with android development tools. 2014. Available from: https://ieeexplore.ieee.org/ abstract/document/7065742/

[4] Straumsheim C, Jaschik S, Lederman D. 2015 survey of faculty attitudes on technology (Rep.). Gallup and Inside Higher Ed. 2015. Available from: https://www.insidehighered.com/ audio/2015/11/12/2015-survey-facultyattitudes-technology

[5] Zastrocky M, Harris M, Lowendahl J-M. E-learning for higher education: Course management systems. Gartner, Inc. 2007

[6] Burns M. Distance education for teacher training: Modes, models and methods. 2011. Available from: http:// go.edc.org/07xd 



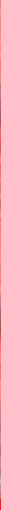

\section{Edited by Fahriye Altlnay}

This book has three sections on the role of technology in education. The first section covers the merits of online learning and environment. The second section of the book gives insight on new technologies in learning and teaching. The third section of the book underlines the importance of new tendencies for the technology in education. I have a firm belief that readers can find great insights on the role of technology in education from different reflections and research.

\section{IntechOpen}
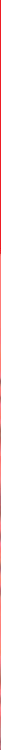